\title{
Development of Improved Models and Designs for Coated-Particle Gas Reactor Fuels
}

\section{ANNUAL PROGRESS REPORT UNDER THE INTERNATIONAL NUCLEAR ENERGY RESEARCH INITIATIVE (I-NERI)}

A Collaboration of Work Performed by:

The Idaho National Engineering and Environmental Laboratory (INEEL), The French Centre d'Etude Atomique (CEA), and The Massachusetts Institute of Technology (MIT)

November 2002

Idaho National Engineering and Environmental Laboratory Bechtel BWXT Idaho, LLC 


\title{
DEVELOPMENT OF IMPROVED MODELS AND DESIGNS FOR COATED-PARTICLE GAS REACTOR FUELS:
}

\author{
ANNUAL PROGRESS REPORT UNDER THE INTERNATIONAL NUCLEAR ENERGY \\ RESEARCH INITIATIVE (I-NERI) \\ Annual Report: November 2002 \\ Lead U.S. Investigating Organization: \\ Idaho National Engineering and Environmental Laboratory \\ (INEEL) \\ Lead U.S. Principal Investigator: \\ David Petti \\ Lead Collaborating Investigating Organization: Centre d'Etude Atomique (CEA) \\ Lead Collaborating Principal Investigator: Alain Languille/Philippe Martin \\ Other Collaborating Institutions: \\ Massachusetts Institute of Technology (MIT) \\ Other Collaborating Principal Investigator: \\ Ronald Ballinger
}

November 2002

\section{Idaho National Engineering and Environmental Laboratory \\ Idaho Falls, Idaho 83415}

Prepared for the

U.S. Department of Energy

Office of Nuclear Energy, Science, and Technology

Under DOE Idaho Operations Office

Contract DE-AC07-99ID13727 


\section{DEVELOPMENT OF IMPROVED MODELS AND DESIGNS FOR COATED-PARTICLE GAS REACTOR FUELS: Annual Report: November 2002 PROJECT STATUS EXECUTIVE SUMMARY}

The objective of this INERI project is to develop improved fuel behavior models for gas reactor coated particle fuels and to develop improved coated-particle fuel designs that can be used reliably at very high burnups and potentially in fast gas-cooled reactors. Thermomechanical, thermophysical, and physiochemical material properties data were compiled by both the US and the French and preliminary assessments conducted. Comparison between U.S. and European data revealed many similarities and a few important differences. In all cases, the data needed for accurate fuel performance modeling of coated particle fuel at high burnup were lacking. The development of the INEEL fuel performance model, PARFUME, continued from earlier efforts. The statistical model being used to simulate the detailed finite element calculations is being upgraded and improved to allow for changes in fuel design attributes (e.g. thickness of layers, dimensions of kernel) as well as changes in important material properties to increase the flexibility of the code. In addition, modeling of other potentially important failure modes such as debonding and asphericity was started. A paper on the status of the model was presented at the HTR-2002 meeting in Petten, Netherlands in April 2002, and a paper on the statistical method was submitted to the Journal of Nuclear Material in September 2002. Benchmarking of the model against Japanese and an older DRAGON irradiation are planned. Preliminary calculations of the stresses in a coated particle have been calculated by the CEA using the ATLAS finite element model. This model and the material properties and constitutive relationships will be incorporated into a more general software platform termed Pleiades. Pleiades will be able to analyze different fuel forms at different scales (from particle to fuel body) and also handle the statistical variability in coated particle fuel. Diffusion couple experiments to study Ag and Pd transport through SiC were conducted. Analysis and characterization of the samples continues. Two active transport mechanisms are proposed: diffusion in $\mathrm{SiC}$ and release through $\mathrm{SiC}$ cracks or another, as yet undetermined, path. Silver concentration profiles determined by XPS analysis suggest diffusion within the SiC layer, most likely dominated by grain boundary diffusion. However, diffusion coefficients calculated from mass loss measurements suggest a much faster release path, postulated as small cracks or flaws that provide open paths with little resistance to silver migration. Work is ongoing to identify and characterize this path. Work on Pd behavior has begun and will continue next year. 
PROJECT ORGANIZATION:

\begin{tabular}{|c|l|l|l|}
\hline Task & \multicolumn{1}{|c|}{ Task Title } & $\begin{array}{c}\text { Responsible } \\
\text { Lead }\end{array}$ & $\begin{array}{c}\text { Principal } \\
\text { investigators }\end{array}$ \\
\hline 1 & Information Exchange & INEEL/CEA & $\begin{array}{l}\text { David Petti, John } \\
\text { Maki, and Philippe } \\
\text { Martin, Mayeaeul } \\
\text { Phelip }\end{array}$ \\
\hline 2 & Model Development & INEEL/CEA & $\begin{array}{l}\text { Gregory Miller, } \\
\text { John Maki, David } \\
\text { Petti, Mayeaeul } \\
\text { Phelip }\end{array}$ \\
\hline 3 & Concept Improvements & MIT/INEEL & $\begin{array}{l}\text { Ron Ballinger and } \\
\text { David Petti }\end{array}$ \\
\hline 4 & $\begin{array}{l}\text { Feasibility of the concept in a } \\
\text { hard spectrum }\end{array}$ & CEA, INEEL & $\begin{array}{l}\text { Philippe Martin and } \\
\text { David Petti }\end{array}$ \\
\hline 5 & $\begin{array}{l}\text { Irradiation of prototype } \\
\text { particles }\end{array}$ & INEEL, CEA & $\begin{array}{l}\text { David Petti and } \\
\text { Philippe Martin }\end{array}$ \\
\hline
\end{tabular}




\section{INTRODUCTION}

The objectives of this INERI project are to:

- develop improved fuel behavior models for gas cooled reactor particle fuels (initially for TRISO-coated fuels),

- develop improved gas cooled reactor particle fuel coating materials and designs that will reliably reach very high burnups,

- assess the extension of the particle fuel concept to hard spectrum gas-cooled cores, and

- develop an irradiation testing strategy for new coated particle fuels.

Preliminary research has indicated that high-temperature gas reactor technology has significant potential to satisfy the safety, economic, proliferation, and waste disposal concerns that face nuclear electric generating technologies. However, numerous technical issues must be addressed before this technology becomes commercially viable. The work in this project will be performed by the Idaho National Engineering and Environmental Laboratory (INEEL) in collaboration with the French CEA and the Massachusetts Institute of Technology. The project has been organized into five tasks to accomplish the objectives above:

- in Task 1, information will be exchanged relative to material property databases and existing fuel models,

- in Task 2, an integrated fuel model will be developed that includes the effects of multi-dimensional failure mechanisms and phenomena not currently in the models,

- in Task 3, deterministic fuel performance calculations will be performed to evaluate the capacity of classical TRISO fuel to reach extended burnups, and thereby establish requirements for fuel materials,

- $\quad$ in Task 4 , the feasibility of using particle fuel in a fast neutron environment will be investigated, and

- in Task 5, an irradiation testing strategy for prototype fuel particles will be developed. 


\section{TASK 1: INFORMATION EXCHANGE ON EXISTING PARTICLE FUEL DATA, MODELS, AND COMPREHENSION}

\section{Responsible Leads: INEEL, CEA}

\section{Brief Description of Objectives:}

The CEA and INEEL will exchange their current databases on coated particle fuel performance during irradiation and the computer models and material property correlations that have been developed to describe that performance. This information will include fission gas release data (e.g., release to birth ratios for various fission gases) from irradiation experiments, and postirradiation examination results documenting the physical state of the TRISO coatings and kernels after irradiation. In addition, information on the pedigree of the fuel including fabrication conditions will be included when available. (Much of the previous U.S. database will be obtained from the open literature or from GA.) Included with this information, the INEEL will provide detailed results from the NPR-1, NPR-1A and NPR-2 experiments that were conducted at the INEEL as part of the New Production Reactor program. Once received, the particle fuel databases will be reviewed and critically assessed. This assessment will identify data needs in regard to implementation and further development of fuel behavior models. Attempts will be made to fulfill those data needs.

\section{Task Technical Status Overview:}

\section{INEEL:}

Work has begun on reviewing and assessing particle fuel material property correlations. These correlations are used in model predictions of fuel performance during irradiation. Such predictions are useful to understand the interplay of important phenomena that could occur outside of the existing irradiation envelope of temperature, burnup and fast neutron fluence. It has been observed that property data are generally lacking for materials exposed to high fuel burnups and neutron fluences. This current lack of data will introduce uncertainty into model 
predictions of fuel performance. Several key material properties that affect fuel performance are briefly discussed below.

\section{PyC Shrinkage and Swelling}

Under irradiation, the PyC layers of the fuel particle experience either shrinkage or swelling which affects the amount of stress experienced by the $\mathrm{SiC}$ layer. The correlations currently used to represent shrinkage, or swelling, of the PyC layers were obtained from empirical fits to data as compiled by the CEGA Corporation (CEGA 1993). These correlations are good up to fluences of $3.7 \times 10^{25} \mathrm{n} / \mathrm{m}^{2}$ and are functions of temperature, anisotropy, density and fast neutron fluence.

Figure 1-1 displays several fits and the underlying data at various temperatures. The amount of data is rather sparse which introduces significant uncertainty when the correlations are extrapolated beyond neutron fluences of $5 \times 10^{25} \mathrm{n} / \mathrm{m}^{2}$.
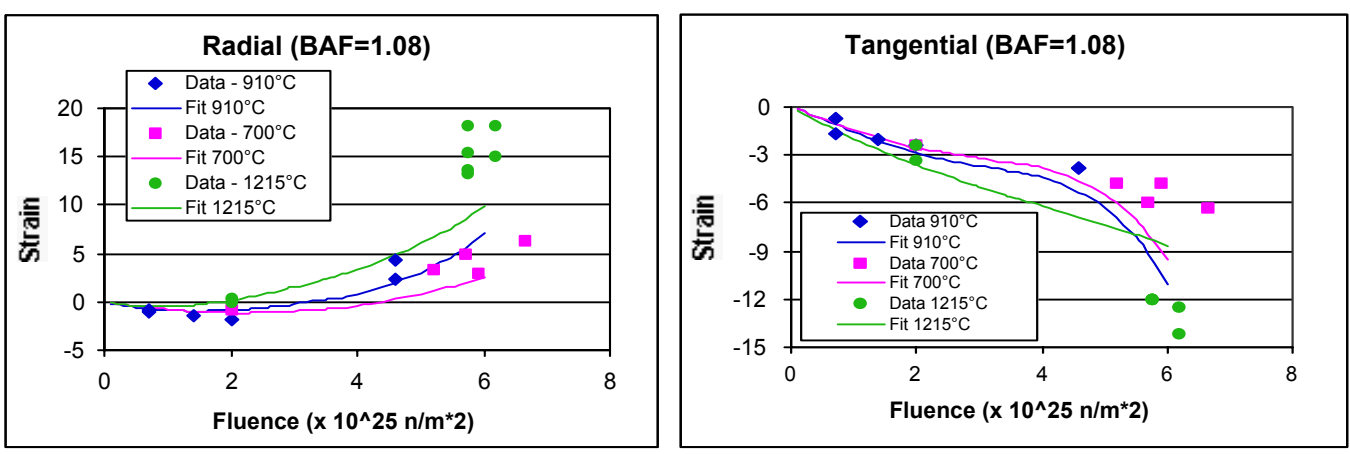

Figure 1-1. Database underlying the CEGA PyC shrinkage correlation expressed in units of \% strain.

Figure 1-2 displays the CEGA shrinkage correlation for several PyC anisotropies (as indicated by the BAF values). The CEGA correlations are also compared to the UK STRESS3 correlations (Martin 2001) in Figure 1-3, for both HTI and LTI high density, low anisotropy PyC. These correlations generally display the same shrinkage trends but differ in magnitude, especially at high neutron fluences. 

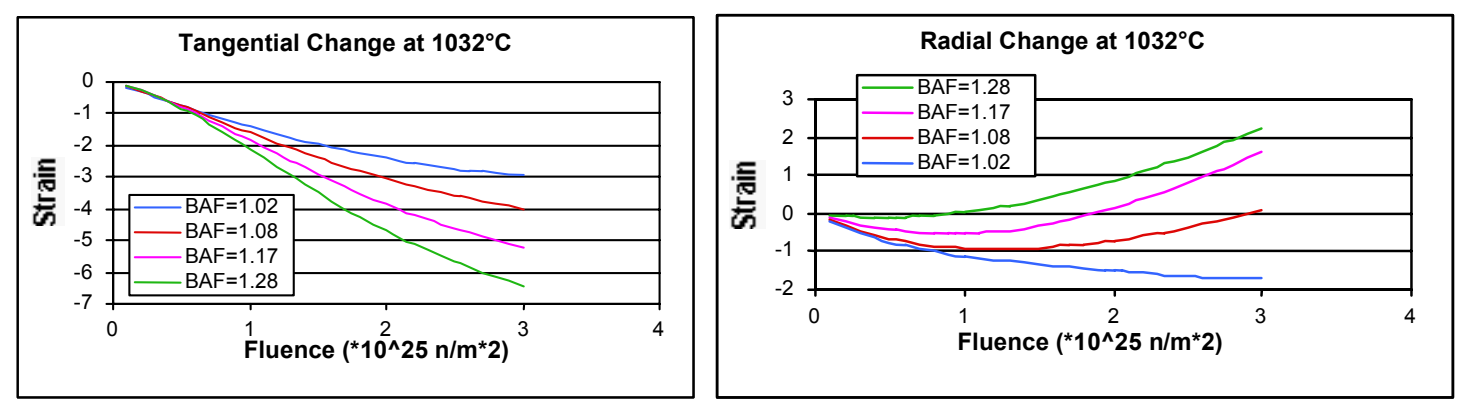

Figure 1-2. CEGA correlation of PyC shrinkage for various anisotropies expressed in units of $\%$ strain.
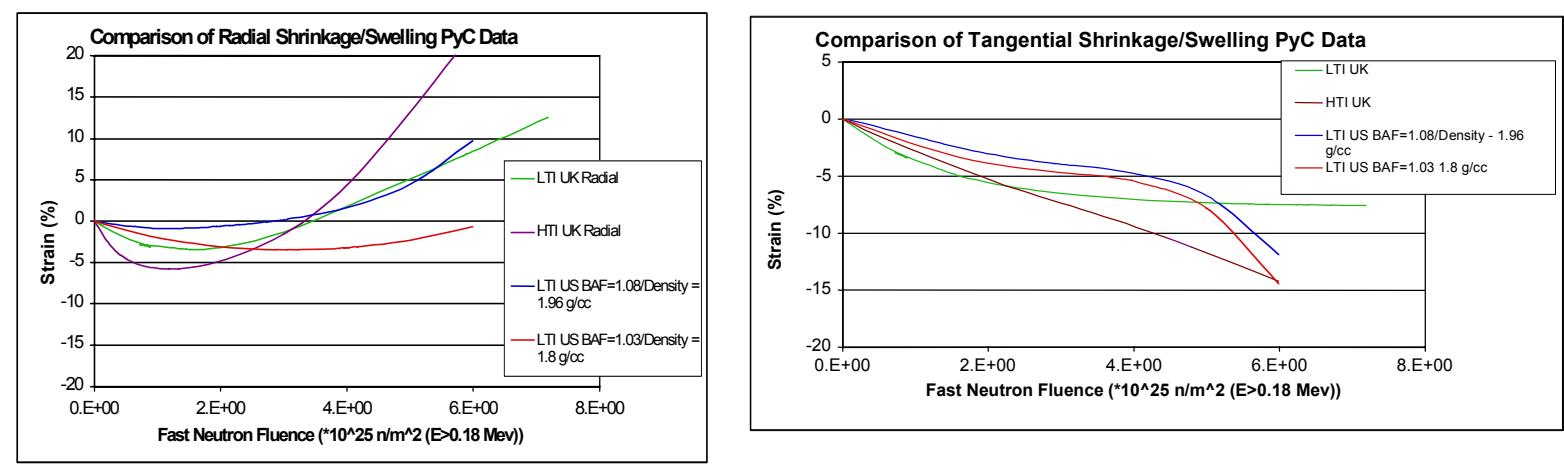

Figure 1-3. STRESS3 and CEGA correlations for PyC shrinkage.

\section{PyC Irradiation-Induced Creep}

Irradiation-induced creep in the PyC layers is another important property that affects the stressstate of the particle. However, there is a considerable range of values reported in the literature as indicated by the sources listed in Table 1-1. Even by disregarding the value from Morgand (which is generally considered to be suspect), the creep constant varies by a factor of about five.

Table 1-1. Selected irradiation induced creep constants for PyC (expressed for neutron fluences with $\mathrm{E}>0.18 \mathrm{MeV}$ ).

Author $\quad$ Creep constant $10^{-29}\left(\mathrm{MPa} \mathrm{n} / \mathrm{m}^{2}\right)^{-1}$

Kaae et al. (1972)

Price and Bokros (1967)

Buckley et al (1975)

Buckley et al. (1975)

Brocklehurst and Gilchrist (1976) 3.3

Brocklehurst and Gilchrist (1976) 1.7

Morgand (1975) 
One of the current creep correlations used in the PARFUME code is the correlation compiled by the CEGA Corporation (CEGA, 1993) and is referred to as the base creep value. However, it has been shown that PARFUME particle failure calculations of past NPR irradiation experiments (Miller, 2002) best match actual test results when this base creep value is multiplied by a factor of 2.5 (when coupled with a Poisson's ratio in creep of 0.5). An amplification factor of 2.0 may be better yet when coupled with a creep Poisson's ratio of 0.4. This amplified value is closer in magnitude to the historical U.S. value and the currently used STRESS3 value than the base value. STRESS3 is the standard particle fuel performance code used primarily by European investigators (Martin 2001). Table 1-2 lists these creep constants at a temperature of $1200{ }^{\circ} \mathrm{C}$. The most recent analysis in Section 2 suggests that an amplification value of 1.8 with the latest statistical method may be somewhat better.

Table 1-2. Various PyC irradiation induced creep constants at $1200{ }^{\circ} \mathrm{C}$ (expressed for neutron fluences with $\mathrm{E}>0.18 \mathrm{MeV}$ ).

Correlation Creep constant $10^{-29}\left(\mathrm{MPa} \mathrm{n} / \mathrm{m}^{2}\right)^{-1}$

Base (CEGA correlation) $\quad 2.0$

Amplified value (base x 2.5) $\quad 5.0$

Historical U.S. $\quad 6.2$

STRESS3 4.9

The magnitude of the PyC irradiation creep value has a large influence on the stress state of the $\mathrm{SiC}$ layer. This is evident in Figure 1-4 which displays the stress experienced by the SiC layer (with a cracked inner PyC layer) assuming the base and amplified creep values at $1200^{\circ} \mathrm{C}$. Clearly more data are needed here.

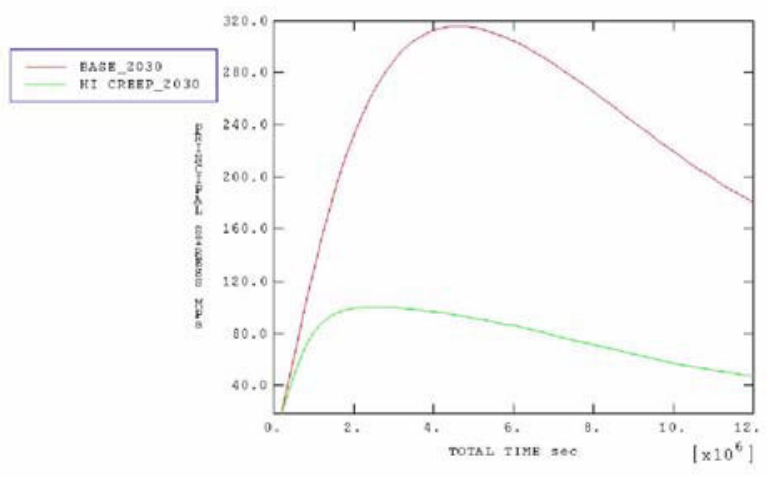

Figure 1-4. Calculated SiC stress using different values of irradiation-induced creep. 


\section{PyC Poisson's Ratio in Creep}

The magnitude of Poisson's ratio in creep for the PyC layer also has a significant affect on the stress-state of the particle. This parameter is quoted with a range of 0.3 to 0.5 in the literature. However, a value of 0.5 implies no volume change and it is generally acknowledged that a realistic value is closer to 0.4 . As illustrated by PARFUME calculations listed in Table 1-3, the stress in the fuel particle can vary by over $20 \%$ depending upon the value of Poisson's ratio.

Table 1-3. Effect of Poisson's ratio in creep on calculated stress levels.

\begin{tabular}{|c|c|c|c|c|}
\hline \multirow[b]{2}{*}{ Case } & \multicolumn{2}{|c|}{$\begin{array}{l}\text { IPyC Stress } \\
\text { (MPa, tension) }\end{array}$} & \multicolumn{2}{|c|}{$\begin{array}{c}\text { SiC Stress } \\
\text { (MPa, compression) }\end{array}$} \\
\hline & $v_{c}=0.4$ & $v_{c}=\mathbf{0 . 5}$ & $v_{c}=\mathbf{0 . 4}$ & $v_{c}=0.5$ \\
\hline Nominal, $\mathrm{T}=1273 \mathrm{~K}$ & 351 & 475 & 697 & 847 \\
\hline Nominal, $\mathrm{T}=873 \mathrm{~K}$ & 488 & 627 & 948 & 1107 \\
\hline NPR-1, compact A9 & 307 & 430 & 610 & 784 \\
\hline NPR-2, compact A4 & 449 & 599 & 895 & 1101 \\
\hline
\end{tabular}

\section{PyC Anisotropy Change Under Irradiation}

Under high strains, some PyC will reorient itself and become more anisotropic leading to higher stresses and the potential for particle failure at high neutron fluences. This phenomenon is dependent on the initial structure of the PyC. The data, as displayed in Figures 1-5 (Tempest 1978) and 1-6 (CEGA 1993), suggests that this effect is more prevalent for lower density PyC and/or for material produced at lower coating rates. However, this effect is not consistent with the German irradiation database which used high density PyC produced at high coating rates (Approximately $1.9 \mathrm{~g} / \mathrm{cm}^{3}$ produced at high coating rates of 4 to $6 \mu \mathrm{m} / \mathrm{min}$ ). 


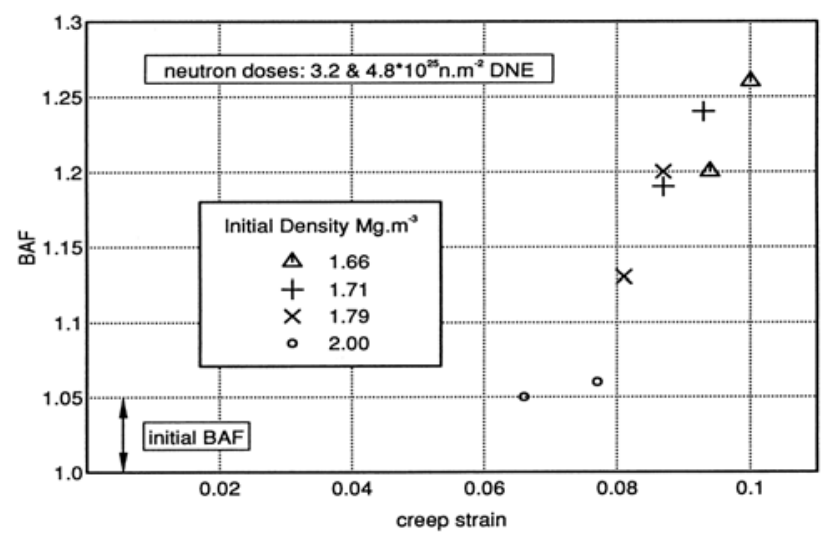

Figure 1-5. Changes in PyC anisotropy due to irradiation (Tempest 1978).

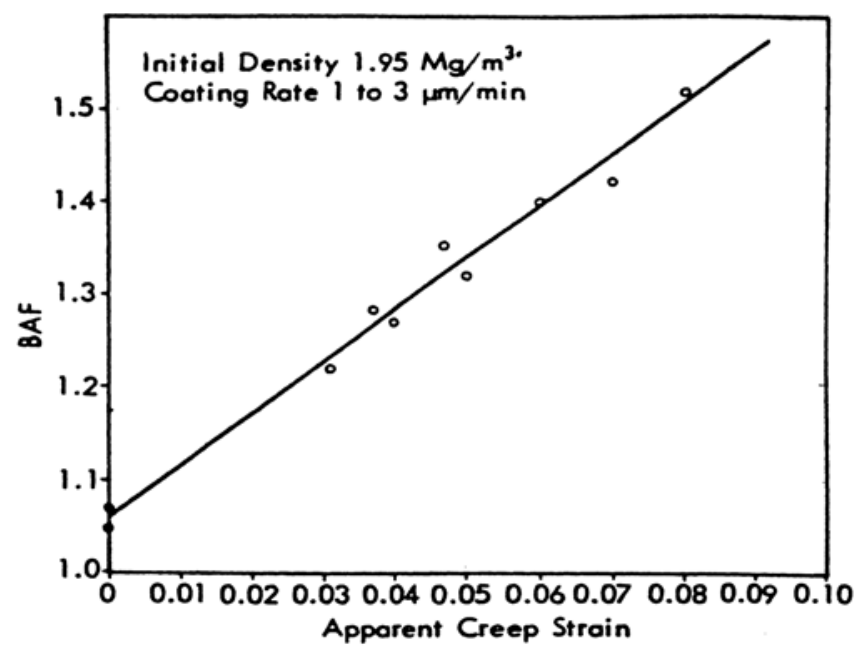

Figure 1-6. Changes in PyC anisotropy due to irradiation (CEGA 1993).

\section{PyC and SiC Fracture Strength}

Weibull theory is widely used to predict particle layer failures. The Weibull failure probability, $\mathrm{P}_{\text {failure }}$, may be expressed as:

$$
\mathrm{P}_{\text {failure }}=1-\exp \left(-\sigma_{\mathrm{c}} / \sigma_{\mathrm{ms}}\right)^{\mathrm{m}}
$$

where $\sigma_{\mathrm{c}}$ is the calculated maximum stress in the material, $\sigma_{\mathrm{ms}}$ is the Weibull mean fracture strength, and $\mathrm{m}$ is the Weibull modulus. The parameters used in the Weibull formulation are indicative of the flaw distribution in a given volume of a material. These values may then be dependent upon a particular production batch of the material. Considerable variation does exist in these parameters among various sources. Table 1-4 lists Weibull parameters from selected sources and the corresponding stress required to reach a failure fraction of $1 \times 10^{-4}$. As suggested 
by Table 1-4, there is a considerable range in predicted failure levels depending upon the choice of Weibull parameters.

Table 1-4. Weibull parameters for particle fuel.

\begin{tabular}{|l|l|c|c|c|}
\hline Material & \multicolumn{1}{|c|}{ Source } & $\begin{array}{c}\text { Weibull mean } \\
\text { Fracture strength } \\
(\mathrm{MPa})\end{array}$ & Modulus & $\begin{array}{c}\text { WeibullStress } \\
\text { required for10 } \\
\text { failure fraction } \\
(\mathrm{MPa})\end{array}$ \\
\hline $\mathrm{PyC}$ & CEGA & 300 & 9.5 & 114 \\
\hline & German & -200 & 5 & 34 \\
\hline $\mathrm{SiC}$ & CEGA & 500 & 6 & 107 \\
\hline & STAPLE (UK) & 200 & 5 & 34 \\
\hline & German (unirrad.) & 834 & 8 & 276 \\
\hline & German (irrad.) & 667 & 6 & 157 \\
\hline
\end{tabular}

\section{PyC CTE and Elastic Modulus}

The coefficient of thermal expansion (CTE) and the elastic modulus of PyC are important material properties especially needed to describe the behavior of particle fuel during thermal transients where differential thermal expansion of the particle layers may lead to significant mechanical interactions. CTE for PyC is different in the radial and tangential orientations and depends upon the anisotropy of the material. The effect of irradiation on this property is unknown. Figure 1-7 displays PyC CTE data at various temperatures. (Martin 2001) Figure 1-8 displays the elastic modulus for $\mathrm{PyC}$ which is a function of anisotropy, neutron fluence, density, and temperature (CEGA 1993).

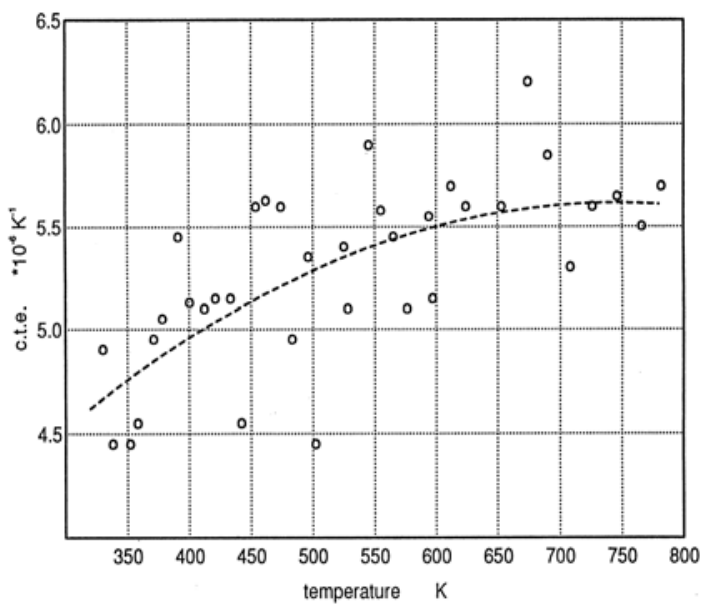

Figure 1-7. Coefficient of thermal expansion for PyC. 

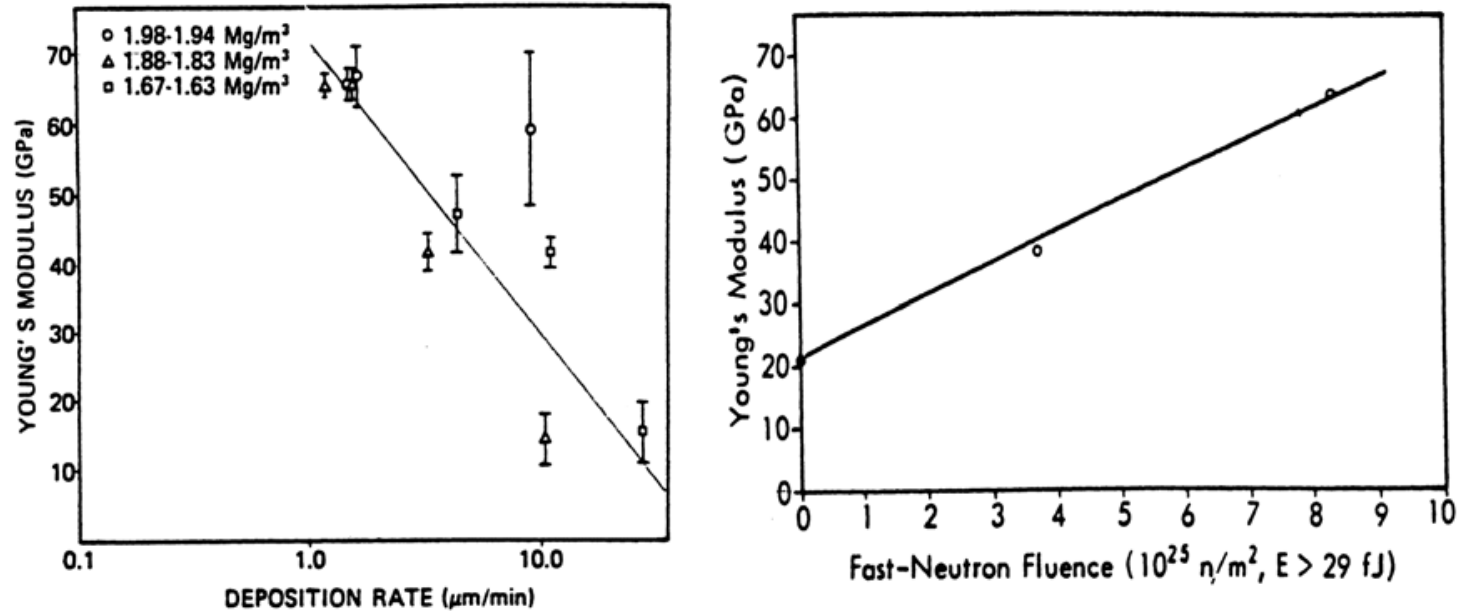

Figure 1-8. Elastic modulus for PyC (CEGA 1993).

\section{Kernel Swelling}

Solid fission product fuel swelling is an important phenomena at high burnups because it can reduce the void volume within the particle which increases the internal gas pressure. Under some conditions, fuel swelling can also lead to kernel - coating layer mechanical interaction which may result in particle failure. Theoretical estimates (Olander 1976) of swelling range from 0.3 to 0.45 $\% \Delta \mathrm{V} / \mathrm{V}$ per atom percent burnup. However, experimental measurements indicate larger values in the range of 0.6 to $1.5 \% \Delta \mathrm{V} / \mathrm{V}$ per atom percent burnup (these larger values may be due to intergranular fission gas bubbles). At $20 \%$ FIMA, this amount of swelling corresponds to a 6 to $30 \%$ increase in the volume of the kernel. For particles with sufficiently thin buffer layers (due to the high coating rates for the buffer, this layer displays the greatest variability in thickness among the particle layers), kernel - coating mechanical interaction may occur. Figure 1-9 presents a STRESS3 calculation indicating such an interaction (Martin 2002). 


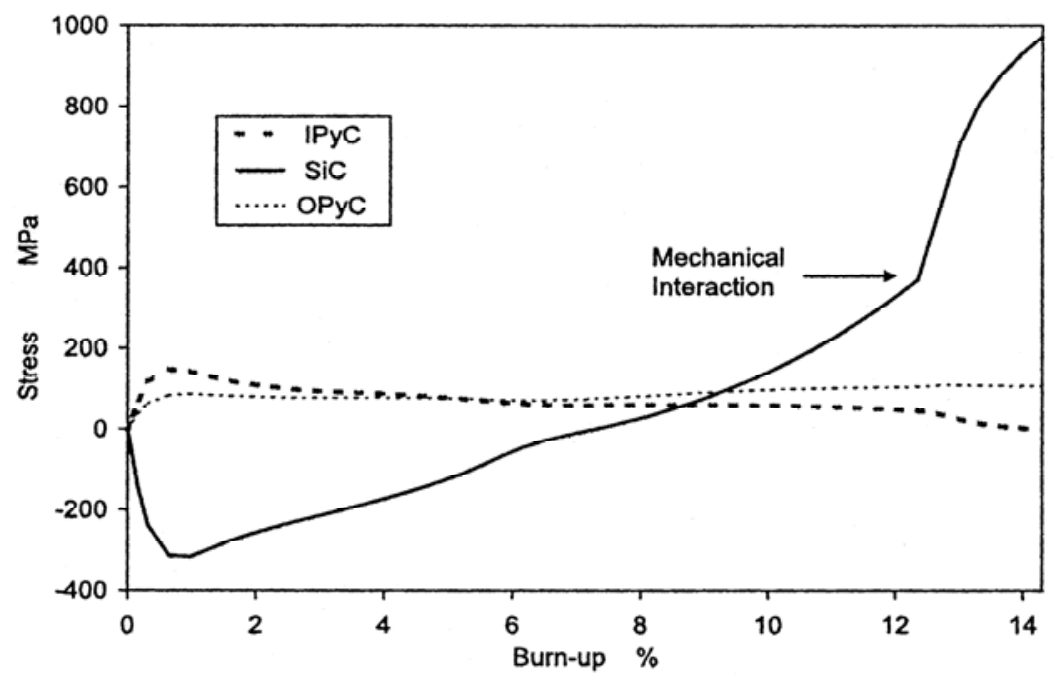

Figure 1-9. A STRESS3 calculation indicating kernel - coating layer mechanical interaction.

\section{CO Production}

The release of excess oxygen in $\mathrm{UO}_{2}$ fuels causes $\mathrm{CO}$ production to become significant at high burnups. Existing experimental data of $\mathrm{CO}$ production is sparse and displays large scatter (by over an order of magnitude). Furthermore, there are no data at high burnups. Figure 1-10 displays the Proksch correlation (Proksch 1982) which is an empirical fit to the data for excess oxygen yield from $\mathrm{UO}_{2}$ fuel and is limited to 550 full power days of irradiation (about one half of full burnup) and displays a quadratic time dependency. Also displayed in Figure 1-10 are historic General Atomics (GA) correlations for oxygen yield from low enriched uranium fuel (Kovacs et al. 1985). The GA correlations depend upon only temperature. A detailed thermodynamic model for CO production has recently been completed and will be used in the code (INEEL 2002). 


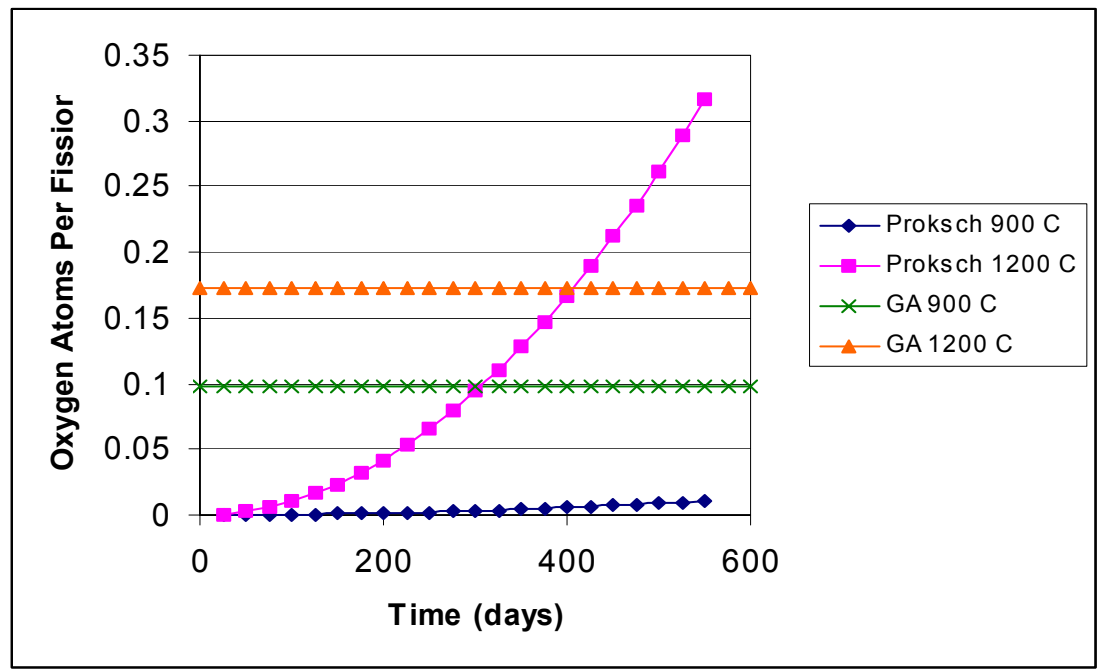

Figure 1-10. Correlations for oxygen release per $\mathrm{UO}_{2}$ fission.

\section{Fission Gas Release}

Particle fuel performance evaluations almost universally use the classic Booth equivalent sphere diffusion model for fission product gas release. Differences in this application arise from different gas diffusivities being used. Generally, the impact of these differences on the fractional gas release is fairly small. This is evident from Table 1-5 which lists fission gas release fractions as calculated by PARFUME and MINIPAT (Martin 1982) which use different fission product gas diffusion coefficients. The diffusivity used in MINIPAT is based upon the work of Horsley (Horsley 1976) and has been also used in German coated particle fuel performance models.

Table 1-5. Calculated fission product gas release fractions.

\begin{tabular}{|l|c|c|}
\hline & German Fuel & U.S. HEU NPR Fuel \\
& $8.5 \%$ FIMA, $900^{\circ} \mathrm{C}, 3 \mathrm{yr}$ irrd. & $79 \%$ FIMA, $1200^{\circ} \mathrm{C}, 3 \mathrm{yr}$ irrd. \\
\hline PARFUME & .23 & .86 \\
\hline MINIPAT & .33 & .95 \\
\hline
\end{tabular}




\section{CEA:}

\section{Kernel}

CEA brings its experience on $\mathrm{UO}_{2}$ and $(\mathrm{U}, \mathrm{Pu}) \mathrm{O}_{2}$ fuels behavior under irradiation. It is proposed to take advantage of this experience and to establish, in the frame of this I-NERI collaboration, a set of properties and models for the kernel of the coated particle. We have recently written a Technical Document in which, we have gathered a collection of physical and mechanical properties for $\mathrm{UO}_{2}$ and $(\mathrm{U}, \mathrm{Pu}) \mathrm{O}_{2}$ fuels taking into account the effects of important parameters such as temperature, burnup and porosity. In addition, we have briefly described a certain number of fuel behavior models concerning in pile densification, fuel swelling, fission gas release and $\mathrm{CO}$ production.

The proposed models come from the CEA knowledge on PWR and FBR oxide fuels. Most are used in CEA codes for several years and were validated. Concerning CO production, we selected an empirical model in the open literature built on experimental data and which was already used in the past in other HTR codes.

\section{Properties of $\mathrm{UO}_{2}$}

Most of the properties of $\mathrm{UO}_{2}$ fuel proposed are based on recommendations for sintered fuels PWR fabrications. There is much less information for $\mathrm{UO}_{2}$ prepared according to the Sol gel process. Nevertheless, we think the future kernel fabrication, the measurement of certain properties need to be carried out to validate the merits of the present recommendations.

The following essential formulations will be considered:

- linear thermal expansion,

- thermal conductivity,

- Young's modulus. 


\section{Linear thermal Expansion}

The linear thermal expansion of $\mathrm{UO}_{2}$ is deduced from the following expression giving the linear expansion:

For $\mathrm{T}_{\mathrm{K}}<923 \mathrm{~K}$ :

$$
\frac{1_{\mathrm{T}_{\mathrm{K}}}}{1_{273}}=9.9734 \times 10^{-1}+9.802 \times 10^{-6} \mathrm{~T}_{\mathrm{K}}-2.705 \times 10^{-10} \mathrm{~T}_{\mathrm{K}}^{2}+4.391 \times 10^{-13} \mathrm{~T}_{\mathrm{K}}^{3}
$$

For $\mathrm{T}_{\mathrm{K}} \geq 923 \mathrm{~K}$ :

$$
\frac{1_{\mathrm{T}_{\mathrm{K}}}}{1_{273}}=9.9672 \times 10^{-1}+1.179 \times 10^{-5} \mathrm{~T}_{\mathrm{K}}-2.429 \times 10^{-9} \mathrm{~T}_{\mathrm{K}}^{2}+1.219 \times 10^{-12} \mathrm{~T}_{\mathrm{K}}^{3}
$$

with $\mathrm{T}_{\mathrm{K}}$ in $\mathrm{K}$.

The averaged linear thermal expansion coefficient between 273 and $\mathrm{T}_{\mathrm{K}}$ is given by:

$$
\alpha_{\left(273-T_{K}\right)}=\frac{1}{\left(T_{K}-273\right)}\left(\frac{l_{T_{K}}}{l_{273}}-1\right)
$$

The correction for substoichiometric mixed oxide fuels $(\mathrm{O} / \mathrm{M}<2)$ is as follows:

$$
\left(\frac{1_{\mathrm{T}_{\mathrm{K}}}-1_{273}}{1_{273}}\right)_{2-\mathrm{x}}=\left(\frac{1_{\mathrm{T}_{\mathrm{K}}}-1_{273}}{1_{273}}\right)_{2}(1+3.9 \mathrm{x}) \quad \text { with }: \mathrm{x}=2-(\mathrm{O} / \mathrm{M})
$$

\section{Thermal Conductivity}

A study on the laws of $\mathrm{UO}_{2}$ thermal conductivity, available in the open literature, was recently conducted. This study allows us to propose a new recommendation, inspired by the "LUCUTA's law" of 1996 and validated on instrumented fuel tests up to 1900K. This law, applicable for stoichiometric $\mathrm{UO}_{2}$ fuel, is henceforth used in the current version of our PWR rod code METEOR. It considers the effects of fission products in solid solution, fission product precipitates, porosity, and radiation damage on the overall conductivity.

$$
\lambda=\mathrm{K}_{1 \mathrm{~d}} \mathrm{~K}_{1 \mathrm{p}} \mathrm{K}_{2 \mathrm{p}} \mathrm{K}_{4 \mathrm{r}} \lambda_{0}
$$


With the law proposed by Harding and Martin for the unirradiated $\mathrm{UO}_{2}$,

$$
\lambda_{0}\left(T_{K}\right)=\frac{1}{0.0375+2.165 \times 10^{-4} T_{K}}+\frac{4.715 \times 10^{9}}{T_{K}^{2}} \exp \left(-\frac{16.361}{T_{K}}\right)
$$

The correction due to FP in solid solution:

$$
\mathrm{K}_{1 \mathrm{~d}}=\left(\frac{1.09}{\tau^{3.265}}+\frac{0.0643}{\sqrt{\tau}} \sqrt{\mathrm{T}_{\mathrm{K}}}\right) \arctan \left[\frac{1}{\left(\frac{1.09}{\left.\tau^{3.265}+\frac{0.0643}{\sqrt{\tau}} \sqrt{\mathrm{T}_{\mathrm{K}}}\right)}\right]}\right]
$$

The correction due to FP precipitates:

$$
\mathrm{K}_{\mathrm{lp}}=1+\frac{0.019 \tau}{3-0.019 \tau} \frac{1}{\left(1+\exp \left(-\frac{\left(\mathrm{T}_{\mathrm{K}}-1200\right.}{100}\right)\right)}
$$

The correction due to porosity:

$$
\mathrm{K}_{2 \mathrm{p}}=\frac{1-\mathrm{P}}{1+2 \mathrm{P}}
$$

The correction due to radiation damages:

$$
\mathrm{K}_{4 \mathrm{r}}=1-\frac{0.2}{\left(1+\exp \left(\frac{\left(\mathrm{T}_{\mathrm{K}}-900\right.}{80}\right)\right)}(1-\exp (-\tau))
$$

where:

$$
\begin{array}{lll}
\lambda, \lambda_{0} & : \text { thermal conductivity } & (\mathrm{W} /(\mathrm{m}-\mathrm{K})) \\
\mathrm{T}_{\mathrm{K}} & : \text { temperature } & (\mathrm{K}) \\
\tau & : \text { burnup } & \text { (at \%FIMA) } \\
\mathrm{P} & : \text { pore fraction } & \\
\mathrm{x} & : \text { 2 }-\mathrm{O} / \mathrm{M} &
\end{array}
$$


Figure 1-11 shown below is a plot of thermal conductivity as a function of temperature burnup.

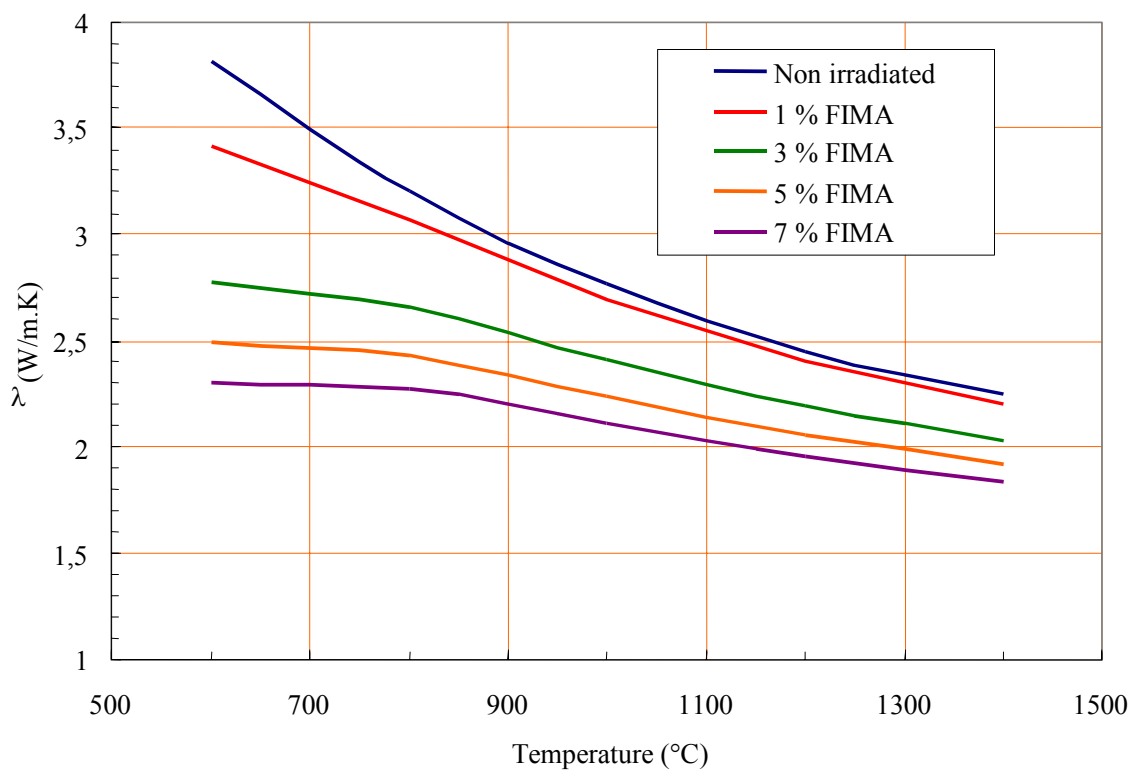

Figure 1-11. Thermal conductivity of $\mathrm{UO}_{2}$.

\section{Young's Modulus}

The evolution of the $\mathrm{UO}_{2}$ Young's modulus with both temperature and porosity is given by the following equations:

For $273 \leq \mathrm{T}_{\mathrm{K}} \leq 2,610 \mathrm{~K}$ :

$$
\mathrm{E}_{0}=2.2693 \times 10^{2}-1.5399 \times 10^{-2} \mathrm{~T}_{\mathrm{K}}-9.597 \times 10^{-6} \mathrm{~T}_{\mathrm{K}}^{2}
$$

For $\mathrm{T}_{\mathrm{K}}>2,610 \mathrm{~K}$ :

$$
\mathrm{E}_{0}=-1.33445 \times 10^{3}+1.18106 \mathrm{~T}_{\mathrm{K}}-2.38803 \times 10^{-4} \mathrm{~T}_{\mathrm{K}}^{2}
$$

The correction due to porosity is as follows:

If $\mathrm{P} \leq 0.3$ :

$$
\mathrm{E}=(1-2.5 \mathrm{P}) \mathrm{E}_{0}
$$

If $\mathrm{P}>0.3$ :

$$
\mathrm{E}=\frac{1-\mathrm{P}}{1+6 \mathrm{P}} \mathrm{E}_{0}
$$

where:

$$
\begin{array}{ll}
\mathrm{E}_{1} \mathrm{E}_{0} & : \text { Young's modulus } \\
\mathrm{T}_{\mathrm{K}} & : \text { temperature } \\
\mathrm{P} & : \text { fuel porosity }
\end{array}
$$




\section{Models}

\section{Densification}

The densification of $\mathrm{UO}_{2}$, at the beginning of the irradiation, results from a sintering under both the temperature and the fission spikes. The fine porosity population $(\mathrm{D}<1.5 \mu \mathrm{m})$ is the natural residue of the sintering, which is mainly removed.

The different mode of manufacture from both types of fuels - sintering for the PWR pellets and Sol gel process for the HTR kernels - can lead to a different size distribution of the porosity. Thus, most of empirical models developed for sintered fuels probably will not be suitable for Sol gel fuels.

Furthermore, the manufactured kernel density of future HTR fuel is required to be $\geq 95 \% \mathrm{TD}$. Consequently, we assume for a first approach, that it is not necessary to take into consideration the in-pile densification because it is of no consequence to the fuel swelling.

\section{Swelling}

\section{Solid FP swelling}

The fuel is considered as an isotropic material. The swelling rate which was determined from density measurements reflects the "solid swelling". The density measurements carried out on post-irradiated PWR and FBR fuels clearly display a linear behavior in relation with the burnup. This solid swelling includes not only the contribution of solid FP, but also that of the fission gas in super saturation in the fuel or partly precipitated as nanosized bubbles.

The solid swelling rate, $\dot{\mathrm{S}}_{\mathrm{S}}$ is given by the equation:

$$
\dot{\mathrm{S}}_{\mathrm{S}}=\frac{\mathrm{dS_{ \textrm {s } }}}{\mathrm{d} \tau}=\frac{\mathrm{d}\left(\frac{\Delta \mathrm{V}}{\mathrm{V}_{0}}\right)}{\mathrm{d} \tau}=0.06
$$

with: $\dot{\mathrm{S}}_{\mathrm{s}} \quad$ : solid swelling rate $\quad\left(\% / \mathrm{GWd} / \mathrm{t}_{\mathrm{HM}}\right)$ 


\section{Gaseous swelling}

The fuel swelling due to gaseous fission products (Xe, $\mathrm{Kr}$ ) mainly results in the increase of the bubble population and the bubble size in the matrix and in the grain boundaries. The mechanisms which lead to this swelling are complex which is why gaseous swelling models are often empirical correlations which depend only on macroscopic parameters such as temperature and burnup. Some models are available in open literature, and we propose to use for the HTR $\mathrm{UO}_{2}$ fuel, the "MATPRO" model. This empirical model simulates the gaseous steady state free swelling between 1000 and $2000 \mathrm{~K}$.

The gaseous swelling rate in relation with local temperature is as follows:

$$
\dot{S}_{g}=\frac{d S_{g}}{d \tau}=2.19912 \times 10^{-28}\left(2800-T_{K}\right)^{11.73} \exp \left[-0.0162\left(2800-T_{K}\right)\right]
$$

with:

$$
\begin{array}{ll}
\dot{\mathrm{S}}_{\mathrm{g}} \text { : gaseous swelling rate } & \left(\% / \mathrm{GWd} / \mathrm{t}_{\mathrm{HM}}\right) \\
\mathrm{T}_{\mathrm{K}} \quad \text { : temperature } & (\mathrm{K})
\end{array}
$$

\section{Fission gas release}

A number of fission gas release (FGR) models are available for steady state conditions. The release process is relatively complex but it may be reduced to a two-stage process: In the first stage, the gas atoms in the grain migrate by several mechanisms towards the grain boundaries. In the second stage, the gas migrates from these boundaries to the free surfaces of the fuel and then it is released in the free volume. For its simplicity, the "equivalent sphere" diffusion model or "Booth model" is usually employed for estimating the FGR of coated particles. More refined FGR models which are for the most part built on the original Booth model, take into account other contributions, for example, the trapping of gas atoms by matrix defects, the resolution of gas atoms from bubbles by fission spikes and, for high burnup, the principle of a gas saturation threshold which leads to an increase in the kinetics of release even at low temperatures.

The CEA model, developed for the FBR mixed oxide fuel takes into account the fact that the fission gas release becomes more intense when the fuel structure changes at high burnup particularly in the temperature range: $600-1200^{\circ} \mathrm{C}$. Consequently, this model is particularly relevant for fuel burnup greater than $10 \%$ FIMA. 
The model takes into account an athermal diffusion of the fission gas atoms which is prevailing below $1000^{\circ} \mathrm{C}$ and a gas saturation threshold function of the temperature. For the calculation of the saturation threshold, the model adopts the SPEIGHT theory which considers that the phenomena is controlled by the resolution into the matrix of the gas atoms from the bubbles as a result of fission spikes. The main consequence is the formation of an intra and intergranular gaseous porosity which interconnects and allows the release of the fission gas.

It is not possible to provide a comprehensive description of the model in the frame of the present document. Figure 1-12 demonstrates the gas saturation phenomena as a function of temperature. Figure 1-13 demonstrates the calculated release of fission gas as a function of burnup at 1000 and $1200^{\circ} \mathrm{C}$.

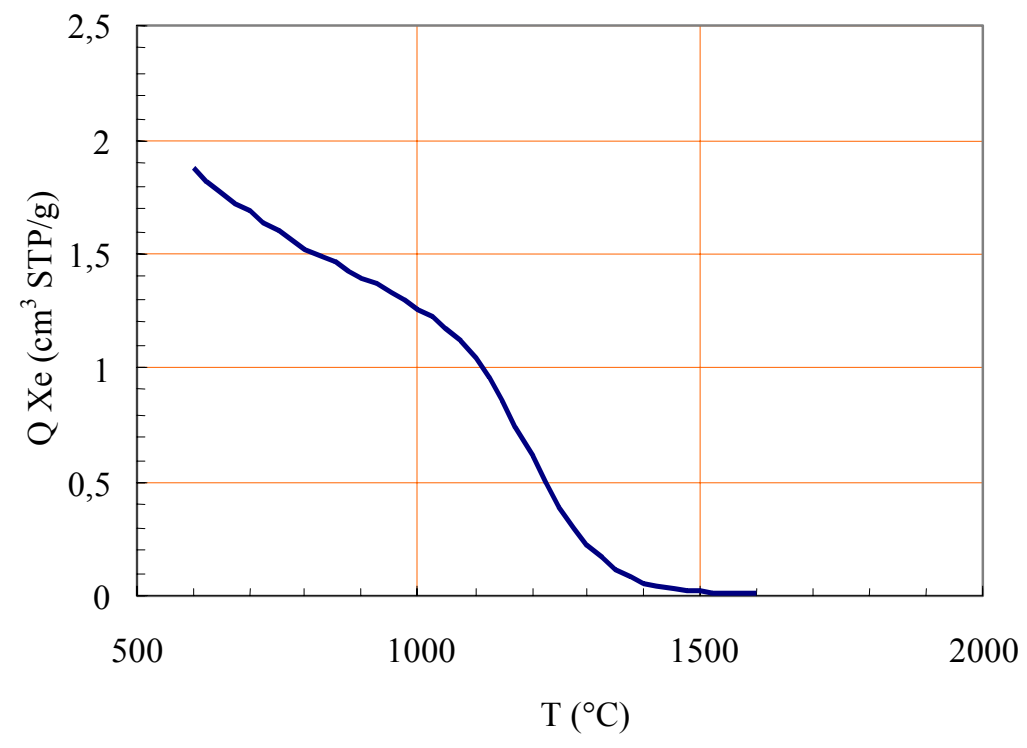

Figure 1-12. Limit of the gas saturation (super saturation in the matrix and in nanosized bubbles) in oxide fuel versus the fuel temperature 


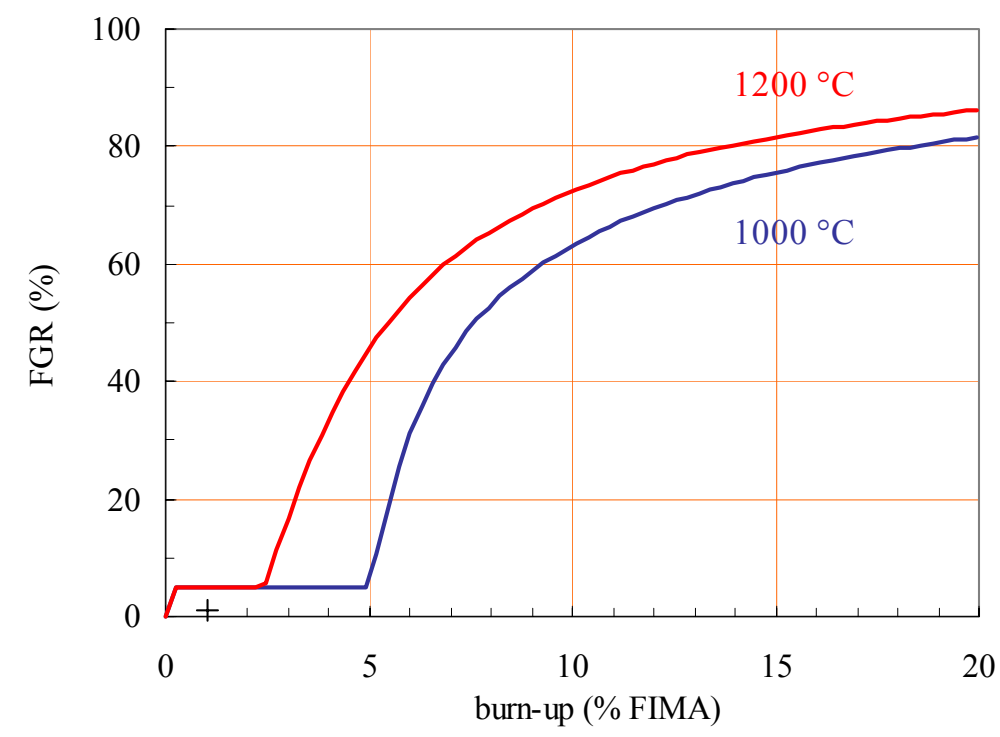

Figure 1-13. Evolution of the fission gas release rate with the fuel burnup

\section{CO production}

Among the different gases that contribute to pressure build-up in the particle, the CO production from the reaction between the free oxygen liberated by fission and the carbon of the inner coatings may become significant. In a large measure, the production of free oxygen depends on the nature of the fuel: oxide, oxi-carbide and on the type of actinide: uranium, plutonium. Fuels containing carbon (i.e., UCO) do not produce free oxygen as does $\mathrm{UO}_{2}$.

The formulation proposed by Homan for low-enriched uranium fuels $\left({ }^{235} \mathrm{U}<20 \mathrm{wt} \%\right)$ takes into account the influence of plutonium fissions on the oxygen production. It is assumed that negligible $\mathrm{CO}_{2}$ is formed under normal operating conditions.

The following equations have been proposed:

$$
\mathrm{O} / \mathrm{f}=1.64 \exp [-3311 / \mathrm{T}]
$$

and

$$
\mathrm{O} / \mathrm{f}_{\max }=0.61
$$

with:

$\mathrm{O} / \mathrm{f}$ : atomic oxygen release per fission

T: temperature 


\section{Pyrocarbons}

Pyrolytic carbons (PyC) are key protective materials in the design of the classical HTR fuel coated particles. The buffer is essentially a low-density pyrocarbon. The inner and outer pyrocarbon layers are made of dense pyrocarbon.

Based on both the temperature of the pyrolysis process and the nature of the hydrocarbon, one commonly considers two classes of "dense" PyC materials: high-temperature isotropic (HTI) PyC $\left(\theta>1800{ }^{\circ} \mathrm{C}\right.$ and $\mathrm{CH}_{4}$ - Ar mixture) and low-temperature isotropic (LTI) $\mathrm{PyC}\left(\theta<1500{ }^{\circ} \mathrm{C}\right.$ and generally $\mathrm{C}_{3} \mathrm{H}_{6}$ - Ar mixture). Many available data come from the first class (HTI), because of the large amount of testing that was performed during the 60's and 70's on this category of materials.

\section{Density}

The theoretical density of graphite material is $2.27 \mathrm{~g} / \mathrm{cm}^{3}$. The value supplied by FZJ and BNFL for a $100 \%$ dense $\mathrm{PyC}$ is a little lower than this value:

Table 1-6. Pyrolytic carbon density.

\begin{tabular}{|l|c|c|}
\hline Reference & FZJ & BNFL \\
\hline Theoretical density $\left(\mathrm{g} / \mathrm{cm}^{3}\right)$ & 2.2 \\
\hline Fabricated density for: & $\sim 1$ (Porosity $>50 \%)$ \\
\hline "buffer" layer $\left(\mathrm{g} / \mathrm{cm}^{3}\right)$ & $1.6<\rho<2$ \\
\hline dense PyC layers $\left(\mathrm{g} / \mathrm{cm}^{3}\right)$ & \multicolumn{2}{|c|}{} \\
\hline
\end{tabular}

\section{Coefficient of thermal expansion}

Very often, the data reported in the literature is not the true linear thermal expansion coefficient $(\alpha)$ but the mean value $(\bar{\alpha})$ given between two temperatures $T_{1}$ and $T_{2}$.

Table 1-7. Pyrolytic carbon coefficient of thermal expansion.

\begin{tabular}{|c|c|c|}
\hline Reference & FZJ & BNFL \\
\hline "buffer" layer $\alpha\left(10^{-6} \mathrm{~K}^{-1}\right)$ & & $\alpha=3.5$ \\
\hline \multirow{2}{*}{$\begin{array}{l}\text { dense isotropic PyC layers } \\
\alpha\left(10^{-6} \mathrm{~K}^{-1}\right)\end{array}$} & \multirow{2}{*}{$\alpha=5.5$} & $\begin{array}{l}\text { For } 300<\mathrm{T}<750 \mathrm{~K}: \\
\alpha=2.5523+8.22 \times 10^{-3} \mathrm{~T}-5.509 \times 10^{-6} \mathrm{~T}^{2}\end{array}$ \\
\hline & & For $\mathrm{T}>750 \mathrm{~K}: \quad \alpha=5.62$ \\
\hline
\end{tabular}




\section{Thermal Conductivity}

The thermal conductivity depends on the porosity and, consequently on the density of PyC.

Table 1-8. Pyrolytic carbon thermal conductivity.

\begin{tabular}{|l|c|lcc|}
\hline Reference & \multicolumn{1}{|c|}{ FZJ } & \multicolumn{3}{|c|}{ BNFL } \\
\hline "buffer" layer $\lambda\left(\mathrm{W} \mathrm{m}^{-1} \mathrm{~K}^{-1}\right)$ & $\lambda=0.5$ & \multicolumn{3}{|c|}{ No recommendation } \\
\hline & & After Bockros' data $(1966):$ & $\lambda:$ \\
dense isotropic PyC layers & & density & BAF* & 9.61 \\
$\lambda\left(\mathrm{W} \mathrm{m}^{-1} \mathrm{~K}^{-1}\right)$ & $\lambda=4$ & 1.55 & 1 & 12.54 \\
& & 1.82 & 1.05 & 7.52 \\
\hline
\end{tabular}

* The BAF (Bacon Anisotropy Factor) is determined by the variation in intensity of the $\{0002\}$ X-ray Debye-

Scherrer diffraction ring. The value 1 corresponds to a perfect isotropic material.

\section{Young's Modulus}

Table 1-9. Young's Modulus as a function of fast fluence for pyrolytic carbon.

\begin{tabular}{|c|c|c|}
\hline Reference & FZJ [1] & BNFL [2] \\
\hline $\begin{array}{l}\text { "buffer" layer E (MPa) } \\
\Phi\left(10^{25} \mathrm{n} / \mathrm{m}^{2}>0.1 \mathrm{MeV}\right)\end{array}$ & $\begin{array}{l}\text { For } 0<\Phi<0.5 \\
\qquad \mathrm{E}=7000+6000 \Phi \\
\text { For } \Phi>0.5 \quad \mathrm{E}=10000\end{array}$ & $\begin{array}{l}\text { For } \Phi<1.35 \\
\qquad E=-5000 \Phi^{2}+13500 \Phi+7000 \\
\text { For } \Phi>1.35 \mathrm{E}=16115\end{array}$ \\
\hline $\begin{array}{l}\text { dense isotropic PyC } \\
\text { layers } \quad \mathrm{E}(\mathrm{MPa}) \\
\Phi\left(10^{25} \mathrm{n} / \mathrm{m}^{2}>0.1 \mathrm{MeV}\right)\end{array}$ & $E=29000$ & $\begin{array}{l}\text { For } \Phi<1.4 \\
\qquad \mathrm{E}=-9554 \Phi^{2}+26750 \Phi+13820 \\
\text { For } \Phi>1.4 \quad \mathrm{E}=32545\end{array}$ \\
\hline
\end{tabular}

[2] Polynomial adjustment according to the constants of compliance used in the code STRESS 3. 


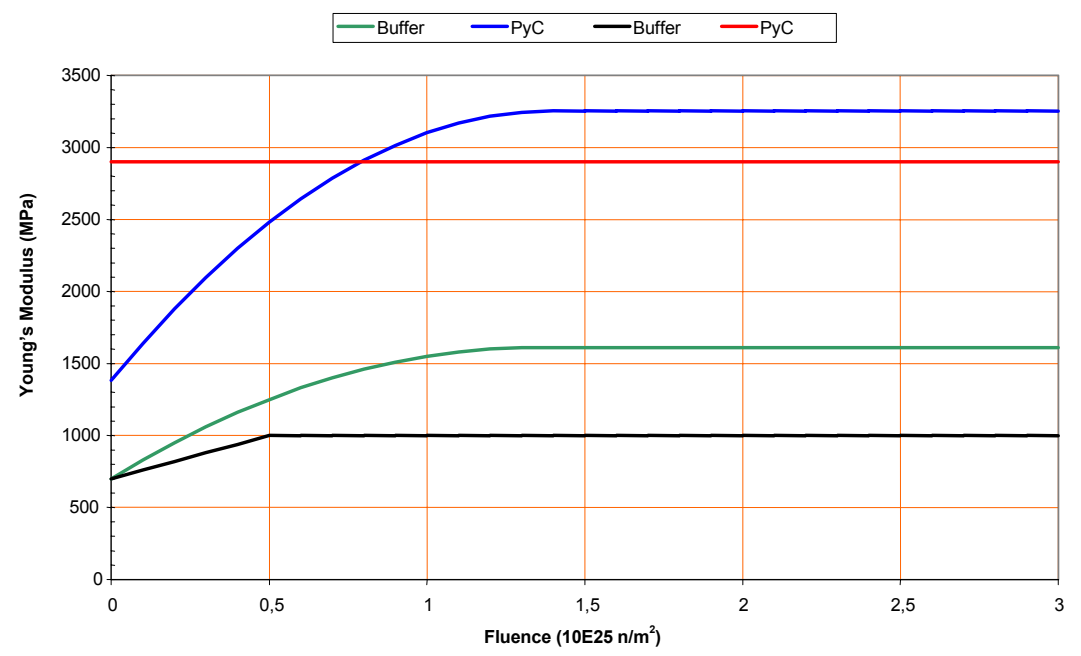

Figure 1-14.Young's modulus deduced from the constants by the relation: $E=1 / E_{11}$

\section{Poisson's Ratio}

Table 1-10. Poisson's Ratio for pyrolytic carbon.

\begin{tabular}{|c|c|c|}
\hline Reference & FZJ & BNFL $^{[1]}$ \\
\hline "buffer" layer $v$ & $v=0.3$ & $v=0.33$ \\
\hline dense isotropic PyC layers $v$ & $v=0.3$ & $v=0.33$ \\
\hline
\end{tabular}

[1] The Poisson's ratio is deduced from the constants of compliance currently used in the code STRESS 3 by the relation: $v=-$ E12/E11

\section{Ultimate Tensile Strength}

Pyrolytic carbons are generally treated as brittle materials. The scatter in the fracture strength (UTS) is often rather large because failure starts from the defects existing inside and at the surface of the material. The distribution density of failure " $\mathrm{f}$ " is given by a statistical distribution expressed in terms of a Weibull equation: 


$$
f=1-\exp \left\{-\ln 2\left(\frac{\sigma}{\sigma_{\text {med }}}\right)^{m}\right\}
$$

where $\sigma_{\text {med }}$ and $\mathrm{m}$ are constants whose values are determined from experiments. Recommended values are shown in the table below.

Table 1-11. Ultimate tensile strength for pyrolytic carbon.

\begin{tabular}{|l|c|c|}
\hline Reference & FZJ & BNFL ${ }^{[1]}$ \\
\hline "buffer" layer & No recommendation & No recommendation \\
\hline $\begin{array}{l}\text { dense isotropic PyC layers } \\
\sigma_{\text {med }}(\mathrm{MPa})\end{array}$ & No recommendation & $\begin{array}{c}\sigma_{\text {med }}=3518 \mathrm{P}^{2}-3277 \mathrm{P}+985 \\
\mathrm{~m}=-7.375 \mathrm{P}+7\end{array}$ \\
\hline
\end{tabular}

[1] Polynomial adjustment versus the porosity according to the data from Bongartz et al. (1976) on results obtained from propylene derived PyC deposits on flat discs.

\section{Irradiation-induced creep}

The irradiation-induced creep rate is given by the following expression:

where:

$$
\begin{array}{ll}
\dot{\varepsilon}_{1}=K\left[\sigma_{1}-v_{c}\left(\sigma_{2}+\sigma_{3}\right)\right] \quad \frac{d \Phi}{d t} \\
\mathrm{~K}: & \text { creep constant } \\
\sigma_{1}, \sigma_{2} \text { and } \sigma_{3} & \text { components of the stress tensor } \\
v_{\mathrm{c}} & \text { Poisson's coefficient for creep } \\
\frac{d \Phi}{d t} & \text { fast neutron flux }
\end{array}
$$

Table 1-12. Creep constant, K, for pyrolytic carbon.

\begin{tabular}{|lc|c|c|}
\hline Reference & & FZJ & BNFL $^{[1]}$ \\
\hline "buffer" layer & & $\mathrm{K}=9.6 \times 10^{-30}$ & $\mathrm{~K}=4.4 \times 10^{-29}$ \\
$\mathrm{~K}\left[\mathrm{MPa} \mathrm{n} \mathrm{m}^{2}(\mathrm{E}>0.1 \mathrm{MeV})\right]^{-1}$ & $v_{\mathrm{c}}$ & $v_{\mathrm{c}}=0.5$ & $v_{\mathrm{c}}=0.4$ \\
\hline Dense isotropic PyC layers & & $\mathrm{K}=1.4 \times 10^{-29}$ & $\mathrm{~K}=4.4 \times 10^{-29}$ \\
$\mathrm{~K}\left[\mathrm{MPa} \mathrm{n} \mathrm{m}^{2}(\mathrm{E}>0.1 \mathrm{MeV})\right]^{-1}$ & $v_{\mathrm{c}}$ & $v_{\mathrm{c}}=0.5$ & $v_{\mathrm{c}}=0.4$ \\
\hline
\end{tabular}

[1] data from Buckley et al. (1975) 


\section{Irradiation-induced dimensional change rate}

Fast neutron irradiation, the buffer and the dense $\mathrm{PyC}$ under irradiation-induced dimensional change. The dimensional change rate is a strong function of the density and anisotropy of the layer. A considerable number of measurements of dimensional change in unrestrained $\mathrm{PyC}$ has been reported in the open literature. Data recommended by both FZJ and BNFL are summarized in the following table:

Table 1-13. Irradiation-induced dimensional change rate for pyrolytic carbon.

\begin{tabular}{|l|c|c|}
\hline Reference & \multicolumn{1}{|c|}{$\mathrm{FZJ}^{[1]}$} & BNFL $^{[2]}$ \\
\hline $\begin{array}{l}\text { "buffer" layer } \\
\dot{\varepsilon}_{\mathrm{r}} \dot{\varepsilon}_{\theta}\left[10^{25} \mathrm{n} / \mathrm{m}^{-2}(>0.1 \mathrm{MeV})\right]^{-1}\end{array}$ & $\dot{\varepsilon}_{r}=\dot{\varepsilon}_{\theta}=-0.176 \exp (-1.75 \Phi)$ & $\dot{\varepsilon}_{r}=\dot{\varepsilon}_{\theta}=-0.241 \exp \left(-2.2 \Phi^{1.05}\right)$ \\
\hline & $\dot{\varepsilon}_{r}=-0.077 \exp (-\Phi)+0.031$ & $\dot{\varepsilon}_{r}=-0.1335 \exp \left(-1.5 \Phi^{0.8}\right)$ \\
& & $-1.12 \times 10^{-3} \Phi^{2}+1.85 \times 10^{-2} \Phi$ \\
dense isotropic PyC layers & $\dot{\varepsilon}_{\theta}=-0.036 \exp (-2.1 \Phi)-0.01$ & $\dot{\varepsilon}_{\theta}=-0.0225 \exp (-0.7 \Phi)$ \\
$\dot{\varepsilon}_{\mathrm{r}} \dot{\varepsilon}_{\theta}\left[10^{25} \mathrm{n} / \mathrm{m}^{-2}(>0.1 \mathrm{MeV})\right]^{-1}$ & & $-2.1 \times 10^{-3} \Phi-8 \times 10^{-3}$ \\
& & \\
\hline
\end{tabular}

[1] Adjustment according to the FZJ recommendation

[2] Adjustment from the data used in the code STRESS 3 and given in the "Tableau" $3 S$

The integrated dimensional change is plotted as a function of fast fluence in Figure 1-15.

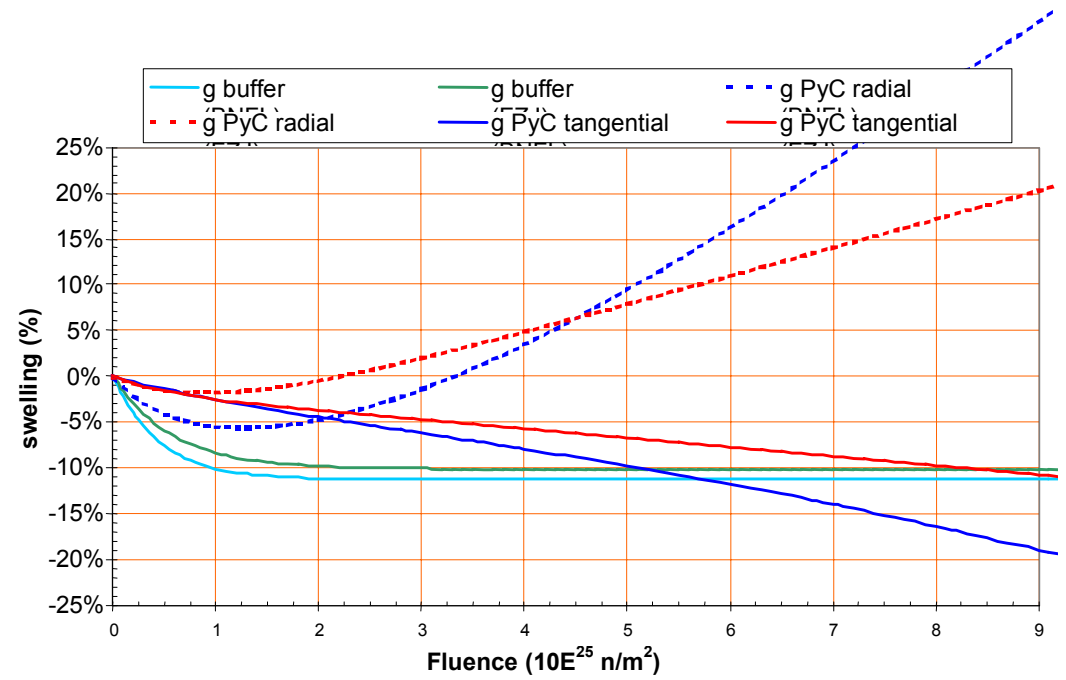

Figure 1-15. Pyrocarbon swelling and shrinkage data issued from FZJ and BNFL 


\section{Silicon carbide}

As the PyC layers, the silicon carbide ( $\mathrm{SiC}$ ) layer of the coated particle is set down from a mix of gases, the more often used is the methyltrichlorosilane (MTS) with $\mathrm{H}_{2}$ and sometimes Ar. The microstructure of pyrolytic $\mathrm{SiC}$ depends on temperature and rate of deposition of MTS. The $\beta$ (cubic) structure dominates but $\alpha$ phase and free silicon may be present at low $\left(<1250^{\circ} \mathrm{C}\right)$ deposition temperature.

Material property considerations are generally less of a problem for the $\mathrm{SiC}$ compared with the PyC materials. However, this layer plays a fundamental role for the mechanical and diffusion resistance of the coated particle; consequently, a good knowledge of the UTS of the SiC layer which can be enhanced by reducing the flaws, is very important for achieving high burnup. In this section, we provide the properties for pyrolytic $\mathrm{SiC}$ that are needed for the calculation of its behavior and the prediction of failure during irradiation and heating of coated particles.

\section{Thermal conductivity}

Due to the carbon-silicon covalent bond, thermal conductivity is proportional to the mean free path of phonons, which depends on impurities, anisotropy and the nature of the grain boundaries type dependent.

Parameters inducing high thermal conductivity of ceramic compounds are as follow:

- Simple crystal structure with high network symmetry.

- Mono-carbide formulation.

- Elements with similar atomic weight and with few isotopes.

- Covalent bonds.

$\beta-\mathrm{SiC}$ has all of these attributes to some degree. A disparity of conductivity values for different types of $\mathrm{SiC}$ is found in the literature: for example, about $500 \mathrm{~W} /(\mathrm{m}-\mathrm{K})$ for a single crystal, 200 $\mathrm{W} /(\mathrm{m}-\mathrm{K})$ for a self-bonded SiC and only $10 \mathrm{~W} /(\mathrm{m}-\mathrm{K})$ for a bad pyrolytic SiC. The selected thermal conductivity model was obtained after fitting Price data (1973) concerning CVD $\beta$-SiC and is as follows:

$$
\lambda(\mathrm{T})=\mathrm{A}+\mathrm{B} / \mathrm{T}+\mathrm{C} / \mathrm{T}^{2}+\mathrm{D} / \mathrm{T}^{3}
$$

with $\mathrm{T}(\mathrm{K}), \lambda(\mathrm{W} /(\mathrm{m}-\mathrm{K}))$ and $\mathrm{A}=42.58, \mathrm{~B}=-1.5564 \times 10^{4}, \mathrm{C}=1.2977 \times 10^{7}$ and $\mathrm{D}=-1.8458 \times 10^{9}$ 
Thermal conductivity decreases under irradiation, especially at low irradiation temperatures. A saturation phenomenon at low fluence occurs and the selected model beyond saturation was obtained after fitting Senor data (1996), and is given as follows:

$$
\lambda_{\text {irradiated }} / \lambda_{\text {unirradiated }}(\mathrm{T})=\mathrm{a} \exp (\mathrm{bT})
$$

with $\mathrm{a}=3.91112 \times 10^{-2}$ and $\mathrm{b}=2.24732 \times 10^{-3}$

To take into account the effect of porosity, the simplified correlation $\lambda(T, p)=\lambda_{0}(T)(1-p)$ is used where $\mathrm{p}$ is the porosity and $\lambda_{0}$ the original conductivity of the SiC. A plot of the thermal conductivity for different porosities and temperatures is shown in Figure 1-16.

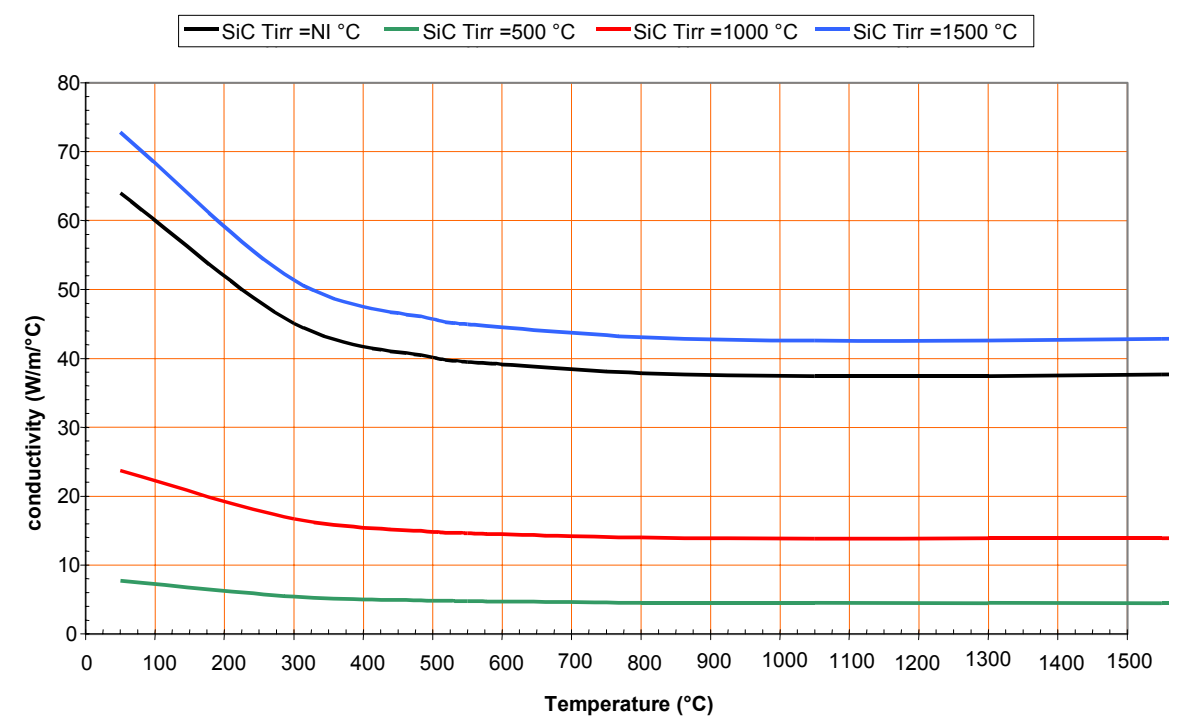

Figure 1-16. Beta $\mathrm{SiC}$ conductivity.

\section{Thermal expansion}

Like another covalent carbide $\left(\mathrm{B}_{4} \mathrm{C}\right)$, the silicon carbide thermal expansion rate is low $\left(4 \times 10^{-6}\right.$ to $\left.5 \times 10^{-6} \mathrm{C}^{-1}\right)$ compared to refractory carbides like $\mathrm{WC}, \mathrm{TiC}$ or $\mathrm{ZrC}\left(7 \times 10^{-6}\right.$ to $\left.8 \times 10^{-6} \mathrm{C}^{-1}\right)$ or oxides like $\mathrm{Al}_{2} \mathrm{O}_{3}\left(8.5 \times 10^{-6} \mathrm{C}^{-1}\right)$ or $\mathrm{MgO} .\left(13.8 \times 10^{-6} \mathrm{C}^{-1}\right)$. A plot is shown in Figure 1-17. 
The selected thermal expansion rate model, well adapted to $\beta$-SiC, was obtained after scanning Popper and Mohyuddin data and is as follows (average value):

$\alpha\left(20^{\circ} \mathrm{C}, \mathrm{T}\right)=3.43846 \times 10^{-6}+1.19402 \times 10^{-9} \mathrm{~T}-2.05716 \times 10^{-13} \mathrm{~T}^{2}$

The thermal expansion rate doesn't change under irradiation.

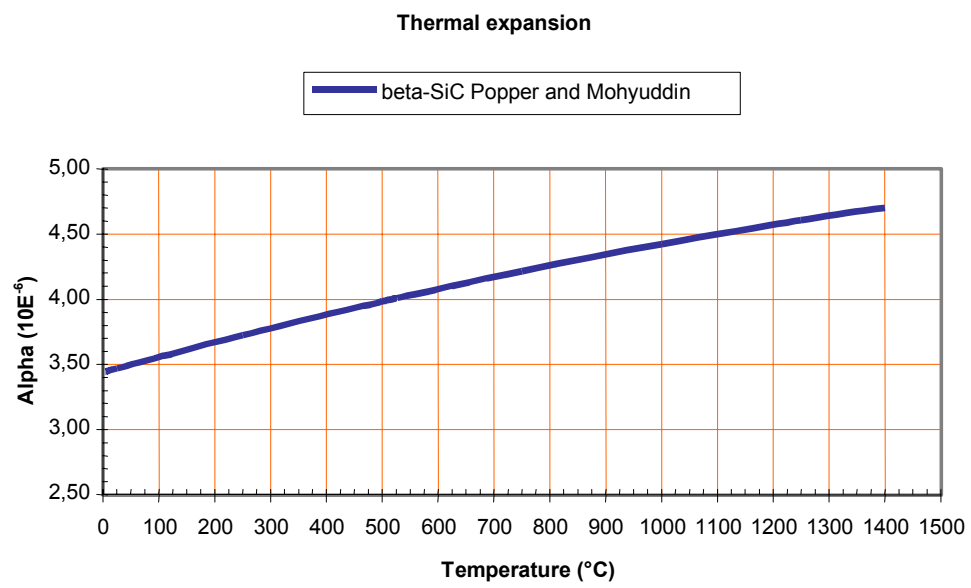

Figure 1-17. Thermal expansion.

\section{Young's modulus}

A disparity of Young's modulus values has been found in the literature, which is typical of brittle materials. Nevertheless, on the whole, Young modulus decreases with temperature, about one hundred GPa between $350^{\circ} \mathrm{C}$ and $1000^{\circ} \mathrm{C}$.

The selected Young's modulus model was obtained from Gulden data that appear to be the most consistent and is as follows:

$$
\begin{aligned}
\mathrm{E}(\mathrm{T})= & 432-(0.0741) \mathrm{T}+\left(1.541 \times 10^{-4}\right) \mathrm{T}^{2}-\left(5.401 \times 10^{-7}\right) \mathrm{T}^{3} \\
& +\left(8.142 \times 10^{-10}\right) \mathrm{T}^{4}-\left(5.18 \times 10^{-13}\right) \mathrm{T}^{5}+\left(1.043 \times 10^{-16}\right) \mathrm{T}^{6}
\end{aligned}
$$

At room temperature, Young's modulus for CVD $\beta$-SiC is about $430 \mathrm{GPa}$. 
To take into account the effect of porosity, the empirical correlation $\mathrm{E}=\mathrm{E}_{0}$. exp $(-\mathrm{C}, \mathrm{p})$ is used where $\mathrm{C}=3.12$ (datum available for $\mathrm{CVD} \beta-\mathrm{SiC}$ ) and $\mathrm{p}$ is the porosity. The Young's modulus of pyrolitic SiC doesn't change under irradiation. Figure 1-17 plots the correlation as a function of temperature for fully dense and $5 \%$ porous $\mathrm{SiC}$.

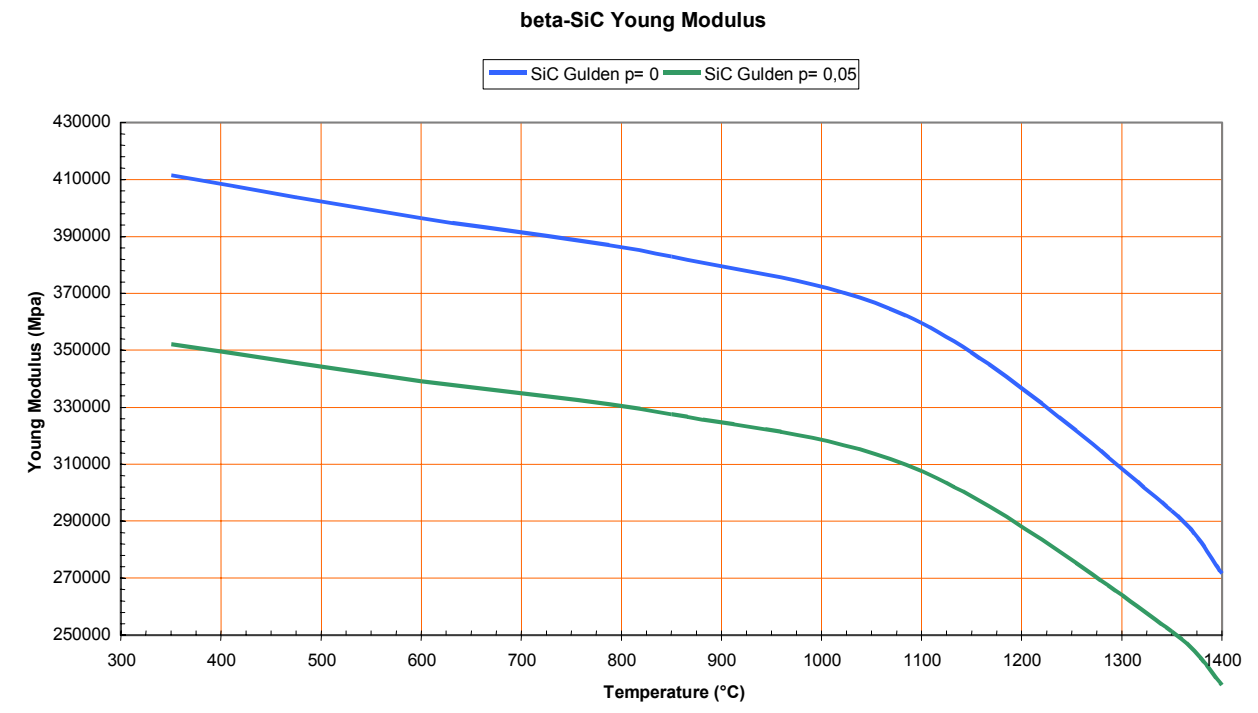

Figure 1-18. Beta SiC Young's Modulus.

\section{Poisson's ratio}

A few values reported in the literature are cited in the following table:

Table 1-14 Poisson ratio for $\mathrm{SiC}$.

\begin{tabular}{|c|c|c|c|}
\hline Reference & $\mathrm{SiC}$ & Density & $v$ \\
\hline Munro, R.G. & $\begin{array}{l}\alpha \text {-SiC Hexoloy SA }{ }^{\mathrm{TM}} \\
\left(2500^{\circ} \mathrm{C}\right)\end{array}$ & 0.98 & 0.160 \\
\hline Carnahan, R.D. & $\begin{array}{l}\alpha \text {-SiC "pressure } \\
\text { sintered" }\left(2100^{\circ} \mathrm{C}\right)\end{array}$ & 0.9993 & 0.168 \\
\hline $\begin{array}{l}\text { Compilation Battelle } \\
\text { Institute }\end{array}$ & "reaction sintered" & 0.975 & 0.13 to 0.24 \\
\hline Gibson, J. & deposition & & 0.18 \\
\hline $\begin{array}{l}\text { Handbook- Pierson, } \\
\text { H.O, } 1996\end{array}$ & & & 0.142 \\
\hline $\begin{array}{l}\text { Yavuz, B.O, Tressler, } \\
\text { R.E. }\end{array}$ & CVD $\beta-\mathrm{SiC}$ & & $0.13 \pm 0.02$ \\
\hline $\begin{array}{l}\text { Slavin, M.J., Quinn, } \\
\text { G.D. }\end{array}$ & "Sintered" $\beta-\mathrm{SiC}$ & $\sim 0.97$ & 0.17 \\
\hline
\end{tabular}




\section{Swelling}

The data concerning the neutron-induced swelling suggest three different regimes:

- Low temperature: swelling is the result of amorphisation and the volume increase is about $11 \%$ for a total phase transformation.

- Intermediate temperature: swelling is moderate and is the result of Frenkel pairs or Frank dislocation loops accumulation.

- Elevated temperature: swelling is the result of voids creation due to vacancy migration and coalescence.

The selected neutron-induced model was obtained after fitting Price data concerning CVD $\beta$-SiC and is as follow:

- Between $25^{\circ} \mathrm{C}$ and $800^{\circ} \mathrm{C}$ :

$$
\mathrm{G}_{\mathrm{sat}}[\%]=-3.3283 \times 10^{-3} \mathrm{~T}+3.1133 \text { and } \mathrm{G}=\mathrm{G}_{\mathrm{sat}}\left(1-\exp \left(-\Phi / \Phi_{0}\right)\right)
$$

- Between $800^{\circ} \mathrm{C}$ and $1000^{\circ} \mathrm{C}$ :

$$
\mathrm{G}_{\mathrm{sat}}[\%]=-1.3528 \times 10^{-3} \mathrm{~T}+1.5329 \text { and } \mathrm{G}=\mathrm{G}_{\mathrm{sat}}\left(1-\exp \left(-\Phi / \Phi_{0}\right)\right)
$$

- Between $1250^{\circ} \mathrm{C}$ and $1500^{\circ} \mathrm{C}$ :

$$
\mathrm{G}[\%]=0.18\left(1-\exp \left(-\Phi / \Phi_{0}\right)\right)+1.297 \times 10^{-26} \Phi
$$

where $\mathrm{T}(\mathrm{K}), \Phi\left(\mathrm{n} / \mathrm{m}^{2}\right), \mathrm{E}>0.1 \mathrm{MeV}$, and $\Phi_{0}=0.3396 \times 10^{25} \mathrm{n} / \mathrm{m}^{2}$.

Linear interpolation is recommended between $1000^{\circ} \mathrm{C}$ and $1250^{\circ} \mathrm{C}$. A plot of the swelling is shown in Figure 1-19. 


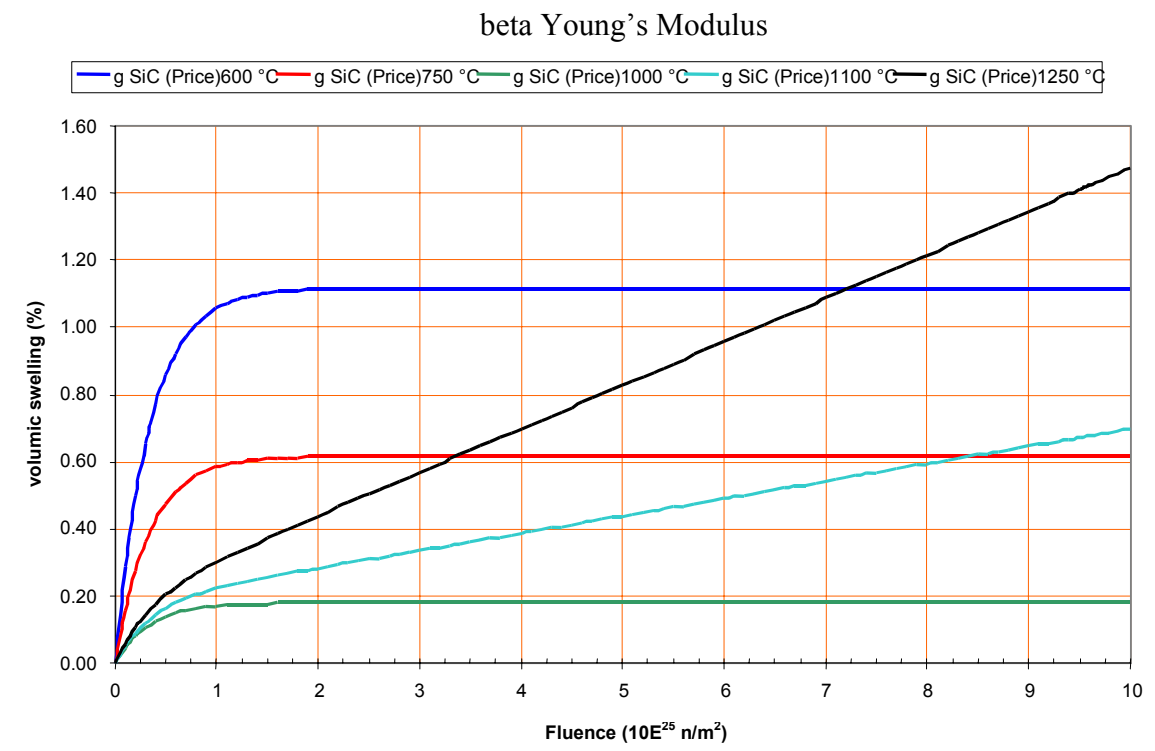

Figure 1-19. Pyrolytic beta SiC swelling.

\section{Irradiation creep}

The neutron-induced creep is assumed to follow the classical relation between creep equivalent strain, equivalent stress, and neutron flux as follows.

$$
\dot{\varepsilon}_{\text {creep }}=K_{I} \dot{\Phi} \sigma_{e}
$$

with different values of $\mathrm{K}_{\mathrm{I}}$ listed below that depend on temperature. These values are about one hundred times smaller than pyrocarbon values.

Table 1-15. Irradiation creep constant for SiC.

\begin{tabular}{cccccc}
\hline SiC & $\begin{array}{c}\theta \\
{\left[{ }^{\circ} \mathrm{C}\right]}\end{array}$ & Reference & Max. fluence & $\begin{array}{c}\text { Irradiation } \\
\text { type }\end{array}$ & $\begin{array}{c}K_{I} \\
{\left[\mathrm{MPa}^{-1} \cdot\left(\mathrm{n} / \mathrm{m}^{2}\right)^{-1}\right]}\end{array}$ \\
\hline$\beta-\mathrm{SiC}$ & 650 & Price & $4.18 \times 10^{25} \mathrm{n}^{-\mathrm{m}^{2}}$ & Neutronic & 0.2 to $0.264 \times 10^{-31}$ \\
$\beta-\mathrm{SiC}$ & 800 & Price & $7.7 \times 10^{25} \mathrm{n} / \mathrm{m}^{2}$ & Neutronic & $0.4 \times 10^{-31}$ \\
$\beta-\mathrm{SiC}$ & 900 & D.G.Martin & $4.62 \times 10^{25} \mathrm{n} / \mathrm{m}^{2}$ & Neutronic & $0.4 \times 10^{-31}$ \\
$\beta-\mathrm{SiC}$ & $>1100$ & CEGA & & Neutronic & $1.82 \times 10^{-31}$ \\
\hline
\end{tabular}




\section{Fracture strength}

CVD $\beta$-SiC mean fracture strength value varies within the range of 60 to $3100 \mathrm{MPa}$.

The wide range of ceramic fracture strength is due to the disparity of size, shape, location and direction of the micro-defects coupled with the lack of ductility of such material. The literature indicates:

- A variation in results for exactly identical test specimens,

- Close correlation between fracture strength mean values and associated loading types, specimen volume, test type (bending, crushing, bursting...)

The fracture strength is not an intrinsic feature of a given ceramic and needs a probabilistic approach. The most useful approach is the Weibull theory, which supposes that:

- The solid is statistically homogeneous (juxtaposition of independent micro-structural elements).

- The fracture of the less resistant element aims to the total collapse of the structure.

The cumulative failure probability of ceramic material is given by the following conventional expression :

$$
P_{R}=1-\exp \left[-\int_{D}\left(\frac{\sigma(x, y, z)}{\sigma_{0 D}}\right)^{m} \cdot d D\right]
$$

where $\mathrm{D}$ is a dimension (Volume, Surface or Line), $\sigma$ is a tensile stress dependant of the location $(\mathrm{x}, \mathrm{y}, \mathrm{z}), \mathrm{m}$ is the Weibull modulus and $\sigma_{0 \mathrm{D}}$ is a characteristic strength (homogeneous to a stress multiplied by a length to the power $\mathrm{i} / \mathrm{m}$ with $\mathrm{i}=1$ (line), 2 (surface) or 3 (volume)).

Concerning the m modulus, values given by the literature are scattered and are dependent on the specific $\mathrm{SiC}$ being manufactured and the method of measurement. At room temperature, $\mathrm{m}$ varies within the range of 1.5 to 14 . Concerning CVD $\beta-\mathrm{SiC}$, a recommended value is 6 .

Concerning $\sigma_{0 \mathrm{D}}$, a few values are given by the literature but results are not very consistent
- CEGA
$\sigma_{0 \mathrm{~V}}=9.64 \mathrm{MPa} \mathrm{m}^{3 / 6}(\mathrm{~m}=6)$
- CEA re-analysis
$\sigma_{0 \mathrm{~V}}=24.6 \mathrm{MPa} \mathrm{m}{ }^{3 / 5,8}(\mathrm{~m}=5.8)$

Another approach, widely used, is to express the cumulative failure probability as :

$$
P_{R}=1-\exp \left[-\ln (2) \cdot\left(\frac{\sigma_{R}}{\sigma_{R 1 / 2}}\right)^{m}\right]
$$

where $\sigma_{\mathrm{R}}$ is the calculated maximum stress in the material and $\sigma_{\mathrm{R} 1 / 2}$ the mean fracture strength, which is dependent of the specimen test and its loading. 


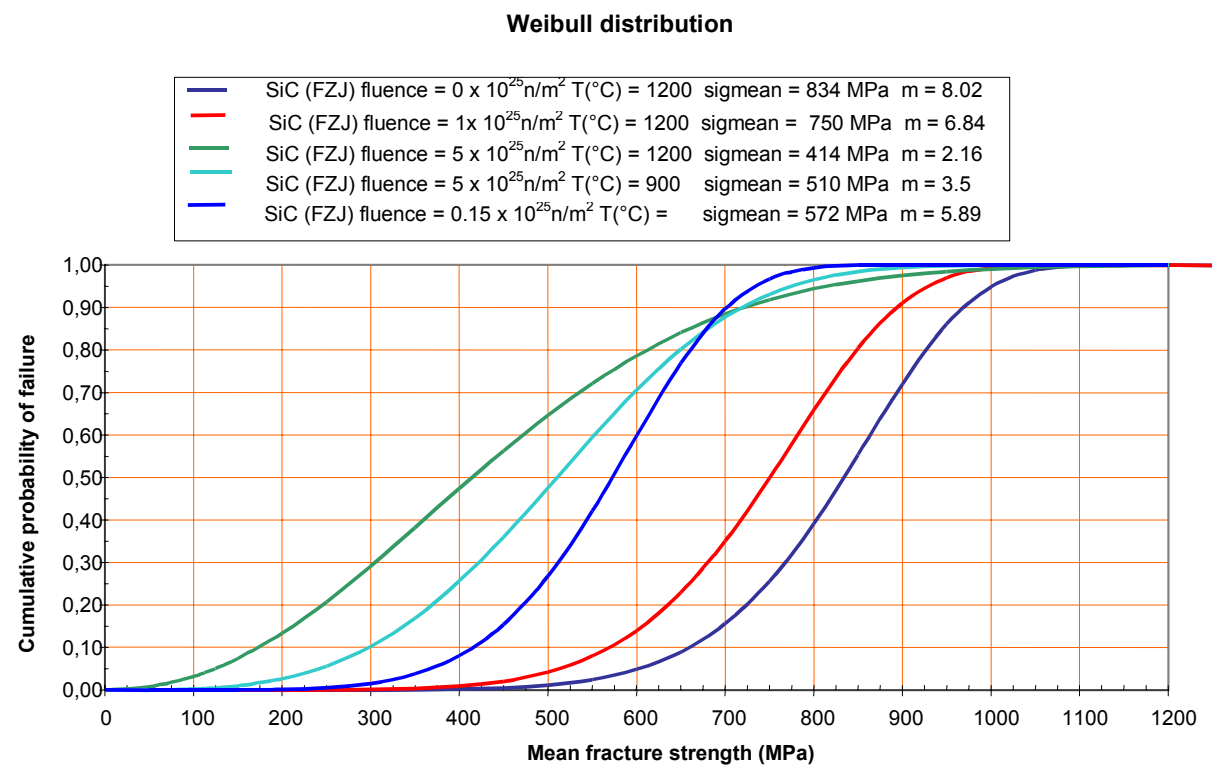

Figure 1-20. Weibull distribution

Next Year Activities: None, task 1 completed

Issues/ Concerns: None 


\section{Task 2: DEVELOPMENT OF AN INTEGRATED MODEL TO EVALUATE THE MECHANISMS OF FAILURE FOR CLASSICAL TRISO PARTICLES IN THERMAL GAS REACTOR SPECTRUM}

\section{Responsible Lead: INEEL}

\section{Brief Discussion of Objectives:}

The purpose of this task is to develop an integrated fuel performance model to evaluate mechanisms that contribute to particle failure. Information obtained from the exchanged of existing models and material property databases will be used in this development. The existing models will be used as a basis for developing the extended model. Specific tasks during the first year of this effort included:

- Compare and benchmark solutions obtained from existing INEEL and CEA models

- Upgrade existing pressure vessel model to address fission gas production associated with certain phenomena not currently in the model.

- Continue work at INEEL towards determining the effects of multi-dimensional mechanisms contributing to particle failure, incorporating these into the performance model.

- Perform numerous multi-dimensional finite element analyses for each failure mechanism, covering a range of parametric variations.

\section{Task Technical Status Overview:}

\section{Background}

The INEEL is in the process of developing an integrated fuel performance model called PARFUME with the objective of physically describing both the mechanical and physico- 
chemical behavior of the fuel particle under irradiation. The model will include multidimensional failure mechanisms in addition to the traditional pressure vessel failure. For example, studies conducted at the INEEL (Miller et al. 2001) indicated that shrinkage cracks in the IPyC could contribute significantly to particle failures. Much effort to date has been directed toward including this failure mechanism in the model. Other multi-dimensional mechanisms, such as partial debonding between the IPyC and SiC layers and particle asphericity, will also be considered. The status of the model development as of October 2001 was documented in a conference paper (Petti et al. 2001) that discussed material properties; statistical, structural, and gas release models; fission product chemistry and transport; calculations on TRISO-coated fuel performance for cracking observed in U.S. gas reactor irradiations; and predictions of behavior of TRISO-coated fuel at high burnup that is currently under consideration in Europe.

\section{Basic Particle Behavior}

A typical TRISO-coated particle is shown in Figure 2-1. Fission gas pressure builds up in the kernel and buffer regions, while the IPyC, $\mathrm{SiC}$, and $\mathrm{OPyC}$ act as structural layers to retain this pressure. The basic behavior modeled in these analyses is shown schematically in Figure 2-2. The IPyC and OPyC layers both shrink and creep during irradiation of the particle while the SiC exhibits only elastic response. A portion of the gas pressure is transmitted through the IPyC layer to the $\mathrm{SiC}$. This pressure continually increases as irradiation of the particle progresses, thereby contributing to a tensile hoop stress in the $\mathrm{SiC}$ layer. Countering the effect of the pressure load is the shrinkage of the IPyC during irradiation, which pulls inward on the SiC. Likewise, shrinkage of the OPyC causes it to push inward on the SiC. Failure of the particle is normally expected to occur if the stress in the $\mathrm{SiC}$ layer reaches the fracture strength of the SiC. Failure of the $\mathrm{SiC}$ results in an instantaneous release of elastic energy that should be sufficient to cause simultaneous failure of the pyrocarbon layers.

Numerous material properties are needed to represent fuel particle behavior in the performance model. These include irradiation-induced strain rates used to represent shrinkage (or swelling) of the pyrocarbon layers, creep coefficients to represent irradiation-induced creep in the pyrocarbon layers, and elastic properties to represent elastic behavior for the pyrocarbons and silicon carbide. The properties currently used were obtained from data that was compiled in a report by the CEGA Corporation (CEGA 1993). 


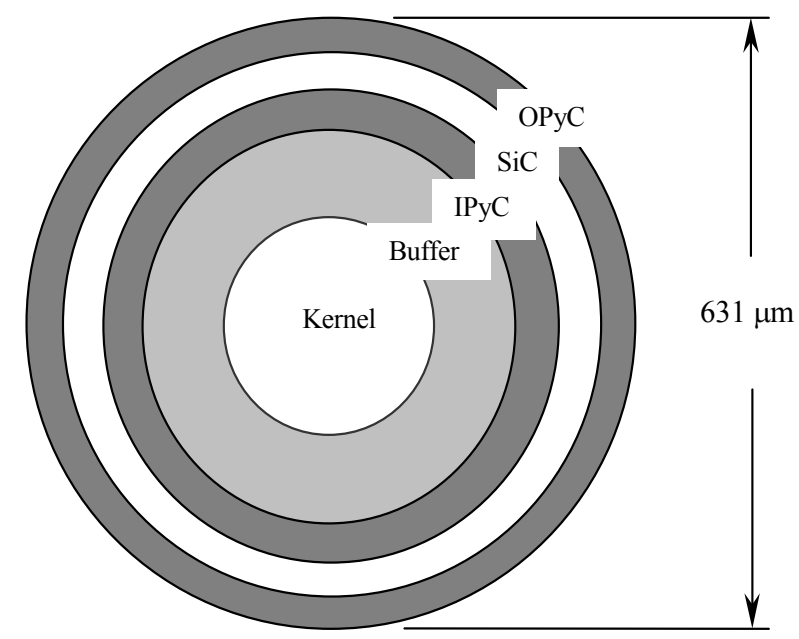

Figure 2-1. Representative fuel particle.

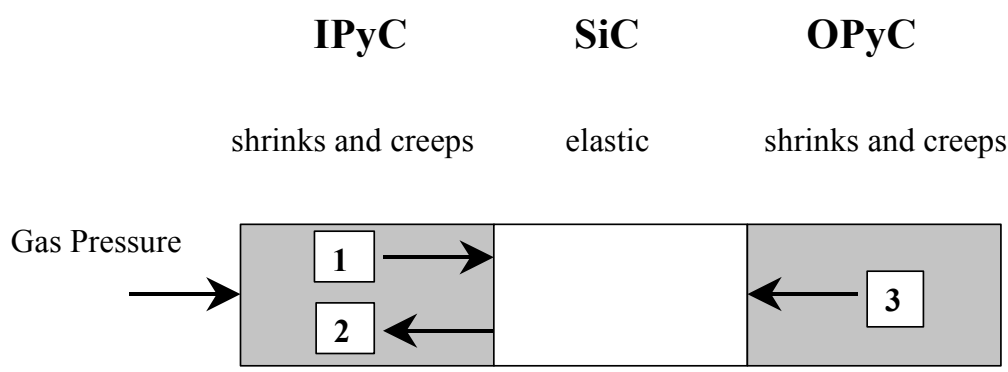

1 Gas pressure is transmitted through the IPyC

2 IPyC shrinks, pulling away from the $\mathrm{SiC}$

3 OPyC shrinks, pushing in on $\mathrm{SiC}$

Figure 2-2. Fuel particle behavior. 


\section{New Statistical Method}

A new statistical method was developed and incorporated into the PARFUME code that treats parametric variations in the multi-dimensional behavior of fuel particles. Multi-dimensional behavior includes cracking of the IPyC layer, partial debonding between the IPyC and $\mathrm{SiC}$ layers, and asphericity in the particle geometry. The statistical approach was needed to develop equations that can be used to efficiently calculate stresses in a random particle, where several design or fabrication parameters may deviate from their nominal values. These equations are used in a Monte Carlo simulation to calculate failure probabilities for a batch of fuel particles. The method has been used to predict failure probabilities for several experiments, considering the effect of shrinkage cracks in the IPyC layer on fuel particle behavior.

Model development activities and predictions made for NP- MHTGR experiments were documented and presented at the HTR-2002 conference in Petten, Netherlands, in April 2002 (Miller et al. 2002). A journal article that presents the new statistical methodology has been completed and submitted to the Journal of Nuclear Materials.

Our initial statistical approach was to perform regression analyses using the Design Expert program (Whitcomb et al. 1993) to produce an algorithm that predicts the stress level in the $\mathrm{SiC}$ layer of particles that have a cracked IPyC. This program used response surface analysis to develop a sixth-order polynomial that statistically fit stress data (obtained from finite element analyses) to a high level of accuracy when variations in six parameters were considered. This involved full-factorial regression analysis that required a total of 972 finite element (FE) analysis runs using the ABAQUS computer program (Hibbitt, Karlsson, and Sorenson 1998). A problem with this statistical treatment is that the number of finite element analyses required becomes overwhelming when 1) additional parametric variations are introduced, 2) the fundamental material properties that were used in the analyses (such as the shrinkage of the pyrocarbons) are changed, or 3) a different failure mechanism is considered.

Therefore, an alternative method was developed that greatly reduces the number of finite element analyses needed. The approach is to perform finite element analyses on just enough cases to determine the effects of varying each parameter individually. The same cases are then analyzed using a closed-form solution that solves for stresses in a normal (uncracked) TRISO fuel particle (Miller and Bennett 1993). Finally, statistical fits are performed on the results of the analyses and 
a correlation is drawn between the stress in an uncracked particle with the stress in a cracked particle for the same parametric variations. Implementing this in the performance model, the stress in the SiC layer of a particle having a cracked IPyC is determined by first computing the stress for the same particle having an intact IPyC. This stress is then converted to a stress for a cracked particle by applying the correlations. The equation used to estimate stress in the $\mathrm{SiC}$ layer, which is a function of multiple parameters, is:

$\sigma_{c}\left(v_{j}, v_{k}, v_{l}, \ldots\right) \cong \frac{\sigma_{c \bar{v}}}{\sigma_{u \bar{v}}} \sigma_{u}\left(v_{j}, v_{k}, v_{l}, \ldots\right) h_{j}\left(\Delta v_{j}\right) h_{k}\left(\Delta v_{k}\right) h_{l}\left(\Delta v_{l}\right) \ldots$

where,

$$
\begin{aligned}
& \sigma_{c}\left(v_{j}, v_{k}, v_{l}, \ldots\right)=\quad \text { maximum stress in the SiC layer of a cracked particle as a } \\
& \text { function of multiple parameters, } \\
& \sigma_{u}\left(v_{j}, v_{k}, v_{l}, \ldots\right)=\quad \text { maximum stress in the SiC layer of an uncracked particle } \\
& \text { for the same parameters, } \\
& \sigma_{c \bar{v}}=\quad \text { maximum stress in the SiC layer of a cracked particle } \\
& \text { having mean values for all parameters, } \\
& \sigma_{u \bar{v}}=\quad \text { maximum stress in the SiC layer of an uncracked particle } \\
& \text { having mean values for all parameters, } \\
& h_{j}\left(\Delta v_{j}\right)=\quad \text { correlation function for parameter } v_{j} \\
& \Delta v_{j}=\quad \text { variation of parameter } v_{j} \text { from its nominal value. }
\end{aligned}
$$

It was shown through benchmark analyses (as shown in Table 2-1) that results obtained from using this equation correlated very well with results from the Design Expert algorithm. The two equations were used in calculating failure probabilities for hypothetical fuel particle batches having statistical variations in six parameters as shown in the table. The difference between the two cases was in the size of the standard deviations for the six parameters. In these calculations, a particle was considered to fail if the SiC layer was determined to fail. 
Table 2-1. Comparison of failure probability calculations for two statistical methods.

\begin{tabular}{|c|c|c|c|c|c|c|c|c|}
\hline Case & \multicolumn{6}{|c|}{ Mean values and standard deviations } & \multicolumn{2}{|c|}{$\%$ Failed } \\
\hline & $\begin{array}{l}\text { IPyC } \\
\text { thick. } \\
(\mu \mathrm{m}) \\
\\
\text { [Std. } \\
\text { Dev.] }\end{array}$ & $\begin{array}{l}\text { SiC } \\
\text { thick. } \\
(\mu \mathrm{m}) \\
\\
\text { [Std. } \\
\text { Dev.] }\end{array}$ & $\begin{array}{l}\text { OPyC } \\
\text { thick. } \\
(\mu \mathrm{m}) \\
\\
\text { [Std. } \\
\text { Dev.] }\end{array}$ & 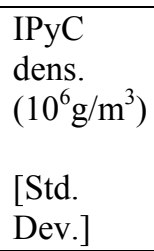 & $\begin{array}{l}\text { IPyC } \\
\text { BAF } \\
\text { [Std. } \\
\text { Dev.] }\end{array}$ & $\begin{array}{l}\text { Irrad. } \\
\text { temp. } \\
\left({ }^{\circ} \mathrm{C}\right) \\
\\
\text { [Std. } \\
\text { Dev.] }\end{array}$ & $\begin{array}{l}\text { Design } \\
\text { Expert }\end{array}$ & $\begin{array}{l}\text { New } \\
\text { method, } \\
\text { Eq. (1) }\end{array}$ \\
\hline 1 & $\begin{array}{l}40 \\
{[5]}\end{array}$ & $\begin{array}{l}35 \\
{[5]}\end{array}$ & $\begin{array}{l}43 \\
{[5]}\end{array}$ & $\begin{array}{l}1.90 \\
{[0.02]}\end{array}$ & $\begin{array}{l}1.16 \\
{[0.02]}\end{array}$ & $\begin{array}{l}1000 \\
{[30]}\end{array}$ & 0.80 & 0.80 \\
\hline 2 & $\begin{array}{l}40 \\
{[8]}\end{array}$ & $\begin{array}{l}35 \\
{[8]}\end{array}$ & $\begin{array}{l}43 \\
{[8]}\end{array}$ & $\begin{array}{l}1.90 \\
{[0.05]}\end{array}$ & $\begin{array}{l}1.16 \\
{[0.05]}\end{array}$ & $\begin{array}{l}1000 \\
{[50]}\end{array}$ & 1.24 & 1.18 \\
\hline
\end{tabular}

Because the equation above does require performing several finite element analyses to develop the correlation functions $h_{i}$, using this equation still entails significant effort if a new set of correlation functions must be developed for every batch of particles considered. This generally is the case if the parametric mean values change significantly from one batch to the next. Therefore, a simplified form of the equation was developed by simply setting the $h$ functions equal to one. The rationale for doing this was that the product of the $h$ functions for the particles in a batch tends to fluctuate (from particle to particle) about an average value that is very near to 1.0. The resulting equation then requires that only one finite element analysis (to calculate $\sigma_{c} \bar{v}$ ) be performed to determine the failure probability for a particle batch:

$\sigma_{c}\left(v_{j}, v_{k}, v_{l}, \ldots\right) \cong \frac{\sigma_{c \bar{v}}}{\sigma_{u \bar{v}}} \sigma_{u}\left(v_{j}, v_{k}, v_{l}, \ldots\right)$

To evaluate the accuracy of Equation 2, results obtained from its use were compared to results obtained from Equation 1 for four cases involving variations in six parameters (Table 2-2). A new set of correlation equations, $h$, was developed for each of the four cases. It is seen that reasonable correlations were attained in all cases. Finally, two cases were evaluated where the number of varying parameters was increased from six to eleven, as shown in Table 2-3. Results from these cases again show a favorable correlation between Equations 1 and 2. 
Table 2-2. Comparison of failure probability calculations for new method, Equation 2 vs. Equation 1.

\begin{tabular}{|l|c|c|c|c|c|c|c|c|}
\hline Case & \multicolumn{9}{|c|}{ Mean values } & \multicolumn{2}{c|}{$\%$ Failed } \\
\hline & $\begin{array}{c}\text { IPyC } \\
\text { thick. } \\
(\mu \mathrm{m})\end{array}$ & $\begin{array}{c}\mathrm{SiC} \\
\text { thick. } \\
(\mu \mathrm{m})\end{array}$ & $\begin{array}{c}\text { OPyC } \\
\text { thick. } \\
(\mu \mathrm{m})\end{array}$ & $\begin{array}{c}\text { IPyC } \\
\text { dens. } \\
\left(10^{6} \mathrm{~g} / \mathrm{m}^{3}\right)\end{array}$ & $\begin{array}{c}\text { IPyC } \\
\text { BAF }\end{array}$ & $\begin{array}{c}\text { Irrad. } \\
\text { Temp. } \\
\left({ }^{\circ} \mathrm{C}\right)\end{array}$ & $\begin{array}{c}\text { w/ } h \\
\text { functions } \\
(\text { Eq. } 1)\end{array}$ & $\begin{array}{c}\text { wo/ } h \\
\text { functions } \\
(\text { Eq. } 2)\end{array}$ \\
\hline 1 & 40 & 35 & 43 & 1.90 & 1.16 & 1000 & 0.80 & 1.10 \\
\hline 2 & 45 & 30 & 40 & 2.00 & 1.10 & 700 & 13.8 & 14.6 \\
\hline 3 & 35 & 40 & 50 & 1.82 & 1.24 & 900 & 0.64 & 0.81 \\
\hline 4 & 30 & 45 & 53 & 1.80 & 1.32 & 600 & 1.51 & 1.62 \\
\hline
\end{tabular}

Table 2-3. Statistical variations and results for eleven-parameter cases.

\begin{tabular}{|l|l|l|l|}
\hline Parameter & Mean value (case 1) & Mean value (case 2) & Standard deviation \\
\hline IPyC thickness $(\mu \mathrm{m})$ & 50 & 40 & 5 \\
\hline SiC thickness $(\mu \mathrm{m})$ & 25 & 35 & 5 \\
\hline OPyC thickness $(\mu \mathrm{m})$ & 50 & 40 & 5 \\
\hline IPyC density $\left(10^{6} \mathrm{~g} / \mathrm{m}^{3}\right)$ & 1.8 & 1.9 & 0.02 \\
\hline OPyC density $\left(10^{6} \mathrm{~g} / \mathrm{m}^{3}\right)$ & 1.8 & 1.9 & 0.02 \\
\hline IPyC BAF & 1.24 & 1.06 & 0.02 \\
\hline OPyC BAF & 1.04 & 1.06 & 0.02 \\
\hline Irradiation temp. $\left({ }^{\circ} \mathrm{C}\right)$ & 700 & 1000 & 30 \\
\hline Creep amplification & 3 & 2 & 0.2 \\
\hline Kernel diameter $(\mu \mathrm{m})$ & 200 & 500 & 20 \\
\hline Buffer thickness $(\mu \mathrm{m})$ & 120 & 100 & 10 \\
\hline & \multicolumn{2}{|l}{} \\
\hline Results & Case 1 & \\
\hline \% failed, per Eq. 1 & 1.31 & 0.004 & \\
\hline
\end{tabular}

Results above indicate that Equation 2 can typically be used to produce reasonable estimates for failure probabilities in a general batch of fuel particles. Equation 1 can be used in situations where a more accurate estimate is desired. This approach has the capacity to treat statistical 
variations in all of the design parameters for TRISO-coated fuel particles. It has been described above in terms of fuel particles having a cracked IPyC, but should also be applicable to other multi-dimensional behavior. It is therefore anticipated that this method will facilitate the development of a fuel performance code that is capable of treating multi-dimensional failure mechanisms together with statistical variations in a wide range of design parameters.

\section{Approach for Determining Whether the SiC Fails}

The correlation equations developed for particles having a cracked IPyC were programmed into the fuel performance code. The next step was to utilize the stresses calculated to determine particle failure probabilities in the fuel performance model. Using a fracture mechanics approach to determine whether a cracked IPyC layer results in failure of the $\mathrm{SiC}$ would require calculation of a stress intensity at the crack tip. Such a calculation is greatly complicated by the fact that there is a material discontinuity at the interface between the IPyC and SiC layers. It is believed that the SiC failures will follow a Weibull statistical distribution, having a mean strength $\sigma_{m c}$ and a modulus $m$. The mean strength is a function of the stress distribution and geometry of the $\mathrm{SiC}$ layer, and is derived below from the characteristic strength $\sigma_{0}$. In the Weibull theory, the failure probability for the $\mathrm{SiC}$ is given by:

$P_{f}=1-e^{-\int_{V}\left(\sigma / \sigma_{0}\right)^{m} d V}$

where,

$$
\begin{aligned}
& P_{f}=\text { probability of failure of the } \mathrm{SiC}, \\
& \sigma=\quad \text { stress in the } \mathrm{SiC} \text { layer, } \\
& \sigma_{0}=\text { Weibull characteristic strength for the } \mathrm{SiC} \text { material, } \\
& m=\quad \text { Weibull modulus for the } \mathrm{SiC} \text { material, } \\
& V=\quad \text { volume of the } \mathrm{SiC} \text { layer. }
\end{aligned}
$$

Once finite element results are obtained from the analysis of a cracked particle, the stress integration above can be performed using the principle of independent action (PIA) model for treating multiaxial stress states (Nemeth et al. 1989):

$$
\int_{V} \sigma^{m} d V=\int_{V}\left(\sigma_{1}^{m}+\sigma_{2}^{m}+\sigma_{3}^{m}\right) d V
$$


where,

$\sigma_{1}, \sigma_{2}, \sigma_{3}=$ the three components of principal stress.

Since only tensile stresses contribute to fracture of the material, compressive stresses are not included in the integration. Only stresses in the finite elements of the $\mathrm{SiC}$ layer in the immediate vicinity of the crack tip make a meaningful contribution to the integral. The integration is performed using stress values calculated at integration points in the ABAQUS analysis. The minimum principal stress $\sigma_{1}$ is always negative, and therefore makes no contribution. This component is neglected in these analyses.

Based on the magnitude of stresses calculated at integration points near the crack tip, the integral above assumes a value which can be written as follows:

$$
\int_{V} \sigma^{m} d V=\sigma_{c}^{m} \int_{V} f(V) d V=\sigma_{c}^{m}(I)
$$

where $\sigma_{c}$ is the maximum value calculated for the stress anywhere in the volume. The integral $I$ is a normalized integration of the stress distribution, where the maximum stress (taken to the $m$ power) has been factored out. The failure probability then becomes

$$
P_{f}=1-e^{-\sigma_{c}^{m}(I) / \sigma_{0}{ }^{m}}
$$

The fuel performance model is set up to calculate the failure probability according to the following:

$$
P_{f}=1-e^{-\left(\sigma_{c} / \sigma_{m s}\right)^{m}}
$$

The mean strength $\sigma_{m s}$ is the stress level at which $63.2 \%$ of the particles would fail if all were stressed equally, as seen by setting $\sigma_{c}=\sigma_{m s}$ in Equation (7). PARFUME executes Equation (7) in a Monte Carlo simulation by calculating a stress $\sigma_{c}$ for each particle and comparing that stress to a strength $\sigma_{s}$ that is sampled for that particle according to the following equation (which is obtained from Equation 7): 
$\sigma_{s}=\sigma_{m s} e^{[\ln (-\ln F)] / m}$

where $F$ is a random number between 0 and 1 .

The mean strength is determined by applying the condition that the failure probability calculated by the fuel performance model per Equation (7) essentially equal that of Equation (6). This is done by equating the exponents for the two equations and using stresses obtained from a finite element analysis on a particle having nominal values for all parameters to determine the integral I. The effective mean strength for the $\mathrm{SiC}$ layer of a particle having a cracked IPyC is then defined to be:

$\sigma_{m s}=\sigma_{0} / I_{n}^{1 / m}$

where the subscript $n$ denotes a particle having nominal values for all parameters. This value for $\sigma_{m s}$ is used in the fuel performance model per Equation (7) to perform Weibull statistical evaluations of failure on those particles having a cracked IPyC.

\section{Flow Diagram for PARFUME Methodology}

The methodology currently envisioned in PARFUME is summarized in Figure 2-3. 


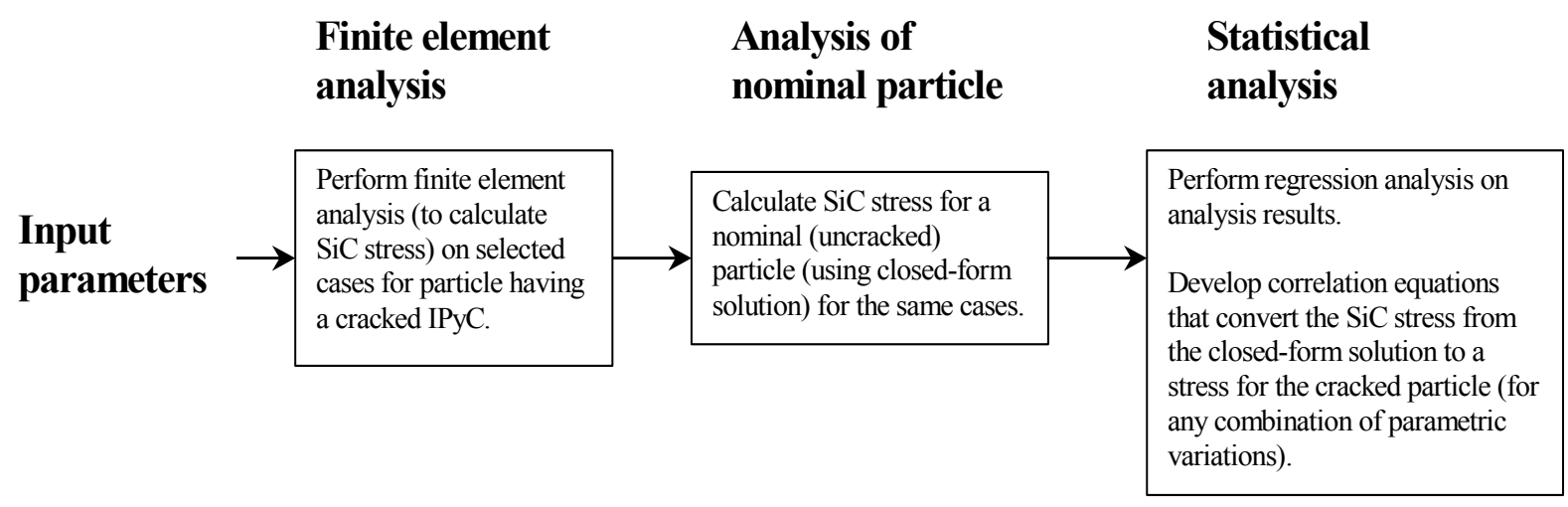

\section{Determine Weibull mean strengths \\ Failure probability determination \\ Cumulative failure probability}

Input correlation equations and Weibull mean strengths into PARFUME.

(Correlation equations are not needed when using Eq. 2.)

Use Monte Carlo sampling and Weibull statistics to determine a failure probability for particles having a cracked IPyC (considering all relevant parametric variations). First, determine whether the IPyC cracks. If so, then determine whether the particle fails.
If the IPyC layer in a sampled particle does not crack, then determine whether the particle fails due to a traditional pressure vessel failure. If so, then include these in a cumulative failure probability.

Similarly, calculate failures due to other failure mechanisms and add these to total.

Figure 2-3. Flow diagram for PARFUME Methodology. 


\section{Predictions for NPR Experiments}

Predictions for fuel particle failure probabilities have been made for three irradiation experiments conducted as part of the New Production - Modular High Temperature Gas-Cooled Reactor (NPMHTGR) program in the early 1990s. These predictions reflect the latest pyrocarbon creep and shrinkage properties and current gas release model used in the PARFUME code. In these experiments, fuel compacts were irradiated at the High Flux Isotope Reactor (HFIR) and the Advanced Test Reactor (ATR) in the United States. TRISO-coated particles containing highenriched uranium were irradiated at temperatures between 750 and $1250{ }^{\circ} \mathrm{C}$, burnups between 65 and $80 \%$ FIMA, and fluences between 2 and $3.8 \times 10^{25} \mathrm{n} / \mathrm{m}^{2}$. On-line fission gas release measurements indicated significant failures during irradiation. Post-irradiation examination (PIE) of individual fuel compacts revealed the presence of radial cracks in all layers of the TRISO coating. The irradiation conditions for the experiments are summarized in Table 2-4, while the levels of cracking measured during PIE are shown in Table 2-5. The particle dimensions, burnup, end-of-life fluence, irradiation temperature, ${ }^{235} \mathrm{U}$ enrichment, densities and BAF for the pyrocarbons, etc., were based on fabrication records for the fuel and on the service conditions measured during irradiation for each experiment.

To assess the effect of temperature variability during irradiation on particle stresses, ABAQUS calculations were performed with both the actual volume averaged temperature history and the time averaged volume averaged temperature for NPR-1 compact A5. The actual volume averaged temperature for the compact varied from about 1150 to $870{ }^{\circ} \mathrm{C}$ during the experiment, while the time averaged, compact volume averaged temperature was $987^{\circ} \mathrm{C}$ (Baldwin et al. 1993). Calculated time histories for principal stresses in the SiC layer are presented in Figure 24, which show that the stress histories compare closely for these two cases. These results indicate that using a time averaged volume averaged temperature in the PARFUME predictions is a good approximation to the use of actual temperature histories.

Included in the results shown in Table 2-5 (column 5) are the percentage of particles predicted to have a cracked IPyC and the percentage of particles predicted to fail because of a cracked SiC. It is seen that PARFUME predicts that the IPyC layer cracks in $100 \%$ of the particles for every compact tested. In reality, the PIE revealed that the actual failure fractions were less than this, as shown in the table. Based on historical literature sources, it is believed that the creep coefficients 
recommended in (CEGA 1993) and currently used in the PARFUME code may be too low, which would allow the calculated shrinkage stresses to reach too high a value before creep relaxation takes effect. If the creep coefficients used in the analyses were amplified by a factor of 1.8 , which is closer to values used in older performance codes (Kaae et al. 1971, Martin 2001), the number of failures in the IPyC and SiC decrease as shown in Table 2-5 (column 6). The higher creep gives better agreement with the experimental results.

It is noted that because the ratio $\sigma_{c} / \sigma_{u}$ in Equation 2 maintained essentially the same value for all four NPR compacts $(\sim 0.79)$, only one finite element analysis of a cracked particle would have been needed to generate the failure probabilities of Table 2-5.

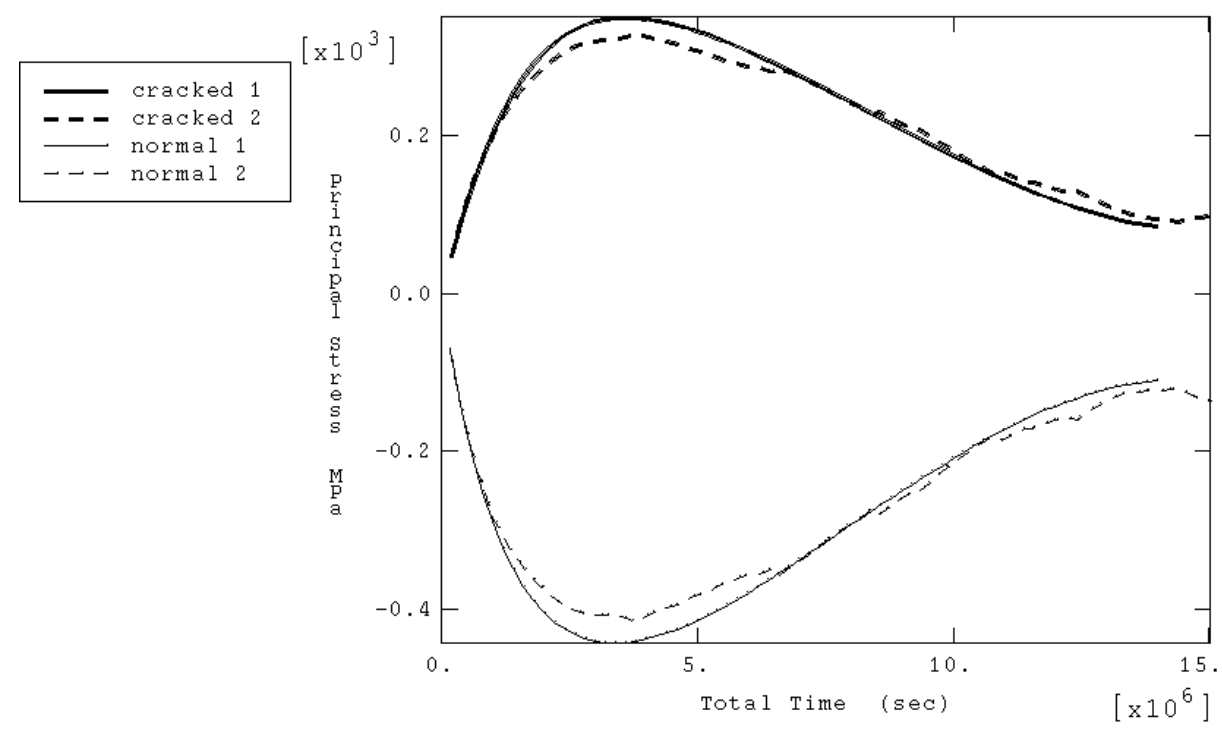

Figure 2-4. SiC stress history comparisons for 1) time averaged temperature vs. 2) actual temperature in cracked and uncracked particles of NPR-1 A5 irradiation experiment.

Table 2-4. Irradiation conditions for NPR experiments.

\begin{tabular}{|l|c|c|c|}
\hline \multicolumn{1}{|c|}{ Fuel Compact ID } & $\begin{array}{c}\text { Fast Fluence } \\
\left(10^{25} \mathrm{n} / \mathrm{m}^{2}\right)\end{array}$ & $\begin{array}{c}\text { Irradiation } \\
\text { temp. }\left({ }^{\circ} \mathrm{C}\right), \text { average }\end{array}$ & $\begin{array}{c}\text { Burnup } \\
(\% \text { FIMA })\end{array}$ \\
\hline NPR-2 A4 & 3.8 & 746 & 79 \\
\hline NPR-1 A5 & 3.8 & 987 & 79 \\
\hline NPR-1 A8 & 2.4 & 845 & 72 \\
\hline NPR-1A A9 & 1.9 & 1052 & 64 \\
\hline
\end{tabular}


Table 2-5. Comparisons of ceramographic observations to PARFUME calculations for TRISO coated fissile fuel particles.

\begin{tabular}{|l|c|c|c|c|c|}
\hline \multicolumn{6}{|c|}{ IPyC Layer(a) } \\
\hline $\begin{array}{l}\text { Fuel } \\
\text { Compact ID }\end{array}$ & Sample Size & $\%$ Failed & $\begin{array}{c}95 \% \text { Conf. } \\
\text { Interval(\%) }\end{array}$ & Calc. & $\begin{array}{c}\text { Calc. with } \\
1.8 x \text { creep }\end{array}$ \\
\hline NPR-2 A4 & 83 & 65 & $54<\mathrm{p}<76$ & 100 & 99.8 \\
\hline NPR-1 A5 & 39 & 31 & $17<\mathrm{p}<47$ & 100 & 34.8 \\
\hline NPR-1 A8 & 53 & 6 & $2<\mathrm{p}<16$ & 100 & 94.0 \\
\hline NPR-1A A9 & 17 & 18 & $5<\mathrm{p}<42$ & 100 & 14.5 \\
\hline \multicolumn{7}{|c|}{ SiC Layer (a) } \\
\hline \multicolumn{7}{|c|}{ Sample Size } & $\%$ Failed & $\begin{array}{c}95 \% \text { Conf. } \\
\text { Interval }(\%)\end{array}$ & Calc. & $\begin{array}{c}\text { Calc. with } \\
1.8 x \text { creep }\end{array}$ \\
\hline NPR-2 A4 & 287 & 3 & $2<\mathrm{p}<6$ & 9.2 & 3.4 \\
\hline NPR-1 A5 & 178 & 0.6 & $0<\mathrm{p}<3$ & 1.8 & 0.22 \\
\hline NPR-1 A8 & 260 & 0 & $0<\mathrm{p}<2$ & 5.9 & 1.8 \\
\hline NPR-1A A9 & 83 & 1 & $0<\mathrm{p}<5$ & 1.1 & 0.044 \\
\hline
\end{tabular}

a. Layer failure is considered to be a through wall crack as measured by PIE.

\section{HRB-21 Experiment}

Initial failure probabilities were also calculated for the HRB-21 experiment. Irradiation conditions for this test are listed in Table 2-6, where it is seen that the primary differences between the compacts are the fast fluence and the irradiation temperature.

Table 2-6. Irradiation conditions for HRB-21 experiment.

\begin{tabular}{|c|c|c|c|}
\hline Fuel Compact ID & $\begin{array}{c}\text { Fast Fluence } \\
\left(10^{25} \mathrm{n} / \mathrm{m}^{2}\right)\end{array}$ & $\begin{array}{c}\text { Irradiation temp. }\left({ }^{\circ} \mathrm{C}\right), \\
\text { average }\end{array}$ & Burnup (\%FIMA) \\
\hline 1C & 1.5 & 800 & 14.0 \\
\hline 2B & 2.3 & 980 & 18.0 \\
\hline 4A & 3.5 & 1000 & 22.5 \\
\hline
\end{tabular}

The observed and calculated failure fractions for the IPyC and SiC layers in the HRB-21 experiment are presented in Table 2-7. The calculated failures for the IPyC and SiC layers (based on $1.8 \times$ creep) were greatest for compact $1 \mathrm{C}$ and least for compact $4 \mathrm{~A}$, contrary to what occurred in the tests. This suggests that the material properties used in the calculations may not accurately represent these particles, or that there was an effect in the experiment not captured in the 
calculations. Further analyses of this experiment, incorporating more exact experimental conditions will be conducted. Since HRB-21 displayed wide temperature variations over time and across the compacts (much wider than that in the NPR experiments), future calculations will first investigate the use of actual temperature histories (as opposed to the time and volume averaged temperature used in the initial calculations).

Table 2-7. Failure fractions during irradiation for HRB-21 experiments.

\begin{tabular}{|c|c|c|c|c|}
\hline \multicolumn{5}{|c|}{ IPyC Layer } \\
\hline Fuel Compact ID & Sample Size & $\%$ Failed & $\begin{array}{c}95 \% \text { Conf. } \\
\text { Interval }(\%)\end{array}$ & $\begin{array}{l}\text { Calc. (with } \\
1.8 \times \text { creep) }\end{array}$ \\
\hline $1 \mathrm{C}$ & 96 & 1 & $0<\mathrm{p}<5$ & 70.6 \\
\hline $2 \mathrm{~B}$ & 70 & 3 & $0<p<9$ & 9.7 \\
\hline $4 \mathrm{~A}$ & 61 & 33 & $18<\mathrm{p}<48$ & 7.3 \\
\hline \multicolumn{5}{|c|}{ SiC Layer } \\
\hline & Sample Size & $\%$ Failed & $\begin{array}{l}95 \% \text { Conf. } \\
\text { Interval }(\%)\end{array}$ & $\begin{array}{l}\text { Calc. (with } \\
1.8 \times \text { creep) } \\
\end{array}$ \\
\hline $1 \mathrm{C}$ & 96 & 0 & $0<\mathrm{p}<4$ & 5.4 \\
\hline $2 \mathrm{~B}$ & 70 & 0 & $0<\mathrm{p}<6$ & 0.16 \\
\hline $4 \mathrm{~A}$ & 61 & 5 & $0<\mathrm{p}<13$ & 0.10 \\
\hline
\end{tabular}

\section{JAERI - Research Experiments}

Collection of data necessary to calculate failure probabilities for the HRB-22 and 91F-1A experiments conducted at the JAERI research center in Japan has been initiated. Irradiation conditions for these irradiations are summarized in Table 2-8.

Table 2-8. Irradiation conditions for JAERI experiments.

\begin{tabular}{|c|c|c|c|}
\hline Capsule ID & $\begin{array}{c}\text { Fast Fluence } \\
\left(10^{25} \mathrm{n} / \mathrm{m}^{2}\right)\end{array}$ & $\begin{array}{c}\text { Maximum irradiation } \\
\text { temp. }\left({ }^{\circ} \mathrm{C}\right)\end{array}$ & $\begin{array}{c}\text { Burnup } \\
(\% \text { FIMA })\end{array}$ \\
\hline HRB-22 & 4.1 & 1150 & 7.0 \\
\hline 91F-1A, Upper & 2.5 & 1350 & 8.0 \\
\hline 91F-1A, Lower & 3.4 & 1200 & 9.5 \\
\hline
\end{tabular}




\section{Debonding Between the IPyC and SiC Layers}

The failure predictions above focus on failures associated with shrinkage cracks that develop in the IPyC layer during irradiation. Another form of multi-dimensional behavior that may contribute to particle failures is debonding between the IPyC and SiC layers. The statistical methodology presented above can be used to evaluate failures caused by debonding as well as failures caused by a cracked IPyC layer.

Figure 2-5 shows a plot from an ABAQUS finite element analysis of a particle undergoing debonding, which occurs when the radial stress at the layer interface exceeds the bond strength between layers. In this process, the IPyC unzips from the $\mathrm{SiC}$ until the radial stress at the tip of the debonded region subsides to something less than the bond strength. Unzipping may also stop if the bond strength is non-uniform over the interface surface, such that the radial stress at the tip of the debonded region reaches a point where it cannot overcome the bond strength.
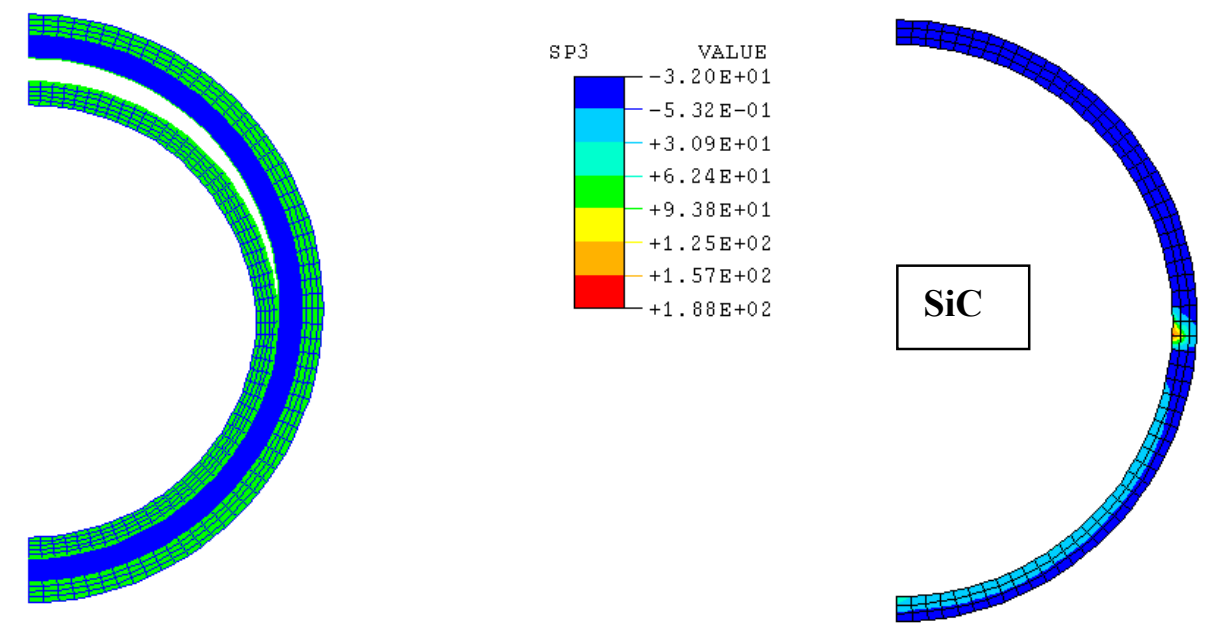

Figure 2-5. Displaced shape and contour stress plot for debonded particle (stress in MPa).

In the debonding process, the $\mathrm{SiC}$ incurs concentrated tensile stresses at the tip of the debonded region (as seen in Figure 2-5). This concentrated area of tensile stress moves with the tip during the unzipping process. The failure evaluation of the $\mathrm{SiC}$ accounts for the magnitude of these stresses, and recognizes that these tensile stresses may challenge any flaw in the $\mathrm{SiC}$ material along the debonded path. Using Weibull statistics, this means that the effective mean strength is based on a volume integration of the stress distribution (as shown above). The stress at each 
point in this distribution must be the maximum stress occurring there throughout the debonding history.

To compare the effects of debonding relative to a cracked IPyC, failure probabilities were calculated for these two mechanisms using the statistical methodology described above. Probabilities are compared in Table 2-9 for a batch of fuel particles having the mean values and standard deviations from case 2 of Table 2-3. To increase the number of predicted failures, cases were also considered where the BAF of the IPyC was increased and/or the irradiation temperature was lowered. The bond strength between the IPyC and SiC layers was in all cases assumed to be uniform over the interface surface, and was set low enough $(<50 \mathrm{MPa})$ that debonding between layers did occur.

The stresses in the SiC due to debonding were not as high as those due to a cracked IPyC, but they challenged a larger portion of the $\mathrm{SiC}$ volume. Results show that the failures due to debonding ranged from 14 to $53 \%$ of the failures caused by a cracked IPyC. Therefore, debonding could make a significant contribution to particle failures.

Table 2-9. Comparison of predicted failures for two failure mechanisms.

\begin{tabular}{|c|c|c|}
\hline Particles & \multicolumn{2}{|c|}{ Predicted failures (per 200,000 particles) } \\
\hline & Cracked IPyC & $\begin{array}{c}\text { Debonding between IPyC and } \\
\text { SiC }\end{array}$ \\
\hline Case 2, Table 2-3 & 7 & 1 \\
\hline Temp. $=700^{\circ} \mathrm{C}$ & 235 & 396 \\
\hline Temp. $=700^{\circ} \mathrm{C}$ & 844 & \\
\hline IPyC BAF $=1.16$ & & 325 \\
\hline
\end{tabular}

Also investigated in this study was how much the bond strength between layers affects the number of particles that fail due to the debonding mechanism. This was examined particularly for the second set of particles of Table 2-10. This was chosen over the first case because its lower temperature boosts the number of failures calculated, allowing for a clearer evaluation of the effects of bond strength. Results of this investigation are presented in Figure 2-6, showing that 
the number of failures (caused by debonding) is rather sensitive to the bond strength. At a zero bond strength, the IPyC and SiC layers are never bonded, so cannot experience tensile debonding stresses. At high bond strengths (>60 MPa), the layers are bonded tightly enough that they do not separate during irradiation. In either case, there are no particle failures associated with debonding.

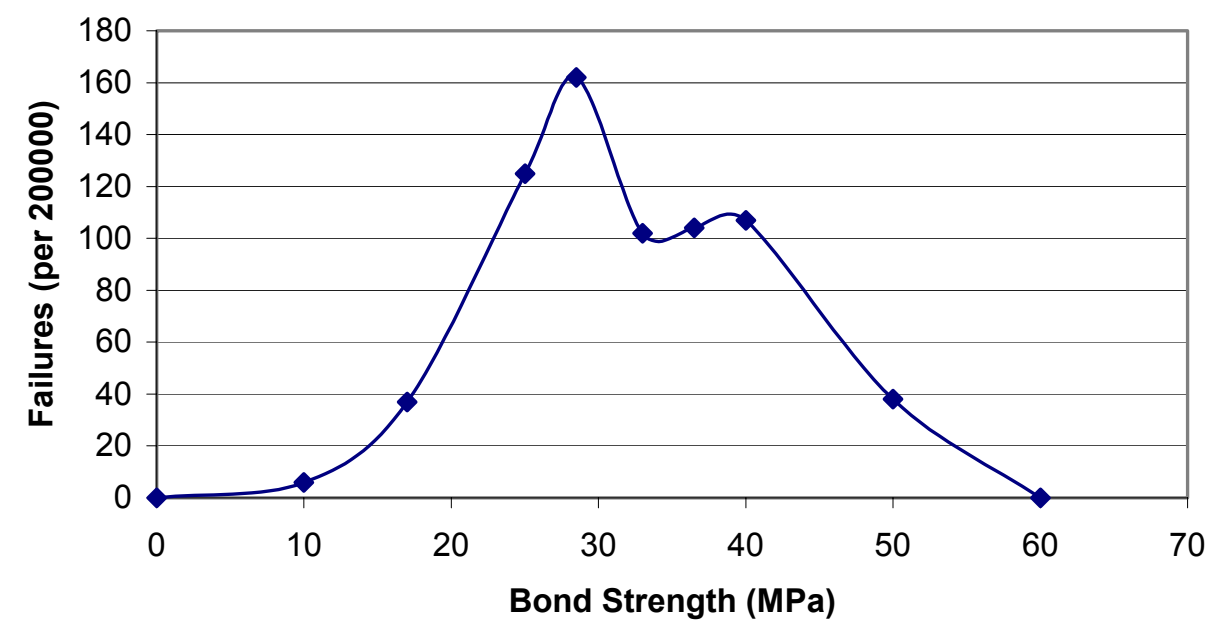

Figure 2-6. Predicted $\mathrm{SiC}$ failures for particles with a debonded IPyC, as a function of bond strength.

\section{CEA}

Atlas code is a finite element simulation code made up of both a generic thermomechanical code (CASTEM) and physical/chemical fuel models. It is generic for all type of particles (the data are taken from a file which specifies the layers and the materials) and coupled with a material and physical behavior data file, common with other types of reactors.

It has been developed on the basis of a two-dimensional model with the future goal of performing three-dimensional calculations. The three dimensional simulation is necessary to simulate specific loads or defaults. The two dimensional simulation and, when relevant, a one-dimensional 
description derived from it, are actually used, because it is faster and more useful to qualify the code and all the physical models.

The simulation takes into account the following phenomena:

- Gaseous and solid kernel swelling.

- Fission gas release.

- CO production.

- Variation of the conductivity of the gaseous layer between Kernel and Buffer.

- Variation of the pressure of the gas located in the gaseous layer and the porosities of the buffer. It changes with gas quantity, strains and open porosities changes.

- Kernel and layer densification.

- Irradiation creep and property changes.

The code will soon incorporate diffusion calculations.

It is being integrated in a unique Pleiades "platform" which will be used for all type of reactors.

Pleiades is a software platform under construction developed to allow the share of all the available fuel models, independently of the reactor type (fuel geometry, irradiation conditions...). After the integration in Pleiades will start the great evolutions of the code, to permit multi scale simulation (from particle to compact) and statistic calculations.

The qualification of the finite element model is in progress. A few results are given below. These calculations correspond to a loose particle which is close from geometry and irradiation conditions of HFR-P4 experiment. 


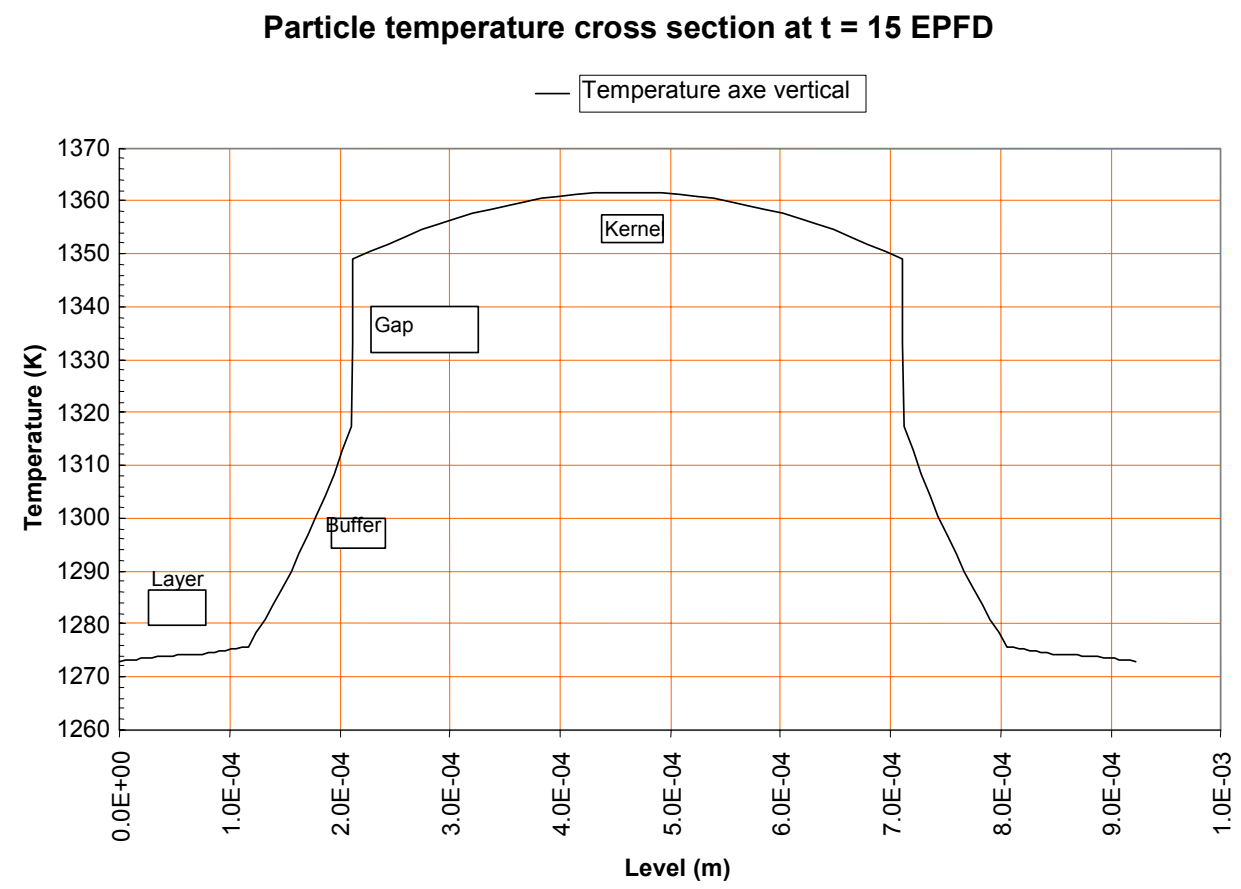

Figure 2-7. Temperature distribution across a particle.

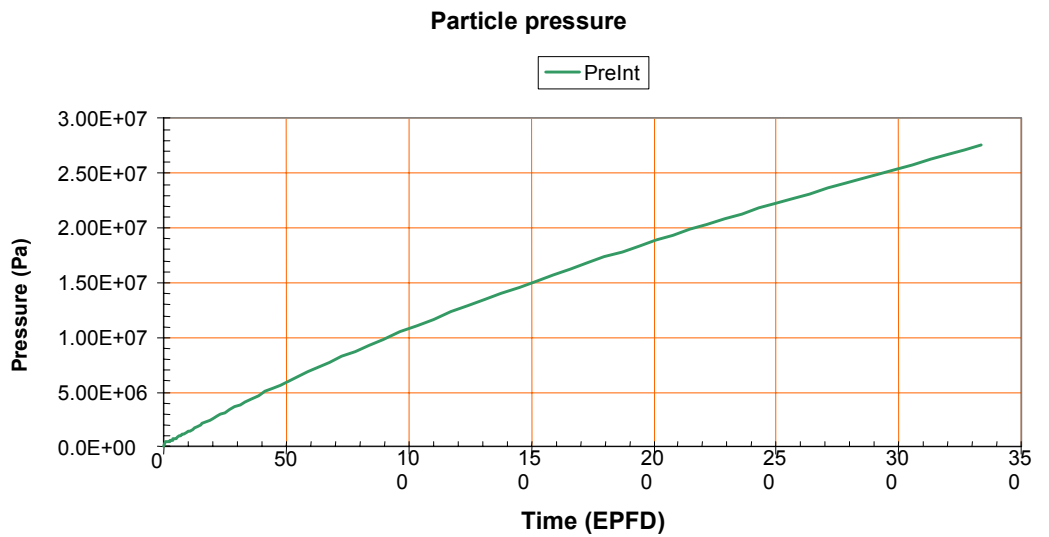

Figure 2-8. Pressure in a particle. 


\section{Layer Circumferential Stresses}

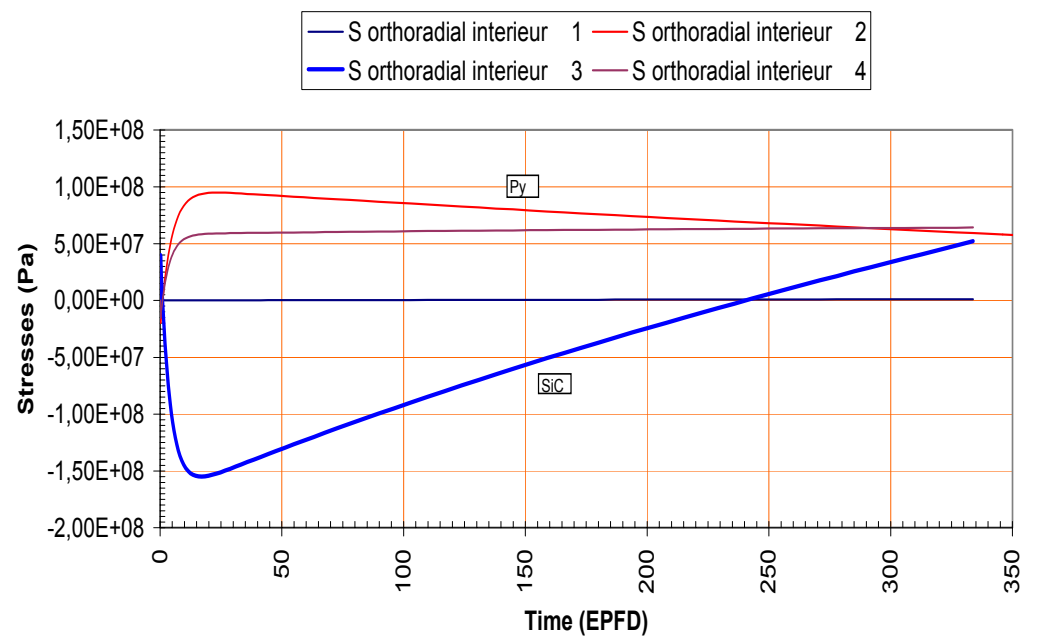

Figure 2-9. Layer circumferential stresses

PyC shrinkage induces compressive stresses in the $\mathrm{SiC}$ layer until equilibrium is established between shrinkage and irradiation creep which occurs in the early irradiation. Simultaneously, the pressure grows and creates tensile stresses which exceeds the compressive stresses at the end of the irradiation.

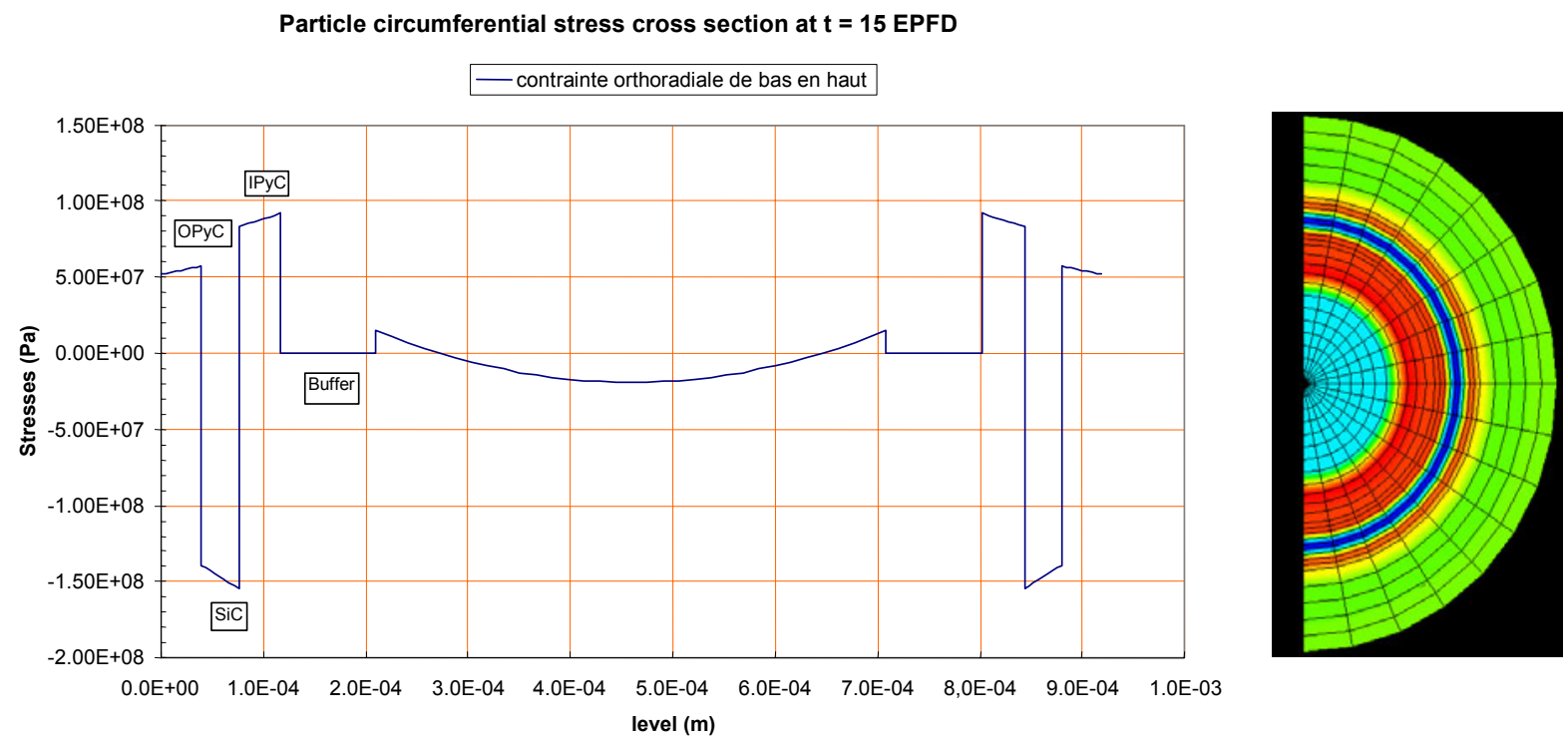

Figure 2-10. Stress distribution in the coated particle. 


\section{Next Year Activities:}

\section{INEEL:}

It is planned to continue work on the effects of debonding between the IPyC and $\mathrm{SiC}$ layers, and to begin using the statistical method above to evaluate the effects of asphericity on particle failures. We will also perform detailed finite element analysis (using ABAQUS) on the behavior of the buffer during irradiation.

\section{CEA:}

CEA will continue to develop the Pleiades software platform.

\section{Issues/ Concerns: None}




\section{TASK 3: CONCEPT IMPROVEMENTS}

\section{Responsible Lead: MIT}

\section{Brief Description of Objectives:}

In order to evaluate the ability of the classical TRISO fuel form to reach extended burnups (100 to $150 \mathrm{MWd} / \mathrm{kg}$ ), deterministic fuel performance calculations will be performed using the models developed in Task 2. As a consequence of these extended fuel life calculations, requirements for fuel materials will be illuminated. These requirements will include that the fuel particles be able to withstand the developed stress levels and the internal chemical environment of the particle. Of particular concern to extended burnup fuel with pure oxide kernels is the production of CO. At high burnup, $\mathrm{CO} / \mathrm{CO}_{2}$ levels will increase significantly $(2 \times)$ compared to the current burnup levels. In addition, and perhaps more importantly, with high burnup fuel and/or fuel with large quantities of $\mathrm{Pu}$, there will be a factor of 10 to 50 increase in the fission yields of $\mathrm{Ag}$ and $\mathrm{Pd}$. These fission products have been shown to have a propensity to be released from the particle (Ag) or to attack the $\mathrm{SiC}$ barrier layer (Pd). It is also possible that these fission products act to weaken the $\mathrm{SiC}$ by their presence on the grain boundaries. Additionally, there is recent evidence to indicate that the transport mechanism for Ag in graphite is not by classical diffusion but by a vapor transport mechanism. However, the exact mechanism of Ag transport has been subject to much debate and the information with regard to Ag transport in graphite is new. These elevated fission product levels may determine the diffusion coefficient of $\mathrm{Ag}$ in $\mathrm{SiC}$ and $\mathrm{ZrC}$ at the temperature range of interest. MIT will also explore the fundamental interaction of $\mathrm{Pd}$ and $\mathrm{Ag}$ with $\mathrm{SiC}$ and $\mathrm{ZrC}$. While there have been several studies of the interaction of Pd with Sic and, to a lesser extent, $\mathrm{ZrC}$, the fundamental nature of the interaction has not been systematically explored. There has been the tacit assumption that $\mathrm{Ag}$ transport in $\mathrm{SiC}$ is by grain boundary diffusion. The exact diffusion path will be determined in this task. No work has been done to examine the effect that the presence of $\mathrm{Ag}$ and/or Pd in the microstructure may have on the mechanical properties of these materials. MIT will also explore the mechanism of Ag transport in graphite/pyrocarbon. The goal of the MIT task will be to develop a sufficient fundamental 
understanding of the mechanisms involved to begin to suggest ways of slowing down the transport and release of these products. The results of these experiments will also be incorporated into the fuel behavior models for more accurate predictions of fuel lifetime.

\section{Task Technical Status Overview:}

\section{MIT Diffusion Couple}

It is well known that the measurement of Ag diffusion is complicated by the fact that the temperatures of interest $\left(1000-1500^{\circ} \mathrm{C}\right)$ exceed the melting point of $\mathrm{Ag}\left(960.85^{\circ} \mathrm{C}\right)$. Thus, the loss of Ag by vapor transport is an issue. The diffusion experiments will be conducted using a unique test article design that has been developed expressly for this purpose. The diffusion couple that will be used for this work is based on a design that was developed at the Knolls Atomic Power Laboratory. The couple is spherical. Ag, or any material of interest, is placed inside the sphere. The initial sphere is made in two sections and is fabricated from pyrocarbon. The two pyrocarbon halves are then bonded and a $\mathrm{SiC}$ (or $\mathrm{ZrC}$ ) layer is deposited by $\mathrm{CVD}$ techniques on the outer surface. An external layer of pyrocarbon is then deposited over the SiC layer. This design not only assures that the Ag can only migrate through the $\mathrm{SiC}$ layer but that the environment $(\mathrm{PyC} / \mathrm{SiC} / \mathrm{PyC})$ is similar to that which would exist in the real fuel particle.

During the first year, most of the work performed by MIT was focused in two areas: (1) the development of an understanding of the relationship between the SiC structure and the transport of $\mathrm{Ag}$ and (2) the effect of $\mathrm{Ag}$ and Pd on the mechanical properties of SiC. Diffusion of $\mathrm{Ag}$ in $\mathrm{SiC}$ was explored as a function of $\mathrm{SiC}$ structure, particularly the morphology of the layer.

Couples were fabricated with variable grain structures by altering the CVD process parameters (temperature, precursor concentrations and deposition rates). The SiC grain structure varied from large radial columnar grains to fine equiaxed grains. This will allow for the determination of the role of grain boundaries in the process. In addition to using the couple design discussed above, an effort will be made to develop a new diffusion couple that makes use of direct, atom by atom, deposition. The goal of this effort will be to develop a couple which has no grain boundaries so that bulk diffusion coefficients can be determined. This will establish the lower limit on the Ag transport through the $\mathrm{SiC}$.

The effect of $\mathrm{Ag}$ and $\mathrm{Pd}$ on the mechanical properties of $\mathrm{SiC}$ will be explored by doing mechanical tests on samples that have been exposed such that a concentration of these elements (Ag or Pd) exists in the material. "Infiltration" by Ag and Pd will be achieved by diffusion. 
Special care will be taken with Pd to insure that chemical reaction zones be removed prior to any testing. Mechanical properties will be measured by bend tests at temperatures of interest.

\section{Silver Diffusion}

Silicon carbide sandwiched between two layers of pyrolytic carbon is most commonly used as the barrier to fission product release in the TRISO coated particle fuel system in high-temperature gas reactors. However, silver release from TRISO fuels has been observed during normal reactor operation, even when the SiC coatings appear to be intact. Previously reported diffusion coefficients for silver transport in silicon carbide have been inferred from silver release measurements during post-irradiation annealing tests. Diffusion coefficients reported in the literature are assumed to represent grain boundary diffusion, though there has been no definitive work that has identified the exact transport mechanism or has published actual silver concentration profiles in silicon carbide layers. In this project we seek to first verify the Ag release data in terms of its actual mechanism and to then use this knowledge to design or suggest designs that show promise for the reduction of Ag release.

\section{Palladium interaction}

Palladium interactions with silicon carbide can result in open pathways for the release of fission products and a weakened $\mathrm{SiC}$ layer subject to premature failure.

The goal of the palladium interaction experimental program is to study the mechanisms controlling palladium attack in both $\mathrm{SiC}$ and $\mathrm{ZrC}$ and to provide a direct comparison of the attack rates in $\mathrm{SiC}$ and $\mathrm{ZrC}$.

\section{Progress: Silver Diffusion}

The goal of silver diffusion experimental program is to study and identify the pathways of silver transport through $\mathrm{SiC}$. These studies are being carried out using both a unique spherical diffusion couple, described in earlier reports, and ion implantation ${ }^{1}$ of $\mathrm{Ag}$ into $\mathrm{SiC}$ using an accelerator followed by thermal treatment. During the past year work has been focused on the measurement of diffusion (or mass transfer) coefficients for $\mathrm{Ag}$ in $\mathrm{SiC}$. Work has focused on both the

1. The ion implantation work was performed at no cost to the project. 
spherical diffusion couple and on the initiation of ion implantation based diffusion coefficient measurement. As in past experiments, spherical diffusion couples consisting of either two layer closed systems (graphite coated with $\mathrm{SiC}$ ) or single layer systems ( $\mathrm{SiC}$ shells coated with CVD $\mathrm{SiC}$ ) containing silver metal are being exposed to constant temperature anneals. After exposure attempts have been made to measure Ag concentration profiles. Ion implantation studies have begun in cooperation with the Argonne National Laboratory. Ag ions have been implanted in CVD SiC using an accelerator. After implantation further heat treatments will be performed and the migration of the implanted Ag tracked. Diffusion coefficients will be derived based on this analysis.

\section{Spherical couple heat treatments}

Thus far in the project thirty heat treatments have been conducted ranging in temperature from 1050 to $1700^{\circ} \mathrm{C}$ and from 2 to 1760 hours. Heating conditions for the heat treatments to date are shown in Figure 3-1.
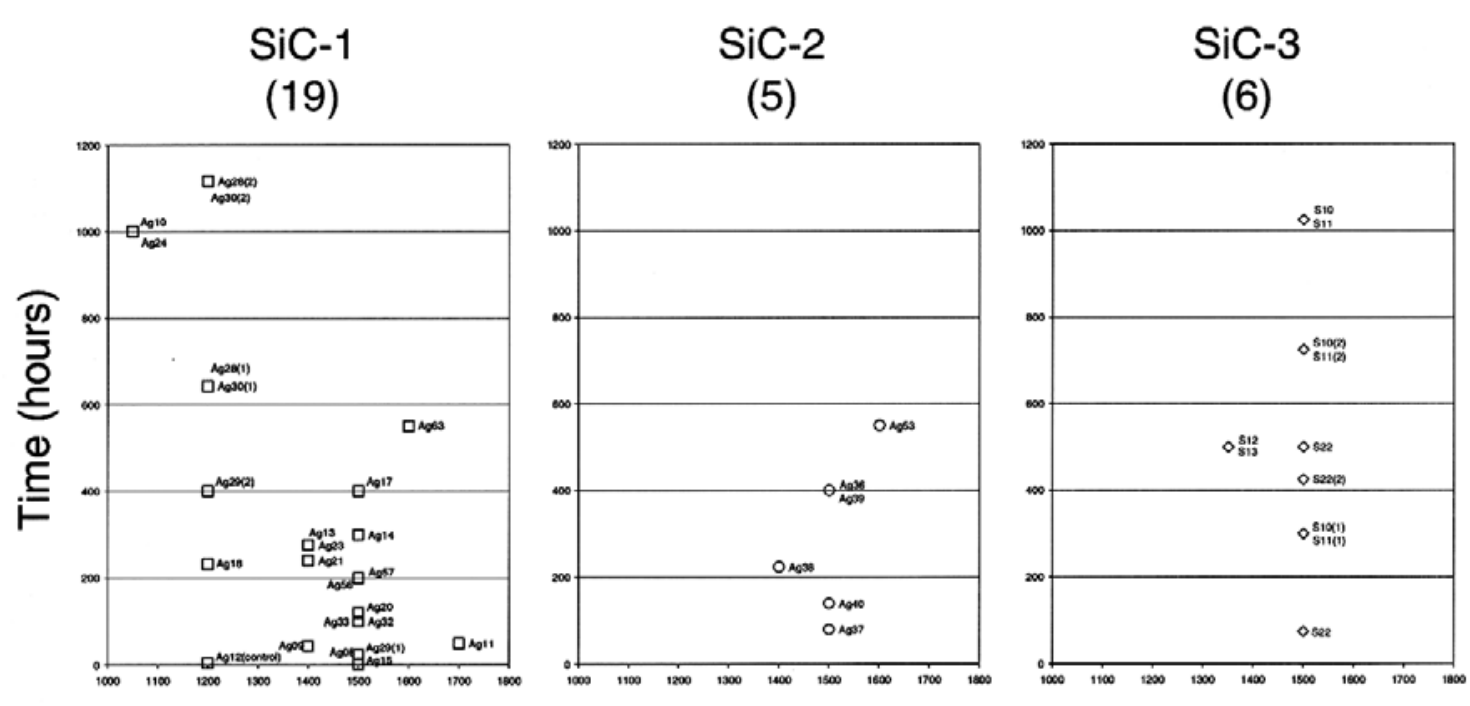

Temperature $\left({ }^{\circ} \mathrm{C}\right)$

Figure 3-1. Heating conditions for silver diffusion experiments conducted to date.

During the later part of this reporting period, we have focused on testing of diffusion couples constructed entirely of $\mathrm{SiC}$ with no graphite inner shell. For reference, $\mathrm{SiC}-1$ and $\mathrm{SiC}-2$ couples 
are constructed using CVD SiC over a graphite shell. The microstructure of SiC-1 consists of elongated grains. The microstructure of $\mathrm{SiC}-2$ consists of a finer, more equiaxed, grain structure. The microstructure of $\mathrm{SiC}-3$ is similar to that of $\mathrm{SiC}-1$. The purpose of the $\mathrm{SiC}-3$ couples was to eliminate the graphite/SiC interface. Previous results showed that $\mathrm{Ag}$ is easily transported through the porous graphite shell to the graphite/SiC interface but that this interface compromised the detection of Ag profiles in the $\mathrm{SiC}$ due to the extremely small penetration depths (less than the surface roughness of the interface) that were thought to exist.

\section{Silver Concentration Profiles}

In an earlier quarterly report we reported preliminary results that indicated that Ag profiles had been measured in SiC. However, more detailed analysis, using the SiC-3 samples, has shown that this initial analysis was compromised by the presence of Ag left over from the cleaning of the graphite/SiC interface prior to analysis. In the earlier analysis exhaustive attempts were made to detect silver concentration profiles after heat treatments using XPS (X-ray photoelectron spectroscopy). Great care was taken to remove all silver from the graphite/ $\mathrm{SiC}$ interface prior to analysis for the SiC-1 and SiC-2 samples. Samples were oxidized and chemically cleaned to remove the graphite layer and reveal the inner surface of the SiC layer. However, surface roughness at the graphite/SiC interface, with dimensions of the same order as the previously reported Ag profiles, have been shown by subsequent analysis to have compromised this analysis. For this reason we shifted to the use of SiC shells that did not use graphite as a base for the CVD SiC layer. Detailed analysis of SiC-3 samples, where the graphite layer does not exist, has not shown any Ag entry into the SiC for any of the test conducted. We have thus concluded that for the conditions of our experiments $\mathrm{Ag}$ did not enter either the matrix or the grain boundaries of the material.

\section{Electron Microscopy}

TEM (transmission electron microscopy) and SEM (scanning electron microscopy), both with EDX (energy dispersive X-ray), were used in an attempt to quantitatively and qualitatively locate the silver in the silicon carbide. In previous reports we had indicated that TEM analysis had showed that the silver concentration was very low, but detectable and in-homogeneously distributed in the SiC. A much more thorough TEM analysis has shown that after testing there is essentially no Ag observed in the $\mathrm{SiC}$ microstructure. It is likely that the previous results were compromised by taking samples at the interface between the graphite and SiC layers. Analysis of 
SiC-3 samples, where this possibility does not exist, has not confirmed the previous analysis results.

\section{Mass Loss}

As was reported in the last report, significant weight loss of many diffusion couples has been measured after heat treatment. The mass loss data for the annealed diffusion couples has been updated and further analyzed and compared to literature data. The mass loss for each sample was assumed to be the result of silver release from the diffusion couple. Using the analytical solution for release from a thin spherical shell, the "diffusion" coefficient necessary to produce that silver release can be calculated for each heat treatment as follows (Crank 1956).

$Q=4 \cdot \pi \cdot a \cdot b \cdot(b-a) \cdot C_{1} \cdot\left[\frac{D \cdot t}{(b-a)^{2}}-\frac{1}{6}-\frac{2}{\pi^{2}} \cdot \sum_{n=1}^{\infty} \frac{(-1)^{n}}{n^{2}} \exp \left[-\frac{D \cdot n^{2} \cdot \pi^{2} \cdot t}{(b-a)^{2}}\right]\right]$

where $Q=$ mass released $(\mathrm{gm})$

$a=$ inner radius of spherical shell (m)

$b=$ outer radius of spherical shell $(\mathrm{m})$

$C_{1}=$ source concentration of silver at $r=a\left(\mathrm{gm} / \mathrm{m}^{3}\right)$

$D=$ diffusion coefficient of silver in $\mathrm{SiC}\left(\mathrm{m}^{2} / \mathrm{s}\right)$, and

$t=$ duration of heat treatment (s).

The effective mass transport coefficients calculated from the mass loss data for the current silver experiment are plotted along with the diffusion coefficients reported in the literature in Figure 3-2 (Nabielek, Brown, and Offerman 1977, Brown and Faircloth 1976, Förthmann et al. 1982, Amian and Stöver 1983). 


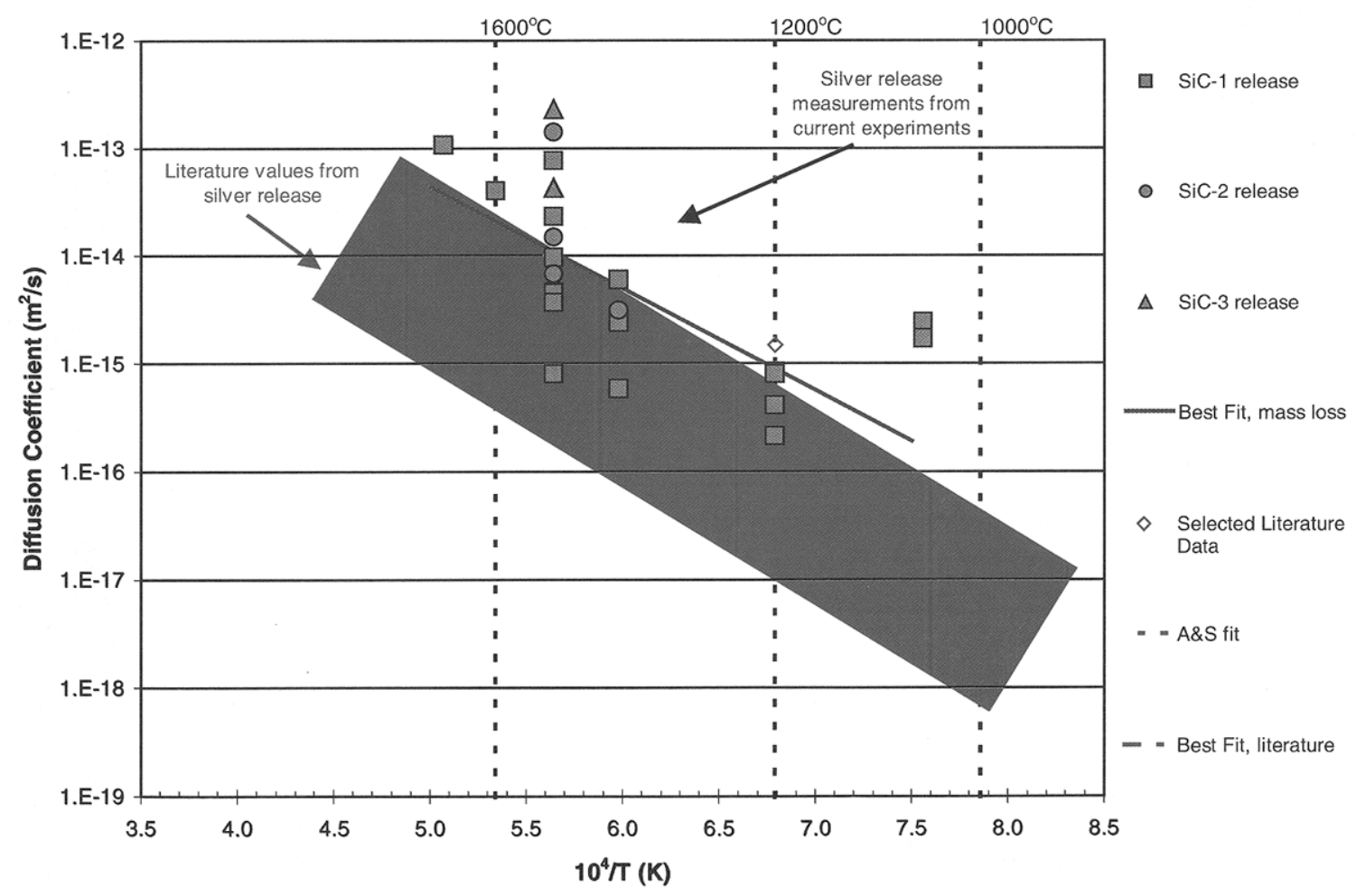

Figure 3-2. Mass transport coefficients for current mass loss measurements and literature data.

The calculated diffusion coefficients from the complete set of experiments continue to appear higher than the literature band, but there is overlap between the data sets. Most of the diffusion coefficients reported in the literature were calculated from silver release measurements where silver was trapped on a cold plate in the furnace during the heat treatments.

\section{Leak Testing}

Due to the unexpected mass loss during most of the heat treatments, leak testing of some of the diffusion couples has continued. Direct read leak testing is performed by soaking the diffusion couple in a pressure chamber under 75 psi of helium for 20 minutes. The sample is then quickly transferred to the leak detector. This chamber is held under vacuum and a spectrometer is tuned to detect helium in the sample chamber. The leak rate is recorded at 15, 30, 60, 120 and 300 seconds. An analytical fit is used to determine the actual leak rate of the samples. Figure 3-3 shows the complete set of results to date. 
In general, the leak rate after heat treatment is larger than before, indicating the possibility that a release path opens during heating, allowing for silver escape in excess of that expected by diffusion alone. The results of the leak testing are shown in Figure 3-3. However, the leak rates measured by helium testing are greater than would be expected based on the silver release, unless the leak path does not become active until sometime during the heat treatment.

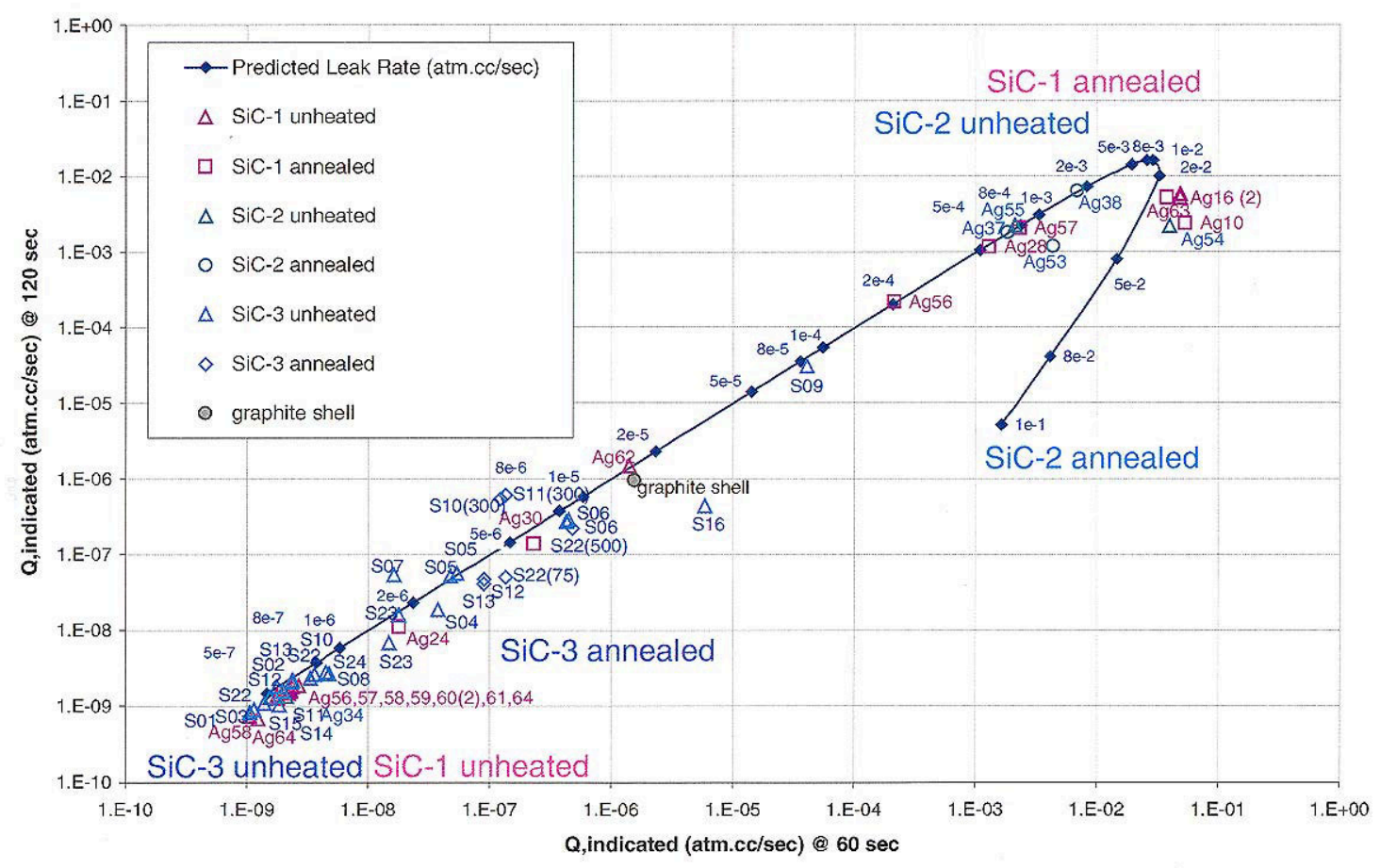

Figure 3-3. Results of leak testing before and after heat treatments.

\section{Silver Migration Pathways}

Based on the work done so far we are faced a number of conflicting observations that make determining the mechanism for $\mathrm{Ag}$ transport difficult at best.

1. On the one hand, there is a clear silver mass loss from the diffusion couples during the experiments. This mass loss is of a magnitude that almost certainly would have left some 
evidence behind in the form of a concentration profile had diffusion been the responsible mechanism for $\mathrm{Ag}$ transport

2. Concentration profile measurements have been attempted using their diffusion couples, that have experienced significant mass loss but still contain residual Ag in the form of solid metal after an experiment. Despite using the most sensitive measurement techniques available, we have been unable to detect even the smallest amount of $\mathrm{Ag}$ in the $\mathrm{SiC}$.

3. The helium leak rate measurements show a clear increase in He leak rate after thermal treatments. The nature of the He leak rate test is such that the only way that He can leak is via mechanical pathways. Thus, there is some form of mechanical pathway opening up as a result of the thermal treatment process. However, exhaustive searches have thus far been unable to identify the pathway. An obvious candidate for such a pathway would be the seam between the two spherical shell halves. This pathway has been extensively investigated. Moreover, the SiC-3 specimens were fabricated entirely from SiC. After assembling the two sections a CVD SiC layer of the order 200-300 $\mu \mathrm{m}$ was put down on the specimen joint. This thickness is 5-10 times the entire thickness of the SiC layer in the SiC-1 and SiC-2 series of experiments. Additionally, the $\mathrm{SiC}-3$ basic shell thickness is 5010 times the thickness of the SiC-1 and 2 layers. Despite their differences in the design of the diffusion couples (SiC-3 vs. SiC-1 and SiC-2), we still observe significant mass loss and do not observe an obvious mechanical pathway. Detailed SEM analysis of the SiC layer has failed to identify any obvious mechanical pathway-cracks.

4. Lastly, there is the "apparent" similarity in the form of the temperature dependence between the release based calculation of "diffusion" coefficients reported in the literature and our mass loss based "diffusion" coefficients. (However the spread in our data at a given temperature is quite large (50-200x)). One might simply say that: (a) based on the temperature dependence of the calculated diffusion coefficients, the release mechanism should be by diffusion and we are just not able to see the concentration profiles. If one assumes a diffusion coefficient based on the literature calculations and the release that is observed, then the resultant linear Ag concentration profile through through the $\mathrm{SiC}$ shell at the end of the experiment should be present at concentrations well above the detection limit of the XPS system. Yet we do not see any Ag in the SiC. As an aside, if one makes the assumption that the observed release from coated particles in the literature is instead due to mechanically leaking fuel particles and then (leaving aside the temperature dependence issue) asks the question "How many particles would have had to release 
their Ag@ $1500^{\circ} \mathrm{C}$ to yield the observed mass release over the time in question? ", the answer is instructive. For this case it would require 250 particles to release $0.5 \%$ of their Ag or 4.2 particles to release $30 \%$ of their $\mathrm{Ag}$ or 1.7 particles to release $75 \%$ of their $\mathrm{Ag}$ or 1.3 particles to release $100 \%$ of their Ag inventory.

\section{Ag Release-Path Forward}

It is clear, based on the above, that there are pieces to the puzzle that are still not identified. We are continuing to address the identification of the as yet unidentified leak path. However, based on the possibility that the release path is not due to diffusion, we are proceeding along parallel paths. The first path is to continue to look to identify the leak path. Second, we are proceeding to establish what the actual diffusion coefficient is for $\mathrm{Ag}$ in $\mathrm{SiC}$. The single literature source that is available that addresses this issue (Nabielek, Brown, and Offerman 1977) is inconclusive. In this work ion implantation was used in an effort to identify the diffusion coefficient. Ag-109 ions were implanted to establish a concentration profile. A thermal treatment of $1180^{\circ} \mathrm{C} / 30 \mathrm{~min}$ was then applied and the profile measured once again. In this case no significant difference was observed. The author then simply calculated what was termed an upper bound for the diffusion coefficient. Thus, no actual diffusion coefficient was measured. It is thus critical that: (1) we know what the diffusion coefficient actually is (2) what the path is during diffusion and (3) is there any effect of radiation damage by way of introducing microcracks or other mechanical damage that might allow more rapid release. Once we know what the actual diffusion coefficient is we can then say something about the source of the release data based "diffusion" coefficients. To this end we have initiated a program to use ion implantation to determine the actual diffusion coefficient in CVD SiC. Ag ion implantation has been performed using the accelerator at the Argonne National Laboratory with high energy (100-165 MeV) Ag ions. CVD SiC plate specimens were obtained for this purpose. These plates were super polished and the surface characterized prior to implantation. Figure 3-4 shows the setup prior to implantation. Figure 3-5 shows the sample after implantation using a $161 \mathrm{MeV}$ Ag ion beam. The sample was "masked" off using a separate CVD SiC layer containing holes to localize the deposition. Figure 3-6 shows the Ag profile that resulted from ion implantation. In this case no "mask" was used. This resulted in a central region of high concentration surrounded by a "halo" region of lower concentration. The insert figure shows results from an RSIM simulation of the damage process. The concentration profile is approximately symmetric, as would be expected. However, the implanted samples have the following characteristics: 
1. The grain size of the material is of the order $5-10 \mu \mathrm{m}$ which is much smaller that the spot size and is approximately the same as in particle fuel.

2. The profile contains a "damaged" side and an undamaged side. The "entry wound" is on the left which will have resulted in extensive radiation damage. This is evidenced by a change in the texture of the sample surface. The right side of the profile will contain no radiation damage. As a result of this we will be able to not only identify the diffusion path but will be able to assess the effect of radiation damage on the migration process.
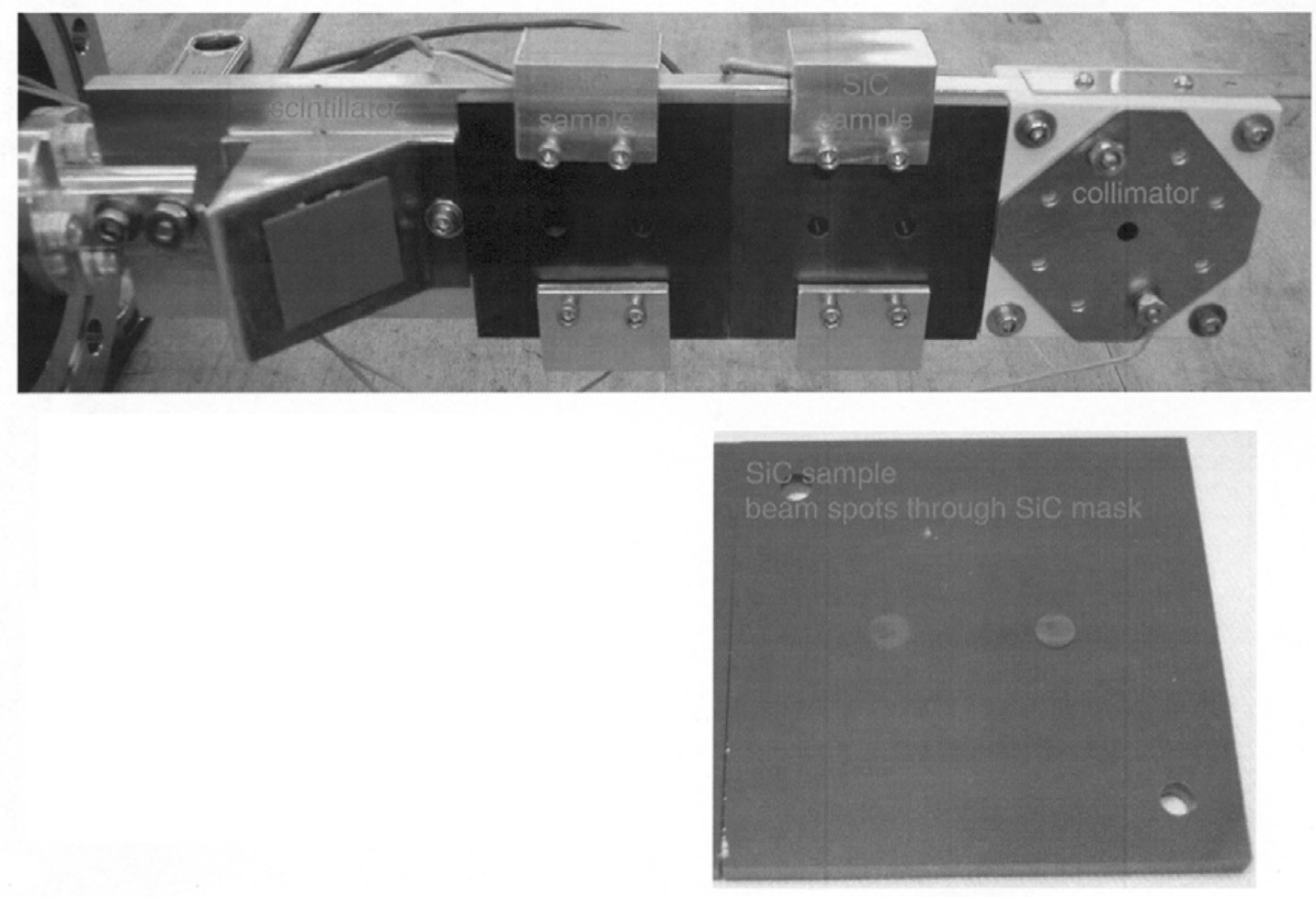

Figure 3-4. Ag ion implantation setup prior to exposure. 

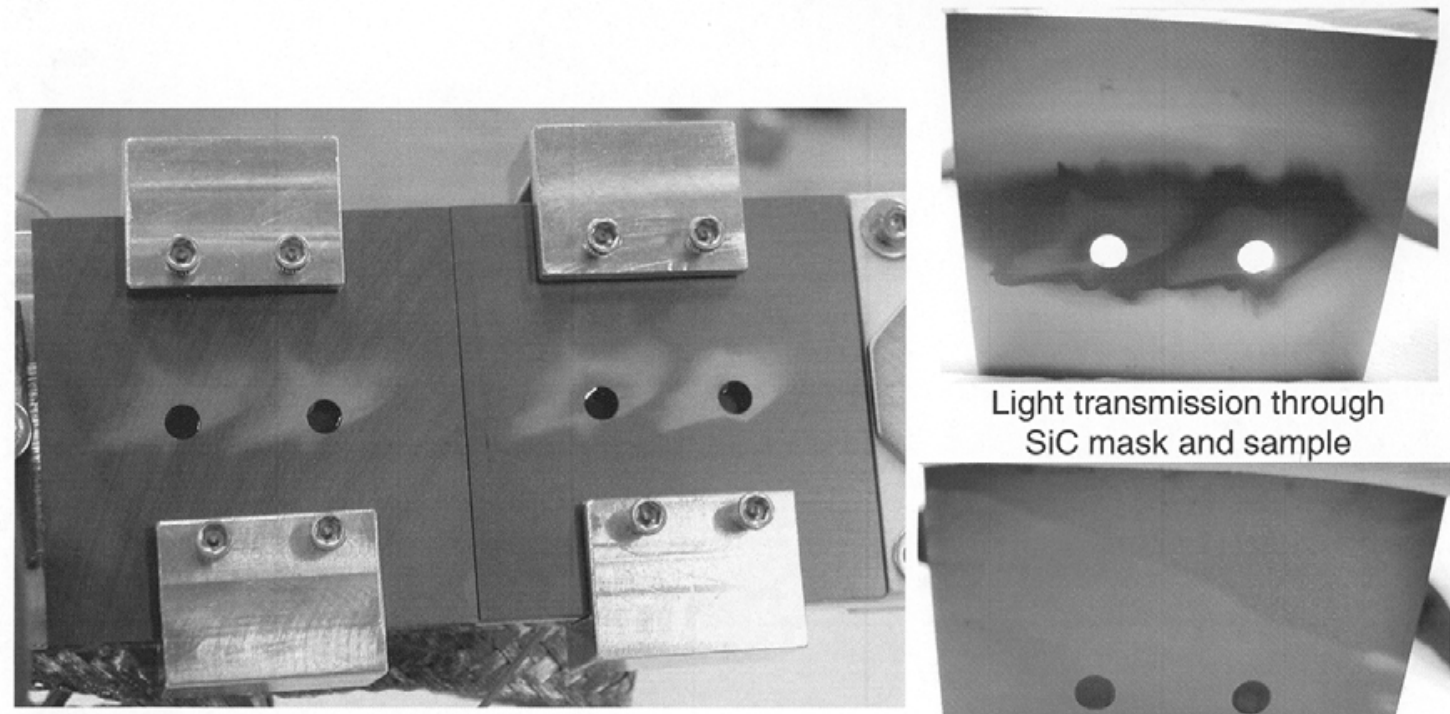

Light transmission through $\mathrm{SiC}$ mask and sample

$\mathrm{SiC}$ masks on sample frame

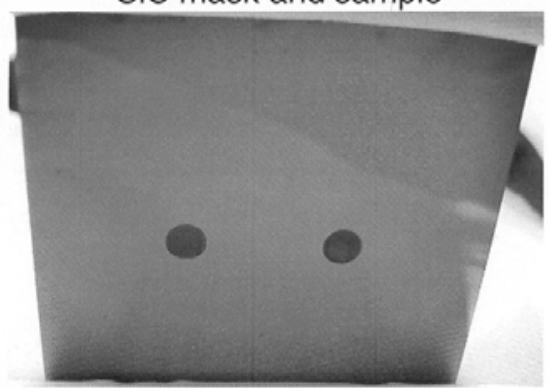

Figure 3-5. SiC sample after exposure

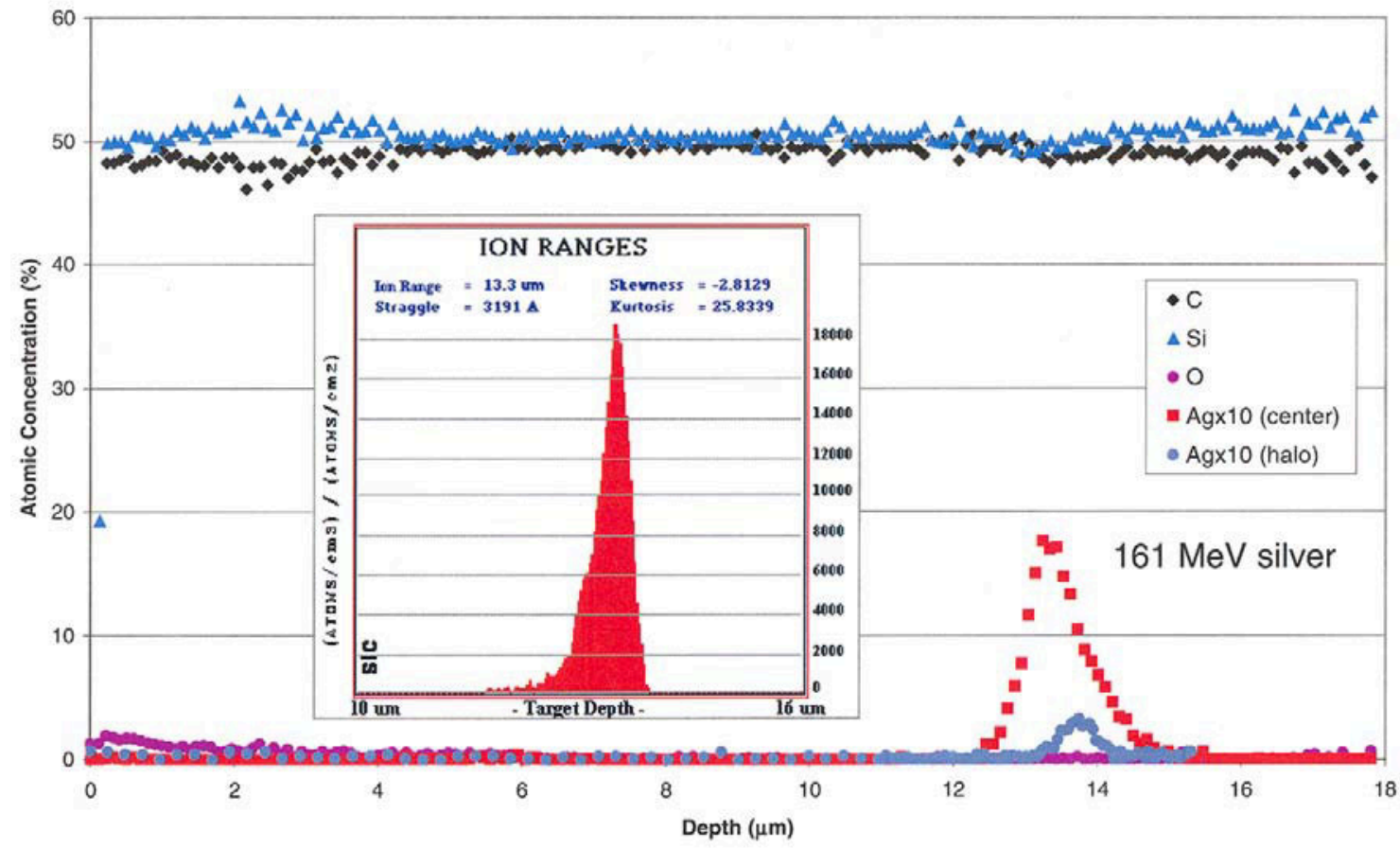

Figure 3-6. Results of ion implantation 
As of this date 11 samples have been produced for analysis. One of these samples has been given a subsequent heat treatment of $1500^{\circ} \mathrm{C}$ for 5 hours. The sample is currently being characterized. Results will be available shortly. However, one must ask what we would expect to see as a result of the heat treatment. Figure 3-7 shows results of calculations based on upper and lower bounds of the literature reported diffusion coefficient values. Clearly, if the diffusion coefficients are as indicated in the literature, we will see a significant change in the profile.

In addition to the ion implantation studies we have initiated an effort to model the interaction between $\mathrm{Ag}$ and $\mathrm{SiC}$ using molecular dynamic simulation. The purpose of this effort is to begin to understand just how $\mathrm{Ag}$ interacts with the $\mathrm{SiC}$ matrix.

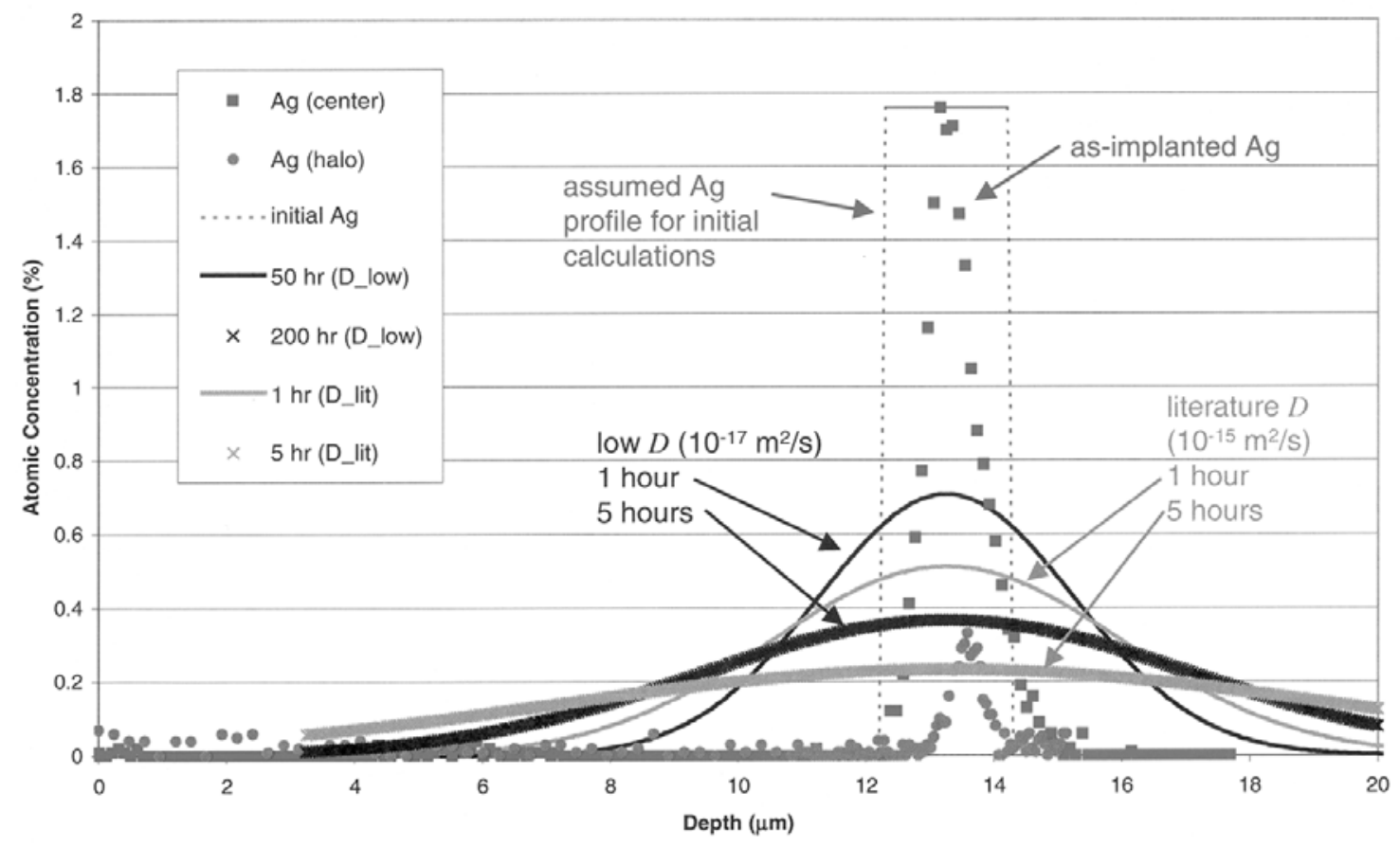

Figure 3-7. Predicted results of anneal at $1500^{\circ} \mathrm{C}$

\section{Palladium Interaction}

The majority of palladium generated as a fission product in $\mathrm{UO}_{2}$ fuel is not radioactive. The release of palladium itself is not a concern; rather, it is the effect palladium has on $\mathrm{SiC}$ and $\mathrm{ZrC}$ that is important. Palladium interacts with the fission product barrier layer through chemical reactions, causing corrosion and destruction of the layer. This attack has been characterized 
previously as an effective thinning of the $\mathrm{SiC}$ layer. Such damage to the $\mathrm{SiC}$ layer reduces its strength and may lead to failure of the coated particle. Palladium has a higher fission yield from plutonium isotopes than uranium isotopes; therefore, palladium attack is of higher concern in LEU and breeder fuels, due to their increased plutonium content, than in HEU fuels.

Palladium-silicon compounds have lower melting temperatures than SiC. At normal operating temperatures, these compounds would be at a significant fraction of or above their melting temperatures, suggesting that they would exist as liquids in the SiC matrix. Palladium attack has also been observed to extend ahead of the main corrosion zone, along SiC grain boundaries. Wetting of the SiC grain boundaries by Pd-Is compounds may increase their mobility, further extending the attack zone into the $\mathrm{SiC}$ layer.

Most examinations of palladium attack in $\mathrm{SiC}$ has been on irradiated fuel where it can be difficult to isolate the effect of palladium in $\mathrm{SiC}$ amid all of the other lanthanide fission products. Other research suggests that zirconium carbide is less susceptible to palladium attack than SiC, but the results are not yet conclusive. The goals of this work are to conduct a clean experiment, free of other fission products, to directly compare the rate of palladium attack in $\mathrm{SiC}$ and $\mathrm{ZrC}$ and to develop an understanding of the mechanisms controlling palladium interactions in $\mathrm{SiC}$ and $\mathrm{ZrC}$.

Another goal of this project is to develop a model of palladium attack in $\mathrm{SiC}$ and $\mathrm{ZrC}$ and to integrate this model with the Fuel Performance Model. This model will include an estimation of the reduction in strength and thickness of the barrier layer as a palladium is produced and then attacks the $\mathrm{SiC}$ or $\mathrm{ZrC}$ during operation.

An experimental setup has been designed to test the attack of palladium in $\mathrm{SiC}$ and $\mathrm{ZrC}$ samples. This system has been demonstrated with the first heat treatment of a silicon carbide sample. Because palladium has a lower vapor pressure and lower mobility than silver, enclosing palladium inside a sample is not as crucial as it is for the silver experiments. Therefore, the palladium experiments can be conducted with more simple samples.

For these experiments, palladium powder is placed inside bowl-like samples made of either SiC or $\mathrm{ZrC}$. These samples are 0.5 inch $\times 0.5$ inch square and 0.2 inch tall with a round, flat-bottom depression in the middle. Palladium powder is pressed into the depression and a lid with the same dimensions is placed on top. These samples will be heated at temperatures between 750 and 
$1500^{\circ} \mathrm{C}$ to evaluate the effect of $\mathrm{Pd}-\mathrm{Si}$ and $\mathrm{Pd}-\mathrm{Zr}$ eutectic formation on the palladium attack rate in $\mathrm{SiC}$ and $\mathrm{ZrC}$. The test conditions for the palladium attack experiments are shown in Table 3-1.

Table 3-1. Palladium interaction couples test matrix.

\begin{tabular}{|c|c|c|c|c|}
\hline \multirow{2}{*}{ Temp ${ }^{\circ} \mathrm{C}$} & \multicolumn{2}{|c|}{$\begin{array}{c}\text { SiC } \\
\text { ID/ Time (hr) }\end{array}$} & \multicolumn{2}{c|}{$\begin{array}{c}\text { ZrC } \\
\text { ID/Time (hr) }\end{array}$} \\
\hline \multirow{2}{*}{1500} & $\begin{array}{c}\text { PdS02 } \\
100\end{array}$ & 50 & $\begin{array}{c}\text { PdZ01 } \\
100\end{array}$ \\
\hline 1200 & $\begin{array}{c}\text { PdS01 } \\
100\end{array}$ & & 150 & 150 \\
\hline 900 & 200 & 200 & 300 & 300 \\
\hline 750 & 400 & 400 & 600 & 600 \\
\hline
\end{tabular}

Shaded boxes: completed heat treatments

Three samples have been heated to date. Palladium interaction was observed in both $\mathrm{SiC}$ samples. Sample PdS01 was heated at $1200^{\circ} \mathrm{C}$ for 100 hours. SEM analysis showed that there was an interaction zone about 12-23 microns deep where the $\mathrm{SiC}$ appears to have undergone complete conversion from $\mathrm{SiC}$ to $\mathrm{Pd}-\mathrm{Si}$ compounds plus some free silicon and free carbon at the surface of the bowl where the palladium powder was initially in contact with the SiC. The exact phase remains to be determined by X-ray analysis. Beyond this complete interaction zone, fingers of palladium were observed extending into the $\mathrm{SiC}$ between 5 and $20 \mu \mathrm{m}$. Again, the exact phase must still be evaluated. It appears that these fingers of palladium and silicon are situated similarly to grain orientation, but it is not clear yet whether or not the palladium compounds are along SiC grain boundaries.

Sample PdS02 exhibited similar behavior to PdSO1, but with greater interaction depths. There was an interaction zone near the center of the sample where there appeared to be complete conversion of the $\mathrm{SiC}$ to $\mathrm{Pd}-\mathrm{Si}$ compounds. This interaction zone varied from approximately 30 to $250 \mu \mathrm{m}$. Along the entire surface of the bowl, fingers of palladium attack into the SiC were observed. These fingers ranged from 15 to $200 \mu \mathrm{m}$ deep in the $\mathrm{SiC}$. 
Sample PdZ01 has a bowl and lid of hot-pressed ZrC. The physical properties of this specific material are currently being investigated. After heating, this sample had a fairly uniform interaction zone ranging from 160 to $200 \mu \mathrm{m}$ thick. Preliminary characterization indicates that this region is predominantly palladium with some zirconium; the phase of this zone will be determined by $\mathrm{X}$-ray analysis. There is also a fairly uniform region into the $\mathrm{ZrC}$ where small areas of palladium are observed. The palladium appears evenly distributed over a depth of 95 to $133 \mu \mathrm{m}$. It is not clear at this time whether this is due to a chemical interaction or another mechanism such as diffusion or transport into $\mathrm{ZrC}$ porosity.

The experimental test samples for the palladium attack study have been redesigned to reduce uncertainties from the previous design that utilized palladium powder and also to improve the similarity of the zirconium carbide samples to material typical of fuel particle coatings. The new experimental samples consist of chemically vapor deposited $\mathrm{SiC}$ or $\mathrm{ZrC}$. Palladium will be deposited by sputter coating onto one face of the $\mathrm{SiC}$ and $\mathrm{ZrC}$ samples. These samples will be heated isothermally under an inert atmosphere. The temperature range for these experiments is 750 to $1400^{\circ} \mathrm{C}$ with the goal of examining the influence of temperature and the effect of lowmelting point eutectics on the rate of palladium attack in both $\mathrm{SiC}$ and $\mathrm{ZrC}$.

As of this date five of the new samples have been given heat treatments. These samples are now being analyzed.

\section{Next Year Activities:}

Experiment and analysis related to $\mathrm{Ag}$ and $\mathrm{Pd}$ transport through $\mathrm{SiC}$ will continue.

\section{Issues/ Concerns:}

None 


\section{Task 4: FEASIBILITY OF THE CONCEPT IN HARD SPECTRUM Responsible Lead: CEA Brief Description of Objectives:}

The feasibility of using particle fuel in a fast neutron environment will be investigated. Service conditions for particle fuel operating in a fast reactor will be determined from reactor physics calculations. Based upon these operating conditions, candidate fuel designs and materials will be evaluated for suitability.

The traditional TRISO fuel particle has been designed for operation in a mild, thermal neutron spectrum. Of particular concern when this design is exposed to a hard spectrum is the influence of radiation damage to the coatings. Radiation damage in excess of 200 dpa can be expected in gas-cooled fast reactors. The influence of He generation (from n-alpha reactions) and void swelling in the $\mathrm{SiC}$ and their influence on $\mathrm{SiC}$ strength will be investigated. In addition, the shrinkage and swelling in the pyrocarbon layers (IPyC and OPyC) at high fast neutron fluences is significant and may limit the lifetime of the fuel. Material properties of other more radiationresistant candidate materials at high neutron fluences will be investigated and incorporated into the fuel behavior models as needed.

Work on this task during the first year will performed by CEA, and will be devoted to assessing the limits of the TRISO particle concept with respect to fast fluence. The approach is to consider the particle as designed for a thermal spectrum and to calculate the stresses and strains generated in the layers by a kernel $\left((\mathrm{U}, \mathrm{Pu}) \mathrm{O}_{2}\right)$ submitted to fast neutron fluence (coupling of the deterministic model with the GERMINAL code dedicated to oxide fuel for fast breeders). Nevertheless, the flux will be adjusted to reflect the fact that the power density in gas cooled fast reactors is significantly reduced to reflect the fact that the power density in gas cooled fast reactors is significantly reduced compared to liquid metal cooled for example. The results will be obtained in terms of the maximum reasonably achievable burnup given known properties of $\mathrm{SiC}$ and their dependence on temperature and fast neutron damage based on data from the literature (e.g. fusion). 


\section{Task Technical Status Overview:}

As indicated in the original proposal, activities on this task do not begin until the second year of the project.

Next Year Activities: Initiate feasibility studies

Issues/ Concerns: None 


\section{TASK 5: IRRADIATION OF PROTOTYPE PARTICLES}

The logical follow on to the development and design of advanced prototype particle fuel is fabrication and irradiation testing. Based upon the predictive model calculations performed for the candidate design, fuel manufacturing and product specifications will be assessed by both the CEA and the INEEL during the third year of this project.

\section{Responsible Lead: INEEL}

\section{Task Status:}

As indicated in the original proposal, this activity will not begin until the third year of the project.

Issues/ Concerns: None 


\section{REFERENCES:}

ABAQUS User’s Manual Version 5.8, 1998, Hibbitt, Karlsson, and Sorenson, Inc.

Amian, W., D. Stöver, 1983, "Diffusion of Silver and Cesium in Silicon-Carbide Coatings of Fuel Particles for High-Temperature Gas-Cooled Reactors,"Nucl. Tech., Vol. 61, pp.475.

Baldwin, C. A., et al., 1993, "The New Production Reactor Fuel Post Irradiation Examination Data Report for Capsules NPR1, NPR2, and NPR1A,” ORNL/M-2849.

Brown, P.E., R.L. Faircloth, 1976, "Metal Fission Product Behaviour in High Temperature Reactors $-\mathrm{UO}_{2}$ Coated Particle Fuel," J. Nucl. Mater, Vol. 59, pp. 29-41.

CEGA Corporation, 1993, "NP-MHTGR Material Models of Pyrocarbon and Pyrolytic Silicon Carbide," CEGA-002820, Rev. 1.

Crank, J., 1956, Mathematics of Diffusion, New York, NY: Oxford University Press.

Förthmann, R.et al., 1982, "Irradiation Performance of Coated Fuel Particles with Fission Product Retaining Kernel Additives,"High Temp. High Press. Vol.14, pp.477-485.

INEEL, 2002, “Modular Pebble Reactor LDRD Annual Report 2002”, in preparation.

Kaae, J., D. Stevens, and C. Luby, 1971, "Predictions of the Irradiation Performance of Coated Particle Fuels by Means of Stress Analysis Models," Nucl. Tech., Vol. 10, pp. 44.

Martin, D. G., 2001, "Physical and Mechanical Properties of the Constituents of Coated Fuel Particles and the Effect of Irradiation," HTR-F WP3 Meeting Lyon.

Miller, G. K. and R. G. Bennett, 1993, "Analytical Solution for Stresses in TRISO-coated Particles," J. Nucl. Mat., Vol. 206, p. 35.

Miller, G. K., et al., 2001, "Consideration of the Effects on Fuel Particle Behavior from Shrinkage Cracks in the Inner Pyrocarbon Layer," J. Nucl. Mat., Vol. 295, pp. 205.

Miller, G. K., D. A. Petti, J. T. Maki, 2002, “Development of an Integrated Performance Model for TRISO-Coated Gas Reactor Particle Fuel," $1^{\text {st }}$ International Topical Meeting on High Temperature Reactor Technology (HTR), Petten, Netherlands.

Nabielek, H., P.E. Brown, P, Offerman, 1977, “Silver Release from Coated Particle Fuel,"Nucl. Tech.Vol. 35, pp. 483.

Nemeth, N.N., J. M. Mandershield, and J. P. Gyekenyesi, 1989, Ceramics Analysis and Reliability Evaluation of Structures (CARES) User's and Programmer's Manual, NASA Technical Paper 2916.

Petti, D. A., et al., 2001, "Gas Reactor TRISO-Coated Particle Fuel Modeling Activities at the Idaho National Engineering and Environmental Laboratory," The Second Information Exchange Meeting on Basic Studies in the Field of High Temperature Engineering, Paris, France. 
Whitcomb, P., et al., 1993, Design Expert, Version 4.0, Stat-Ease Inc. 
Project Milestone/ Deliverable Summary:

\begin{tabular}{|c|c|c|c|}
\hline Milestone & $\begin{array}{l}\text { Deliverable } \\
\text { Description }\end{array}$ & $\begin{array}{c}\text { Planned } \\
\text { Completion } \\
\text { Date }\end{array}$ & $\begin{array}{c}\text { Actual } \\
\text { Completion } \\
\text { Date }\end{array}$ \\
\hline 1 & $\begin{array}{l}\text { Document results of the data exchange } \\
\text { and the description of fuel particle } \\
\text { models. }\end{array}$ & Oct 2002 & Oct 2002 \\
\hline 2 & $\begin{array}{l}\text { Document the first year modeling } \\
\text { accomplishments }\end{array}$ & Oct 2002 & Oct 2002 \\
\hline 3 & $\begin{array}{l}\text { Document interim status of concept } \\
\text { improvement, results to date on } \\
\text { experiments to measure Ag and Pd } \\
\text { diffusion through coating layers, and } \\
\text { assessment of failure mechanisms of } \\
\text { classical TRISO particles }\end{array}$ & Oct 2003 & Pending \\
\hline 4 & $\begin{array}{l}\text { Document final results of project } \\
\text { including feasibility of extending the } \\
\text { coated particle fuel concept to a fast } \\
\text { spectrum, and outlining the types of } \\
\text { irradiations needed to test prototype } \\
\text { particles }\end{array}$ & Oct 2004 & Pending \\
\hline
\end{tabular}

\section{Task Projection}

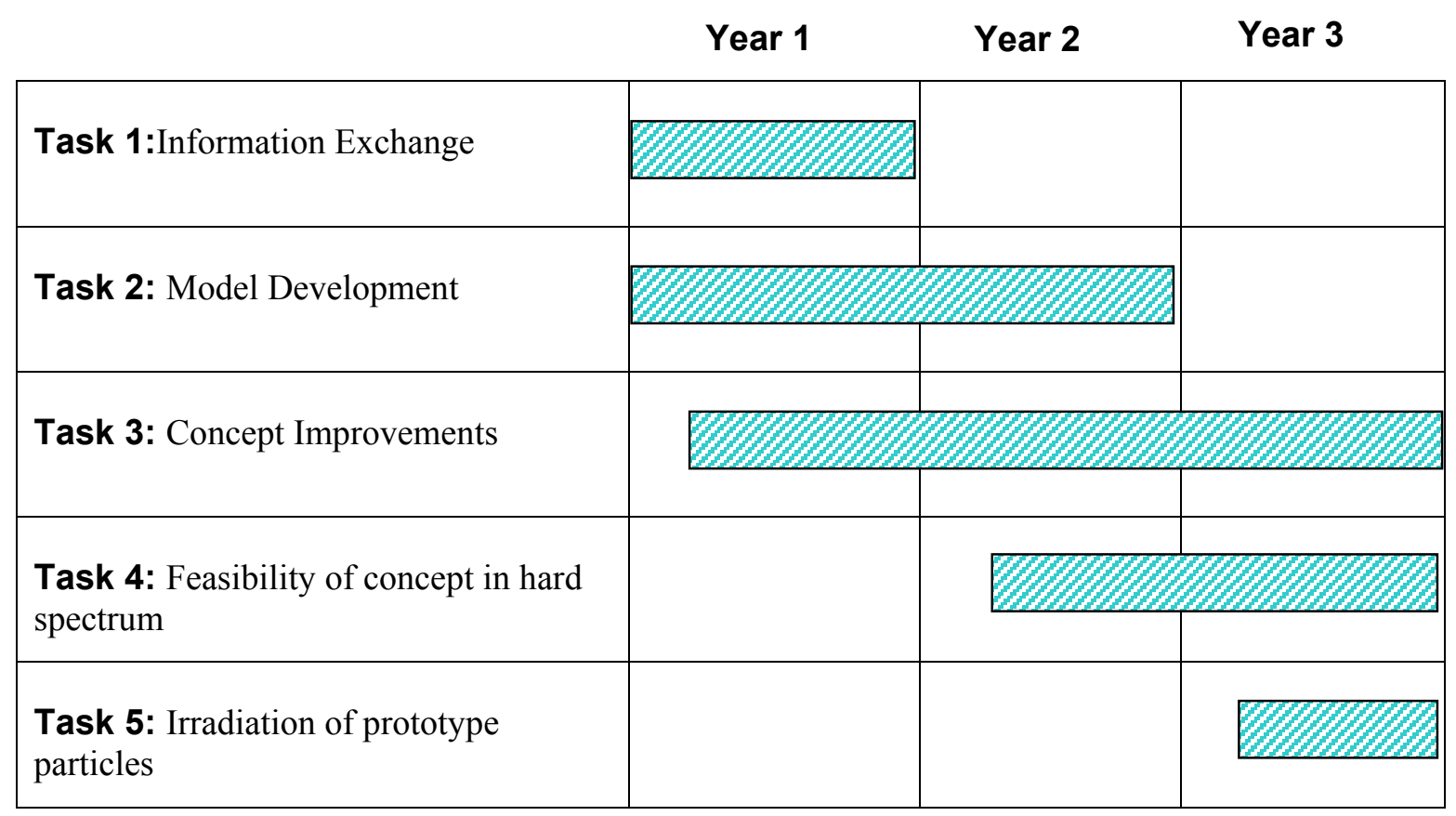


